INSTITUTO DE PESQUISAS ENERGÉTICAS E NUCLEARES

Autarquia associada à Universidade de São Paulo

\title{
ESTUDO DO COMPORTAMENTO DE UM DETECTOR DE RADIAÇÃO PASSIVO PARA FINS AERONÁUTICOS UTILIZANDO O MÉTODO MONTE CARLO
}

\section{LEONARDO DE HOLANDA MENCARINI}

Dissertação apresentada como parte dos requisitos para obtenção do Grau De Mestre em Ciências na Área de Tecnologia Nuclear - Aplicações.

Orientadora:

Profa. Dra. Linda V. E. Caldas 
Ȧ Profa. Maria da Penha Barbosa Holanda, bem amada avó, educadora nata e incansável, que soube transmitir o valor do conhecimento a todos com quem conviveu durante a sua iluminada vída (in memoriam).

À Ana Crístina Malacarne Mencariní, com amor. 


\section{AGRADECIMENTOS}

À Profa. Dra. Linda V. E. Caldas, pela confiança e orientação segura durante o período do mestrado. Privilégio de ter sido aluno de uma real educadora.

Ao Prof. Dr. Claudio Antonio Federico, que colaborou desde a concepção do plano de trabalho deste mestrado, sempre acreditando na viabilidade da pesquisa. Um verdadeiro co-orientador.

Ao Dr. Alexandre David Caldeira, pela amizade sincera e pelas palavras de incentivo.

Ao Cel Eng Marco Antonio Sala Minucci, Ex-Diretor do IEAv, pelo apoio irrestrito para que eu pudesse realizar este mestrado.

Ao IPEN/CNEN-SP, pela oportunidade de realização do curso de mestrado em um centro de excelência na área nuclear. 
“...nos alegramos também nas tríbulações, sabendo que a tribulação produz a perseverança, a perseverança, uma virtude comprovada, a esperança.

$\mathcal{E}$ a esperança não decepciona..." São Paulo, Romanos, 5, 3-5 



\title{
ESTUDO DO COMPORTAMENTO DE UM DETECTOR DE RADIAÇÃO PASSIVO PARA FINS AERONÁUTICOS UTILIZANDO O MÉTODO MONTE CARLO
}

\author{
LEONARDO DE HOLANDA MENCARINI
}

\begin{abstract}
RESUMO
Profissionais da área aeronáutica, como pilotos e comissários de bordo, são submetidos a doses de radiação de origem cósmica, que podem ser maiores do que as doses médias dos trabalhadores da indústria nuclear. A diversidade de partículas de altas energias presentes no campo de radiação a bordo das aeronaves torna complexa a mensuração da dose e requer cuidados especiais em relação aos sistemas de dosimetria a serem empregados nesta área. A Força Aérea Brasileira, por meio de seu Instituto de Estudos Avançados (IEAv /DCTA), em conjunto com o Instituto de Pesquisas Energéticas e Nucleares (IPEN / CNEN -SP) vem estudando o assunto desde 2008. Um protótipo de detector de radiação passivo para medições em aeronaves foi previamente construído e testado em condições de voo e de laboratório. O detector é capaz de medir a grandeza dosimétrica conhecida como dose absorvida (usando dosímetros passivos), que serão posteriormente correlacionados ao equivalente de dose ambiente e à dose efetiva recebidos por profissionais da área aeronáutica. Neste contexto, uma abordagem teórica por meio de simulações Monte Carlo com os códigos computacionais MCNP5 e MCNPX, foi usada para modelar e caracterizar a resposta do detector em determinadas condições experimentais. Este trabalho apresenta os resultados preliminares da modelagem computacional, com ênfase especial na comparação entre a grandeza fundamental dose absorvida (mensurada e simulada) e sua relação com o equivalente de dose ambiente e dose efetiva para este detector.
\end{abstract}




\title{
PERFORMANCE STUDY OF A PASSIVE RADIATION DETECTOR FOR AVIATION PURPOSES USING THE MONTE CARLO METHOD
}

\author{
LEONARDO DE HOLANDA MENCARINI
}

\begin{abstract}
Aircrews, as pilots and flight attendants, are subjected to cosmic ray doses which can be higher than the average doses on workers from the nuclear industry. The diversity of particles of high energies present in the radiation field on board of aircrafts, turns the determination of the incident dose and requires special care regarding dosimetric systems to be used in this kind of field. The Brazilian Air Force, through the Institute for Advanced Studies (Instituto de Estudos Avançados, IEAv/DCTA) in conjunction with the Institute of Energetic and Nuclear Research (Instituto de Pesquisas Energéticas e Nucleares - IPEN/CNEN-SP) are working on this subject since 2008. A prototype of a radiation detector for aircraft measurements was previously built and tested in flight and laboratory conditions. The detector is able of measuring a quantity known as absorbed dose (using passive dosimeters), which will subsequently be correlated to the ambient dose equivalent and the effective dose received by aircrews. In this context, a theoretical approach through Monte Carlo simulations with the computational codes MCNP5 and MCNPX was used to model and characterize the detector response at such experimental conditions. This work presents the preliminary results of the computational modeling, with special emphasis on the comparison between the absorbed dose quantity (measured and simulated) and its relationship with the ambient dose equivalent and the effective Dose for this detector.
\end{abstract}




\section{LISTA DE TABELAS}

Página

Tabela 1 - Exemplos de tipos de tallies disponíveis.

Tabela 2 - Avaliação de volume de controle a ser empregado nas

simulações computacionais.

Tabela 3 - Comparação entre os valores obtidos com o código MCNP5 ....

Tabela 4 - Comparação entre os valores obtidos com o código MCNP5, utilizando diferentes capacidades computacionais.

Tabela 5 - Valores obtidos para os 20 grupos de energia estipulados para os feixes monoenergéticos da fonte usada durante as simulações envolvendo a esfera ICRU.

Tabela 6 - Comparação dos valores da grandeza dosimétrica equivalente de dose ambiente utilizando os valores de $W_{R}$ apresentados na ICRP $74 \mathrm{e}$ ICRP 103

Tabela 7 - Resultados das simulações envolvendo o detector de PMMA....

Tabela 8 - Valores da simulação computacional empregando o espectro de emissão de nêutrons do ${ }^{241} \mathrm{Am} / \mathrm{Be}$

Tabela 9 - Valores experimentais obtidos da irradiação do detector passivo com uma fonte de ${ }^{241} \mathrm{Am} / \mathrm{Be}$.

Tabela 10 - Valores da simulação computacional empregando o espectro de emissão de nêutrons do ${ }^{252} \mathrm{Cf}$.

Tabela 11 - Valores experimentais obtidos da irradiação do detector passivo com uma fonte de ${ }^{252} \mathrm{Cf}$.

Tabela 12 - Valores da simulação computacional empregando o espectro de emissão de nêutrons de RC 


\section{LISTA DE SIGLAS E ABREVIATURAS}

CERN Centré European de Recherché Nucleaire

CNEN

Comissão Nacional de Energia Nuclear

DCTA

Departamento de Ciência e Tecnologia Aeroespacial

ENDF

Evaluated Nuclear Data File

FAPESP Fundação de Amparo à Pesquisa do Estado de São Paulo

ICRP

International Commission on Radiological Protection

ICRU International Commission on Radiation Units and Measurements

IEAv Instituto de Estudos Avançados

IRD Instituto de Radioproteção e Dosimetria

LANL Los Alamos National Laboratory

LET Linear energy transfer

MCNP5 Monte Carlo $N^{\circ}$ Particles version 5

MCNPX Monte Carlo $N^{\circ}$ Particles eXtended

NIST National Institute of Standards and Technology

PMMA Polimetilmetacrilato 


\section{LISTA DE FIGURAS}

\section{Página}

Figura 1 - Taxa de equivalente de dose ambiente em função da altitude barométrica padrão para vários componentes da radiação cósmica atmosférica em época de mínimo solar de $465 \mathrm{MV}$, em um local com rigidez magnética de 1,0 GV

Figura 2 - Taxa normalizada de fluência espectral de nêutrons (ISO 207851, 2006). Os fatores de normalização são apresentados no gráfico, para cada condição de ciclo solar, rigidez magnética e altitude.

Figura 3 - Seção de choque microscópica para a reação de captura radiativa ${ }^{1} \mathrm{H}(\mathrm{n}, \mathrm{Y})^{2} \mathrm{H}$

Figura 4 - Seção de choque microscópica para a reação de absorção ${ }^{14} \mathrm{~N}(\mathrm{n}, \mathrm{p}){ }^{14} \mathrm{C}$

Figura 5 - Comparação entre os fatores de qualidade pontual (cruz) e médio (quadrado) para prótons (em preto) e partículas alfa (em cinza).

Figura 6 - Fatores de qualidade $Q$ e fatores de ponderação de radiação $W$ para nêutrons em função da energia do nêutron. Valores de $W_{R}$ ( - - - -) oriundos de um ajuste de curva dos dados contidos no relatório ICRP 60; fator de qualidade efetivo $Q_{\mathrm{EFF}}$ (- . - . -) do relatório ICRP 21; fator de

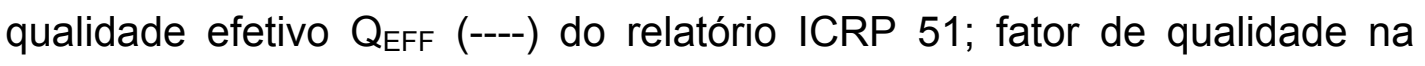
esfera ICRU à $10 \mathrm{~mm}$ oriundos de Schuhmacher $(\Delta)$ e Leuthold $(0)$ 
Figura 7 - Fatores de ponderação para nêutrons, onde a linha sólida representa $W_{R}$ e o ajuste da curva é uma aproximação para $W_{N}$

Figura 8 - Curvas de emissão termoluminescente de pastilhas de TLD-600 e TLD-700 após exposição em um campo misto nêutron - gama, mostrando a curva resultante da subtração do sinal do TLD-700 no sinal do TLD -600, cujo resultado corresponde ao sinal referente a nêutrons

Figura 9 - Fórmula estrutural do monômero Metacrilato de Metila

Figura 10 - Desenho esquemático do detector de PMMA com algumas posições de TLD utilizadas.

Figura 11 - Representação de um campo expandido e alinhado de nêutrons monoenergéticos incidentes na esfera ICRU

Figura 12 - Variação da energia depositada e sua incerteza associada em função do raio da esfera do volume de controle

Figura 13 - Curvas do equivalente de dose ambiente por unidade de fluência do feixe de nêutrons $\left(H^{*}(10) / \Phi\right)$ na esfera ICRU (LEUTHOLD et al.,1992; ICRP,1997). A incerteza máxima dos dados foi de $10 \%$

Figura 14 - Coeficientes de conversão de referência para equivalente de dose ambiente, em função da energia do nêutron, de institutos participantes do grupo de trabalho da ICRP 74 
Figura 15 - Variação entre os coeficientes de conversão para equivalente de dose ambiente de diferentes institutos, $\mathrm{H}^{*}(10) / \Phi$. A razão entre os dados obtidos por cada membro do grupo de trabalho e o melhor ajuste da curva avaliado pelo grupo é fornecido pela linha pontilhada, em função da energia do nêutron

Figura 16 - Curvas da dose absorvida por unidade de fluência do feixe de nêutrons $\left(D^{*}(10) / \Phi\right)$ na esfera ICRU

Figura 17 - Curvas do equivalente de dose ambiente por unidade de fluência do feixe de nêutrons $\left(H^{*}(10) / \Phi\right)$ na esfera ICRU

Figura 18 - Relação entre os coeficientes de conversão para equivalente de dose ambiente fornecido (ICRP 74) e calculado (MCNPX), $\mathrm{H}^{*}(10) / \Phi$. A razão entre os dados é fornecida pelos pontos, em função da energia do nêutron

Figura 19 - Curvas do equivalente de dose ambiente por unidade de fluência do feixe de nêutrons $\left(H^{*}(10 / \Phi)\right)$ na esfera ICRU em função da energia da radiação incidente, empregando-se os valores de fator de ponderação para nêutrons da ICRP 74 e ICRP 103.

Figura 20 - Variação entre os coeficientes de conversão para equivalente de dose ambiente em função da energia da radiação incidente, empregando-se os valores de fator de ponderação para nêutrons da ICRP 74 e ICRP 103. A razão entre os dados é fornecida pelos pontos, em função da energia do nêutron.

Figura 21 - Curvas do equivalente de dose ambiente por unidade de fluência do feixe de nêutrons $\left(H^{*}(10) / \Phi\right)$ na esfera ICRU 
Figura 22 - Resultados das simulações envolvendo o detector de PMMA.....

Figura 23 - Comparação dos resultados das simulações envolvendo o detector de PMMA e a esfera ICRU, em pGy $\times \mathrm{cm}^{2}$

Figura 24 - Comparação dos resultados das simulações envolvendo o detector de PMMA e a esfera ICRU, em pSv $\times \mathrm{cm}^{2}$

Figura 25 - Curva de calibração do detector em termos de dose absorvida em relação à esfera ICRU

Figura 26 - Relação entre as doses absorvidas na esfera ICRU e no detector $\left(D^{*}(10) / D(10)\right)$ em função da energia do nêutron incidente.

Figura 27 - Curva de calibração do detector em termos de equivalente de dose por unidade de fluência $(H(10) / \phi)$ em relação ao equivalente de dose ambiente por unidade de fluência $\left(H^{*}(10) / \phi\right)$.

Figura 28 - Curva de calibração do detector em termos de equivalente de dose por fluência em relação ao equivalente de dose ambiente por fluência.

Figura 29 - Curvas dos fatores de qualidade efetivos (Qeff) do detector e da esfera ICRU em função da energia incidente.

Figura 30 - Curva dos fatores de qualidade efetivos (Qeff) do detector e da esfera ICRU em função da energia, em formato tridimensional

Figura 31 - Espectro de nêutrons normalizados emitidos por fontes de ${ }^{241} \mathrm{Am} / \mathrm{Be}$ e ${ }^{252} \mathrm{Cf}$. 
Figura 32 - Comparação dos valores experimentais com os valores simulados computacionalmente das pastilhas do tipo TLD 600, irradiadas com uma fonte de ${ }^{241} \mathrm{Am} / \mathrm{Be}$

Figura 33 - Comparação dos valores experimentais com os valores simulados computacionalmente das pastilhas do tipo TLD 700, irradiadas com uma fonte de ${ }^{241} \mathrm{Am} / \mathrm{Be}$

Figura 34 - Comparação dos valores experimentais com os valores simulados computacionalmente das pastilhas do tipo TLD 600, irradiadas com uma fonte de ${ }^{241} \mathrm{Am} / \mathrm{Be}$, nas posições na direção radial do detector em relação à fonte

Figura 35 - Comparação dos valores experimentais com os valores simulados computacionalmente das pastilhas do tipo TLD 700, irradiadas com uma fonte de ${ }^{241} \mathrm{Am} / \mathrm{Be}$, nas posições na direção radial do detector em relação à fonte

Figura 36 - Comparação dos valores experimentais com os valores simulados computacionalmente das pastilhas do tipo TLD 600, irradiadas com uma fonte de ${ }^{252} \mathrm{Cf}$.

Figura 37 - Comparação dos valores experimentais com os valores simulados computacionalmente das pastilhas do tipo TLD 700, irradiadas com uma fonte de ${ }^{252} \mathrm{Cf}$

Figura 38 - Comparação dos valores experimentais com os valores simulados computacionalmente das pastilhas do tipo TLD 600, irradiadas com uma fonte de ${ }^{252} \mathrm{Cf}$, nas posições na direção longitudinal do detector em relação à fonte 
Figura 39 - Comparação dos valores experimentais com os valores simulados computacionalmente das pastilhas do tipo TLD 700, irradiadas com uma fonte de ${ }^{252} \mathrm{Cf}$, nas posições na direção longitudinal do detector em relação à fonte. 


\section{SUMÁRIO}

Página

1 INTRODUÇÃO

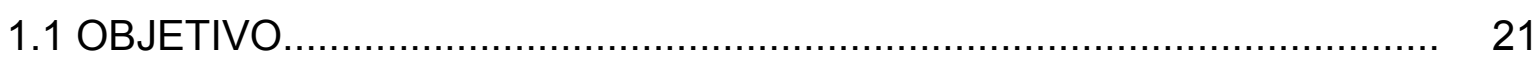

1.1.1 Objetivos específicos.................................................................... 21

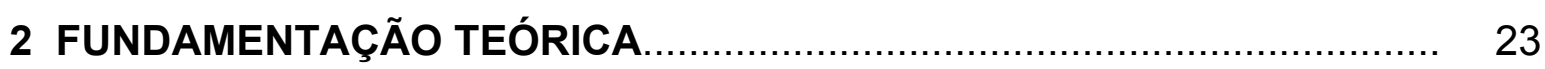

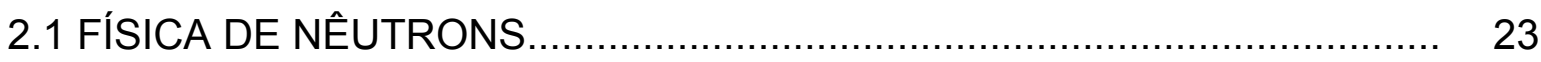

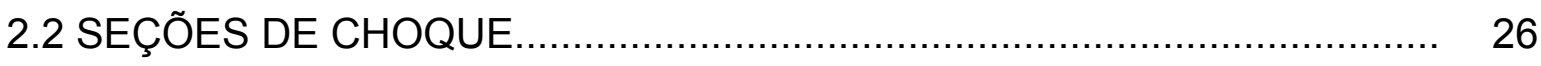

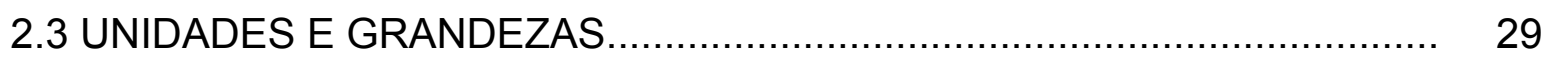

2.3.1 Grandezas de proteção................................................................. 36

2.3.2 Grandezas operacionais............................................................. 37

2.4 DOSIMETRIA TERMOLUMINESCENTE............................................. 38

3 MATERIAIS E MÉTODOS................................................................. 40

3.1 MÉTODO MONTE CARLO ................................................................... 40

3.1.1 Breve histórico............................................................................... 40

3.1.2 Transporte de radiação.......................................................... 41

3.1.3 Estrutura dos códigos computacionais MCNP5-1.60 e MCNPX 2.7.0. 41

3.2 RECURSOS COMPUTACIONAIS....................................................... 42

3.3 CÓDIGOS COMPUTACIONAIS EMPREGADOS ..................................... 43

3.3.1 Código computacional MCNP5-1.60 ............................................... 43

3.3.2 Código computacional MCNPX ...................................................... 44

3.3.3 Códigos computacionais "Star codes"............................................... 45

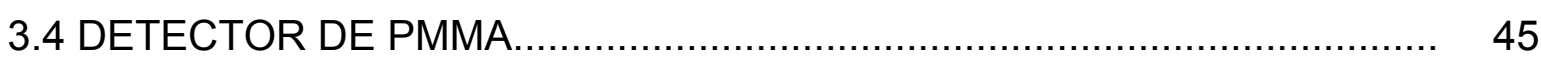

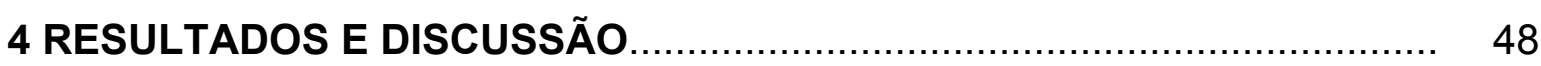

4.1 DETERMINAÇÃO DO EQUIVALENTE DE DOSE AMBIENTE SIMULANDO A ESFERA ICRU.............................................................. 48 
4.1.1 Determinação do equivalente de dose ambiente simulando a esfera ICRU com as sugestões da ICRP 103 para cálculo do fator $W_{R}$

4.2 DETERMINAÇÃO DO EQUIVALENTE DE DOSE SIMULANDO O

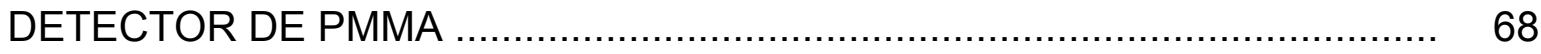

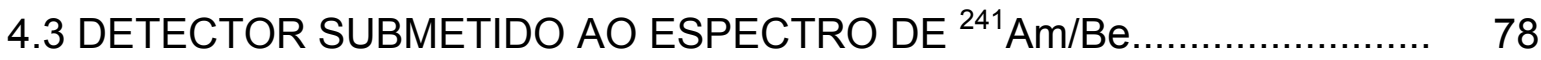

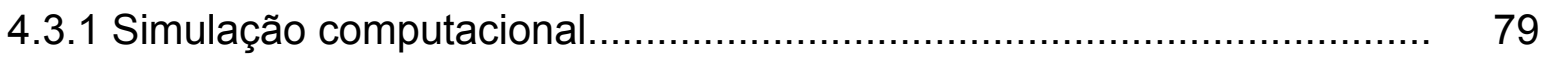

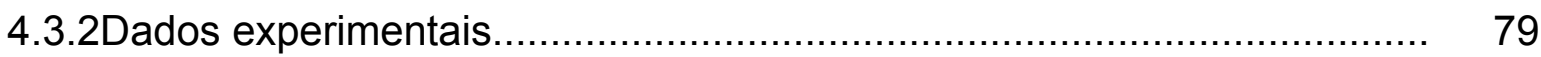

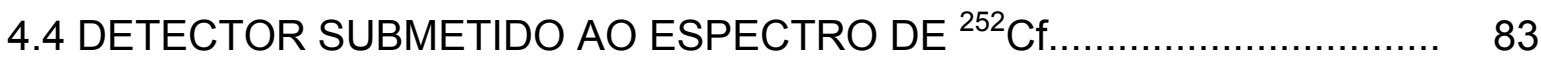

4.4.1 Simulação computacional........................................................ 84

4.4.2Dados experimentais...................................................................... 84

4.5 DETECTOR SUBMETIDO AO ESPECTRO DE RADIAÇÃO CÓSMICA .... 88

4.5.1 Campo de RC expandido e alinhado......................................... 89

4.5.2 Simulação computacional da fonte de RC isotrópica........................... 89

5 CONCLUSÕES........................................................................ 91

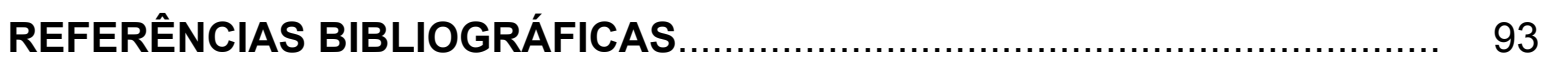




\section{INTRODUÇÃO}

O homem está continuamente exposto à radiação ionizante de origem tanto natural como artificial, sendo que, das fontes naturais de radiação, uma parcela importante é aquela de origem cósmica. Esta radiação cósmica $(R C)$ é constituída de partículas de energias altas provenientes do espaço, que atingem a Terra à velocidade próxima à da luz e colidem com as moléculas de nitrogênio e oxigênio da atmosfera terrestre.

A formação bem como o comportamento dos raios cósmicos vem sendo estudado por meio de dois projetos temáticos da Fundação de Amparo à Pesquisa do Estado de São Paulo (FAPESP), denominados "Investigação de fenômenos de altas energias e plasmas astrofísicos: teoria, observação e simulações numéricas - n06/50654-3" e "Estudo dos raios cósmicos de mais altas energias com o Observatório Pierre Auger - n`10/07359-6”. Segundo consta na edição de número 200 da revista Pesquisa FAPESP, o primeiro estudo indica que "... os raios cósmicos poderiam se formar em consequência do encontro e da aniquilação de campos magnéticos de polaridades opostas em atmosferas de estrelas e de objetos cósmicos compactos como buracos negros de massas estelares ou núcleos ativos de galáxias." (FIORAVANTI, 2012). A edição de número 200 informa ainda que "... O outro estudo - em parceria com 0 Observatório Pierre Auger - ... analisa as colisões dos raios cósmicos de alta energia com os núcleos dos átomos da atmosfera e apresenta a área de interação dos raios cósmicos de energia de $10^{18}$ a $10^{18,5} \mathrm{eV}$ com os núcleos dos átomos da atmosfera.". Segundo Carola D. Chinellato, pesquisadora do Instituto de Física da Universidade Estadual de Campinas (UNICAMP) e coordenadora da equipe paulista no Observatório Pierre Auger, "Nenhum outro experimento havia feito essa medida da seção de choque próton-ar ou da seção de choque próton-próton nessas energias altíssimas".

Ao atingirem a Terra, uma fração dessas partículas será defletida ou aprisionada pelo campo magnético terrestre. Outra parte penetrará na atmosfera gerando um chuveiro secundário de radiação, o qual pode atingir a superfície 
terrestre. Os chuveiros de radiação secundária são produzidos pela interação da radiação cósmica primária com os átomos da atmosfera (FURUKAWA, 2005).

Como consequência da interação do chuveiro de radiação primário originado pelos raios cósmicos e os núcleos dos átomos de nitrogênio e oxigênio presentes na atmosfera, os diversos componentes gerados no campo de radiação cósmica, como nêutrons, prótons, elétrons, fótons, múons e píons, contribuem para o equivalente de dose ambiente, $\mathrm{H}^{*}(10)$ (ambient dose equivalent). Neste trabalho, a contribuição neutrônica do campo da RC é priorizada devido a sua preponderância em altitudes de voo (acima de 5000 metros), conforme a Figura 1.

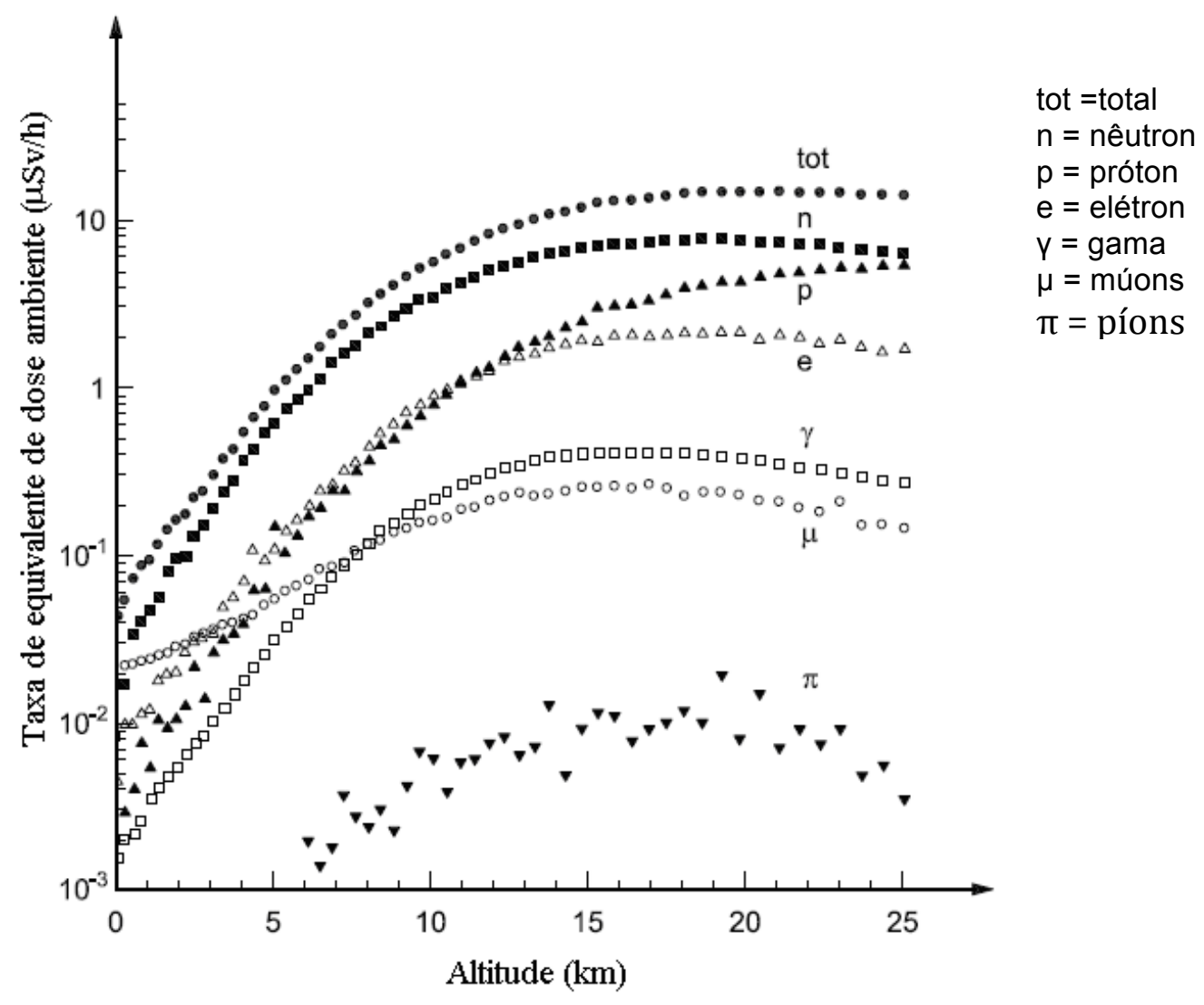

Figura 1 - Taxa de equivalente de dose ambiente em função da altitude barométrica padrão para vários componentes da radiação cósmica atmosférica em época de mínimo solar de $465 \mathrm{MV}$, em um local com rigidez magnética de 1,0 GV (extraído e adaptado da ISO (ISO, 2006)). 
Nestas últimas décadas, não só com o desenvolvimento de aeronaves com teto de operação mais alto e o aumento do fluxo aéreo, como também com a maior autonomia de certas aeronaves, o problema do controle do nível de dose de radiação ionizante recebida pelos pilotos e tripulação de aeronaves, bem como pelos equipamentos sensíveis, os aviônicos, passou a ser gradualmente mais importante nas áreas de saúde ocupacional, proteção radiológica, radiobiologia e segurança de voo.

Com relação à saúde ocupacional, o fato de que pilotos e tripulações podem receber doses de radiação superiores aos limites aplicáveis ao público em geral, motivou a elaboração de normas e recomendações em diversos países com a finalidade de controlar as doses ocupacionais recebidas por estes profissionais. Como exemplo, destacam-se o procedimento dos EUA, FAA 120-52 (FAA, 1990) e o procedimento Canadense AC-0183 (Transport Canada, 2011).

O Brasil, apesar de estar localizado em uma região tropical, sofre os efeitos de uma anomalia magnética (South Atlantic Magnétic Anomaly) que pode implicar em modificações nas doses recebidas pelas tripulações de aeronaves que operam nesta região. Os níveis de dose podem superar o limite de dose anual proposto pela Agência Internacional de Energia Atômica para indivíduos do público de $1 \mathrm{mSv}$ (IAEA,1996), limite este que pode ser facilmente ultrapassado por tripulações de aeronaves, que podem voar tipicamente até cerca de 600 a 800 horas por ano.

Em face do exposto, a Força Aérea Brasileira está desenvolvendo um trabalho de pesquisa voltado para avaliar as doses de radiação cósmica recebidas por pilotos e tripulações que operam no espaço aéreo brasileiro, onde parte importante do referido projeto é a caracterização de sensores de radiação para serem utilizados em voo, de forma a poder efetuar um mapeamento das doses nesta região e tirar conclusões a respeito dos riscos à saúde ocupacional das tripulações (FEDERICO et al., 2010).

Este problema motivou diversos estudos sobre esse assunto, publicados na literatura especializada internacional (FEDERICO, 2011). Destaque especial pode ser dado para o transporte civil de altas velocidades (High Speed Civil Transport), que possuía na aeronave Concorde seu melhor exemplo, pela 
forma como era operada em alta altitude, estando sujeita a doses da ordem de 2 a 3 vezes maiores que nos voos subsônicos usuais (WILSON et al., 2008).

Devido às dificuldades técnicas e financeiras envolvidas neste campo de estudo, optou-se por uma abordagem por meio de simulações computacionais, empregando-se códigos computacionais reconhecidos e utilizados pela comunidade cientifica, para fins de estudo do comportamento de detectores passivos em ambiente de radiação cósmica.

Dessa forma, o Instituto de Estudos Avançados (IEAv) da Força Aérea Brasileira, organização militar com a missão de realizar pesquisa aplicada no campo aeroespacial, por meio de suas Divisões de Energia Nuclear e de Física Aplicada, em colaboração com o grupo da Gerência de Metrologia das Radiações do Instituto de Pesquisas Energéticas e Nucleares (IPEN), da Comissão Nacional de Energia Nuclear (CNEN), optaram por desenvolver estudos referentes à dosimetria de radiação ionizante no ambiente aeronáutico, bem como propor detectores passivos para serem utilizados em aeronaves.

A calibração de detectores para utilização em voo torna-se complexa, pois somente no laboratório do Centré European de Recherché Nucleaire (CERN) existe um campo de radiação cuja distribuição em energia e taxa de fluência são adequadas para calibração de equipamentos a serem utilizados para medições dos campos presentes em altitudes de voo de aeronaves. Este campo de radiação foi empregado para verificação dos detectores utilizados nas medidas experimentais feitas pelo IEAv.

Entretanto, tal procedimento é extremamente difícil e custoso, ressaltando a importância da simulação computacional para a reprodução do comportamento de sensores expostos ao campo da RC em função da altitude.

Neste contexto, o Método Monte Carlo foi empregado por meio dos códigos computacionais Monte Carlo $N^{\circ}$ Particles 5 (MCNP5) (X-5 MONTE CARLO TEAM, 2008) e Monte Carlo $N^{\circ}$ Particles eXtended (MCNPX) (PELOWITZ, 2011) para modelar e caracterizar um detector de radiação que foi construído e está sendo testado para medidas em aeronaves, com a finalidade de se mensurar a grandeza dosimétrica equivalente de dose ambiente, $H^{*}(10)$, que será posteriormente relacionada a doses efetivas recebidas pelos profissionais de aviação. 


\subsection{OBJETIVO}

O objetivo geral do presente trabalho é simular o comportamento do sistema dosimétrico utilizado por Federico (2011) para nêutrons, por meio dos códigos computacionais MCNP5 e MCNPX, avaliando as técnicas de modelagem adequadas para uso de detectores termoluminescentes, com a finalidade do emprego de tais detectores na dosimetria de radiação em altitude de voo (campo de alta energia). Com este objetivo, o presente trabalho almeja elucidar aspectos referentes ao uso de simulação computacional, empregando o método Monte Carlo no campo aeroespacial, e desta forma melhorar o nível de conhecimento e confiança sobre os processos de simulação computacional da RC, visando empreender novos esforços para o projeto computacional de novos layouts de sensores de RC com melhores características de eficiência e portabilidade.

\subsubsection{Objetivos específicos}

Os objetivos específicos do presente trabalho são:

- Obter a curva referente ao equivalente de dose ambiente por unidade de fluência $\left(H^{*}(10) / \Phi\right)$ de nêutrons em função da energia (ICRP, 1997), em um campo expandido e alinhado, em uma esfera ICRU, por meio de simulação computacional, comparando os resultados com os existentes na literatura, para fins de validação da metodologia a ser empregada;

- Empregando a mesma metodologia, obter a curva referente ao equivalente de dose por unidade de fluência $\left(H^{*}(10) / \Phi\right)$ de nêutrons em função da energia (ICRP, 2007), em campo expandido e alinhado, em uma esfera ICRU, por meio de simulação computacional;

- Utilizando a mesma metodologia, obter a curva referente ao equivalente de dose por unidade de fluência $(H(10) / \Phi)$ de nêutrons em função da energia (ICRP, 1997), em campo expandido e alinhado, no detector de PMMA, por meio de simulação computacional;

- Submeter o detector de polimetilmetacrilato (PMMA) ao mesmo campo expandido e alinhado utilizado na esfera ICRU, visando confeccionar uma provável curva de calibração entre a esfera ICRU e o detector; 
- Realizar simulações do detector de PMMA com as pastilhas de fluoreto de lítio (LiF) inseridas em suas posições, para avaliação dos resultados obtidos com o detector submetido aos espectros de nêutrons do ${ }^{241} \mathrm{Am} / \mathrm{Be}$ e do ${ }^{252} \mathrm{Cf}$;

- Comparar as simulações do detector com diferentes tipos de fontes $\left({ }^{241} \mathrm{Am} / \mathrm{Be}\right.$ e $\left.{ }^{252} \mathrm{Cf}\right) \mathrm{com}$ as irradiações realizadas pelo $\mathrm{Dr}$. Claudio A. Federico no detector, durante seu doutoramento (FEDERICO, 2011);

- Simular o detector em um ambiente submetido ao espectro de raios cósmicos, para comprovação de sua possível utilidade. 


\section{FUNDAMENTAÇÃO TEÓRICA}

Neste capitulo são abordados alguns conceitos fundamentais necessários para uma melhor compreensão dos assuntos discutidos neste trabalho.

\subsection{FÍSICA DE NÊUTRONS}

Nêutrons são partículas pesadas desprovidas de carga elétrica, que possuem um comportamento diferenciado em relação às outras partículas (prótons, elétrons, dêuterons, etc.) e por isso algumas peculiaridades merecem atenção. Por não possuírem carga elétrica, os nêutrons não interagem com a matéria por meio da força coulombiana. Dessa forma, a presença de elétrons atômicos não altera a trajetória ou a energia cinética de nêutrons que incidem na matéria. Nêutrons, portanto, somente perdem energia cinética interagindo com a matéria por meio dos fenômenos decorrentes das interações com núcleos atômicos.

A classificação destes fenômenos segue a seguinte formulação:

$$
\mathrm{n}+\mathrm{X} \rightarrow \mathrm{Y}+\mathrm{g}
$$

onde n é o nêutron incidente, $\mathrm{X}$ é o núcleo-alvo, Y é um núcleo-produto e g é um produto da interação. Conforme a natureza de $\mathrm{g}$, o fenômeno será de espalhamento ou de absorção (DUDERSTADT e HAMILTON, 1976). Segundo Terremoto (2004), esse fenômeno será de:

1) espalhamento elástico ( $g$ é um nêutron e a energia cinética total do sistema nêutron incidente + núcleo-alvo se conserva);

2) espalhamento inelástico (g é um nêutron, a energia cinética total do sistema nêutron incidente + núcleo-alvo não se conserva e o núcleo-alvo é levado a estados excitados);

3) captura (g é uma ou mais partículas carregadas pesadas: partículas $\alpha$, prótons, dêuterons, etc.);

4) captura radiativa (g é um raio-gama); 
5) emissão de nêutrons (g é dois ou mais nêutrons); e

6) fissão (g é um núcleo atômico mais dois ou três nêutrons em média).

Os nêutrons que compõem o campo da RC em altitude de voo possuem energias que variam de $0,01 \mathrm{eV}$ a $400 \mathrm{MeV}$, conforme espectro apresentado na Figura 2.

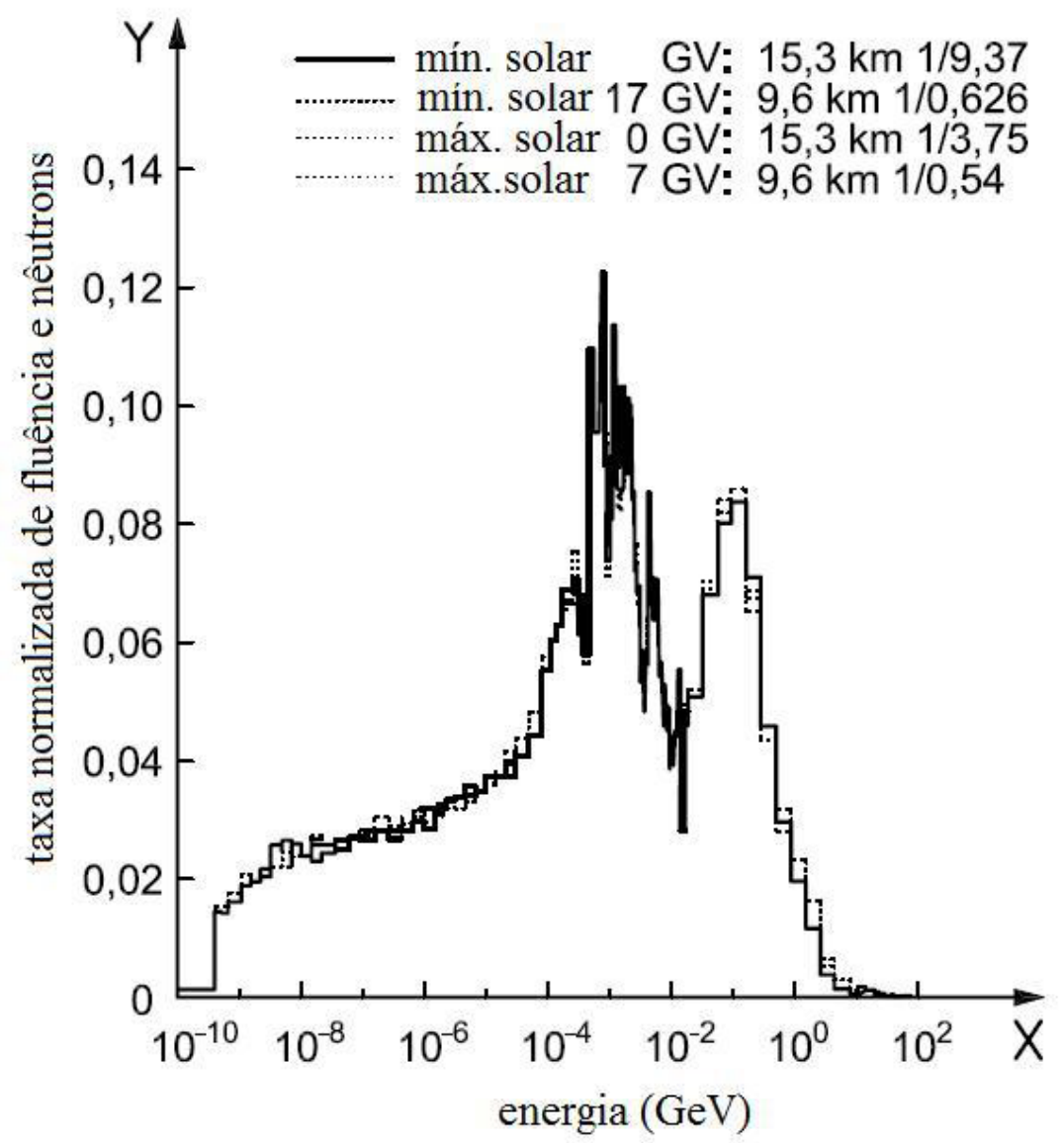

Figura 2 - Taxa normalizada de fluência espectral de nêutrons (ISO 20785-1, 2006). Os fatores de normalização são apresentados no gráfico, para cada condição de ciclo solar, rigidez magnética e altitude.

Devido ao fato de que o espectro da RC possui uma significativa presença de nêutrons de alta energia, faz-se necessário considerar o processo pelo qual os nêutrons rápidos $(\geq 0,5 \mathrm{MeV})$ são convertidos em nêutrons lentos ( $\leq$ $0,5 \mathrm{MeV}$ ), chamado de moderação de nêutrons, pois as seções de choque para os fenômenos de fissão (item 6) e captura radiativa (item 4) aumentam com a diminuição da energia cinética do nêutron incidente. Os processos de moderação que ocorrem com maior frequência na altitude de voo são o de espalhamento elástico por núcleos leves e o de espalhamento inelástico por núcleos 
intermediários ou pesados, sendo importante ressaltar que para nêutrons com energia cinética maior que $200 \mathrm{MeV}$ (nêutrons relativísticos), são necessários modelos físicos específicos, como por exemplo, o modelo físico de Bertini, presente na estrutura do código computacional MCNPX, para prever a probabilidade de ocorrência desse tipo de interação (PELOWITZ, 2011).

Com o processo de moderação em andamento ou realizado, os nêutrons podem alcançar um equilíbrio energético com as moléculas do meio onde se encontram, de tal maneira que tanto os ganhos quanto as perdas energéticas oriundas de colisões se tornam equiprováveis. Quando o nêutron atinge este estágio energético, é denominado de nêutron térmico (ou nêutrons com energia $k T$ ) e seu comportamento é similar àquele dos átomos de um gás e pode ser descrito aproximadamente pela teoria cinética dos gases, com uma distribuição maxwelliana de velocidades, dada por

$$
n(v) d v=4 \pi n\left(\frac{m}{2 \pi k T}\right)^{3 / 2} v^{2} e^{-m v^{2} / 2 k T} d v
$$

onde $n$ é o número total de nêutrons por unidade de volume, $n(v) d v$ é o número de nêutrons por unidade de volume que possuem velocidades entre $v$ e $v+d v, m$ é a massa de um nêutron, $k$ é a constante de Boltzmann e $T$ é a temperatura absoluta do moderador (TERREMOTO, 2004).

Com relação às alterações estruturais no material produzidas pelas interações neutrônicas, tanto os nêutrons lentos quanto os nêutrons rápidos podem produzir importantes modificações nas propriedades mecânicas dos materiais com que interagem. No caso das reações nucleares de captura radiativa (item 4), como estas reações devem conservar a quantidade de movimento, a emissão de radiação gama (fóton) virá acompanhada do recuo do núcleo residual. As energias de recuo podem alcançar valores de centenas de eV, sendo suficientes para produzir um número considerável de deslocamentos atômicos. Este efeito é muito importante em materiais que possuem seções de choque de captura radiativa elevadas.

Os efeitos das radiações nas substâncias orgânicas cristalinas e materiais não cristalinos, como por exemplo o polimetilmetacrilato utilizado na confecção do detector, se devem a mecanismos distintos, sendo o mais relevante 
a ruptura das ligações covalentes. O limiar de energia para esta ruptura é da ordem de $25 \mathrm{eV}$, logo podem provocar alterações físicas no material citado tanto pelos nêutrons rápidos quanto nêutrons térmicos, como consequência das emissões secundárias originadas no processo de espalhamento e de captura, respectivamente (GLASSTONE e SESONSKE,1962).

\subsection{SEÇÕES DE CHOQUE}

O conceito de seção de choque serve para descrever as interações dos nêutrons com os núcleos atômicos, de modo que quando se expõe um material qualquer à interação com nêutrons, a velocidade com que ocorre uma determinada reação nuclear é função do número de nêutrons, de sua velocidade, do número e da natureza dos núcleos existentes no material irradiado. A seção de choque de um elemento, para uma reação nuclear específica é uma propriedade do núcleo e da energia do nêutron incidente (GLASSTONE e SESONSKE,1962) e sua definição é para nêutrons com uma energia cinética bem definida (monoenergéticos) incidindo em um núcleo atômico conhecido, a probabilidade de ocorrência correspondente a cada um dos fenômenos mencionados é uma constante. Esta probabilidade é denominada seção de choque $\sigma$ (também usualmente designada como seção de choque microscópica), possui dimensão de área, sendo medida em unidades de área, denominada barn (b), sendo que $1 \mathrm{~b}$ corresponde a $10^{-24} \mathrm{~cm}^{2}$.

A grandeza denominada seção de choque macroscópica $\Sigma$ resulta da multiplicação da seção de choque $\sigma$ pelo número $\mathrm{N}$ de núcleos atômicos por unidade de volume $\left(\mathrm{cm}^{3}\right)$ :

$$
\Sigma=\mathrm{N} . \sigma
$$

sendo que $\Sigma$ possui a dimensão de $\mathrm{cm}^{-1}$. A seção de choque macroscópica total resulta da soma das seções de choque macroscópicas correspondentes a cada um dos fenômenos mencionados (espalhamento elástico- $\Sigma$ ee , espalhamento inelástico $-\Sigma$ ei , captura $-\Sigma \mathrm{c}$, captura radiativa $-\Sigma \mathrm{cr}$, emissão de nêutrons $-\Sigma e n$, fissão $-\Sigma f)$ :

$$
\Sigma \mathrm{t}=\Sigma \mathrm{ee}+\Sigma \mathrm{ei}+\Sigma \mathrm{c}+\Sigma \mathrm{cr}+\Sigma \mathrm{en}+\Sigma \mathrm{f}
$$

e deste modo $\Sigma$ t fornece a probabilidade, por unidade de comprimento 
atravessado, de que qualquer um destes fenômenos venha a ocorrer (TERREMOTO, 2004).

A energia depositada e o equivalente de dose ambiente produzido pelos nêutrons é gerado pela sua energia cinética, em grande parte pelo espalhamento elástico no hidrogênio e das reações nucleares exotérmicas. Abaixo de $100 \mathrm{eV}$, observa-se prótons gerados pela reação ${ }^{14} \mathrm{~N}(n, p){ }^{14} \mathrm{C}$.

Segundo o relatório ICRU 66 (ICRU, 2001), o espalhamento e a moderação de nêutrons de altas energias na esfera ICRU eleva a dose absorvida no ponto de interesse.

Uma parcela importante da dose absorvida merece atenção especial devido aos fótons gerados na reação de captura radiativa ${ }^{1} \mathrm{H}(n, \gamma){ }^{2} \mathrm{H}$, produzindo fótons de 2,2 MeV. A captura radiativa ocorre ao longo de toda a esfera ICRU e a probabilidade de captura do nêutron aumenta à medida em que ocorre o decréscimo de energia do nêutron como resultado de sua moderação (termalização do nêutron) devido aos múltiplos espalhamentos. Como resultado da reação ${ }^{1} \mathrm{H}(\mathrm{n}, \mathrm{y})^{2} \mathrm{H}$, o espalhamento Compton destes fótons de 2,2 MeV surge como fonte geradora de fótons secundários na faixa de energia de até $1 \mathrm{MeV}$.

$\mathrm{Na}$ profundidade de $10 \mathrm{~mm}$ da superfície da esfera ICRU, fótons secundários contribuem em torno de $90 \%$ da dose absorvida da irradiação por nêutrons térmicos e intermediários ( $\leq 10 \mathrm{keV})$. A partir dessa faixa energética, a contribuição dos fótons secundários para a dose absorvida diminui de tal forma que representa menos de $20 \%$ para nêutrons incidentes de $1 \mathrm{MeV}$ (DIETZE e SIEBERT, 1994). Para nêutrons incidentes com energia superior a $1 \mathrm{MeV}$, os fótons terciários ou de ordem superior depositam a maior fração de dose absorvida na esfera.

Sendo assim, todo o volume da esfera ICRU contribui para a geração destes fótons secundários que poderão resultar em dose absorvida no ponto de interesse.

Na Figura 3 pode-se observar a curva referente à seção de choque microscópica para a reação de captura radiativa ${ }^{1} \mathrm{H}(\mathrm{n}, \mathrm{y})^{2} \mathrm{H}$. 


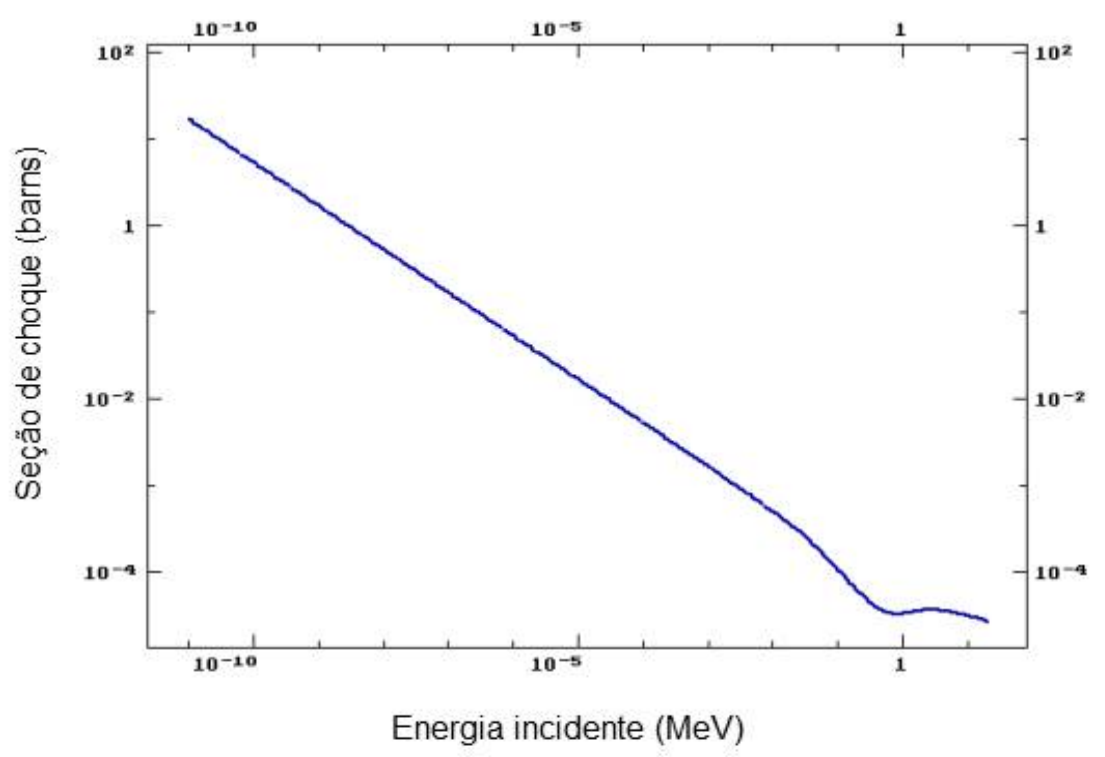

Figura 3 - Seção de choque microscópica para a reação de captura radiativa ${ }^{1} \mathrm{H}(\mathrm{n}, \mathrm{\gamma})^{2} \mathrm{H}(\mathrm{IAEA}, 2013)$.

Esta reação possui uma seção de choque que, em sua região térmica, varia proporcionalmente a $1 / \mathrm{v}$, onde $\mathrm{v}$ representa a velocidade do nêutron, $\mathrm{e}$ claramente representa um decréscimo linear na região da energia, conforme explicado anteriormente.

À medida que a energia do nêutron incidente aumenta, outras reações começam a desempenhar um papel relevante na deposição de energia. Depois dos fótons, os prótons são a fonte de radiação mais importante em termos de dose absorvida. Na faixa de energia de nêutrons térmicos, a reação de absorção ${ }^{14} \mathrm{~N}(\mathrm{n}, \mathrm{p}){ }^{14} \mathrm{C}$, que produz prótons de aproximadamente $600 \mathrm{keV}$, contribui em grande parte para a parcela de dose absorvida dos prótons, conforme Figura 4. 


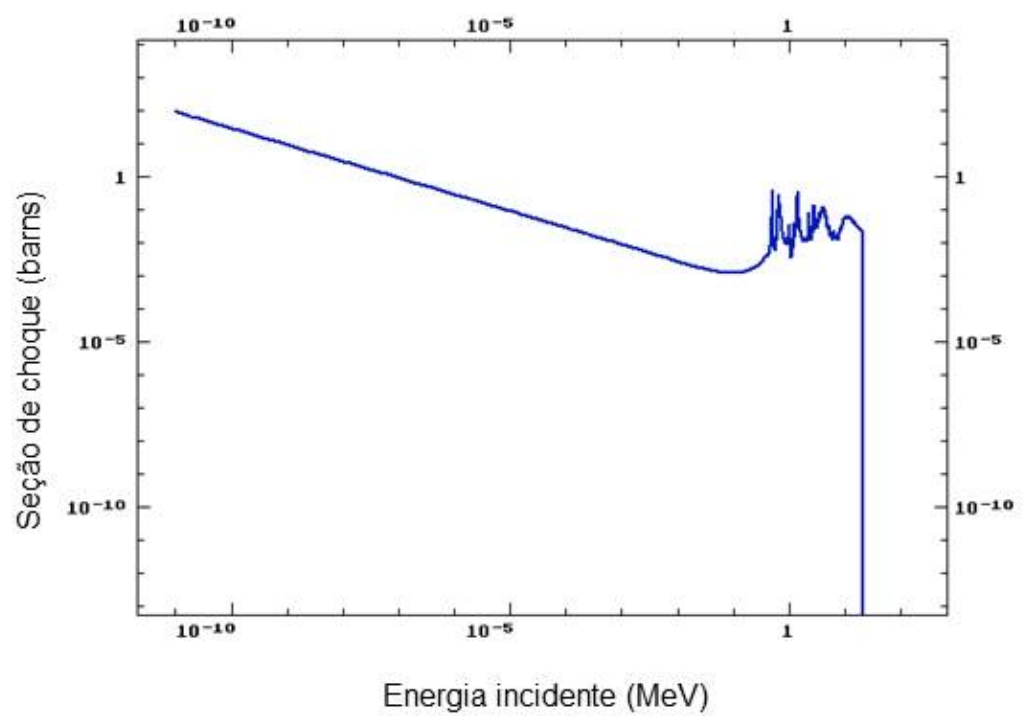

Figura 4 - Seção de choque microscópica para a reação de absorção ${ }^{14} \mathrm{~N}(\mathrm{n}, \mathrm{p}){ }^{14} \mathrm{C}(\mathrm{IAEA}, 2013)$.

\subsection{UNIDADES E GRANDEZAS}

De acordo com o relatório 51 da International Commission on Radiation Units and Measurements (ICRU), intitulado Quantities and Units in Radiation Protection Dosimetry (ICRU,1993), as grandezas e unidades anteriormente definidas nos relatórios ICRU 33 (ICRU,1980) e ICRU 39 (ICRU,1985) permaneceram válidas, sendo alteradas as grandezas referentes à equivalente de dose pessoal $\left(\mathrm{H}_{\mathrm{P}}(\mathrm{d})\right)$ (personal dose equivalent), conforme sua seção de número I.4.3.2 (ICRU,1993). Seguem algumas definições e conceitos que serão empregados ao longo deste trabalho:

- Fluência, $\Phi$, é o quociente de $\mathrm{dN}$ por $\mathrm{dA}$, onde $\mathrm{N}$ é o numero de partículas incidentes em uma esfera de área de seção transversal $A$, logo

$$
\Phi=\frac{\mathrm{dN}}{\mathrm{dA}}\left(\mathrm{m}^{-2}\right)
$$

- Kerma, $\mathrm{K}$, é o quociente de $\mathrm{dE}_{\mathrm{tr}}$ por $\mathrm{dm}$, onde $\mathrm{dE}_{\mathrm{tr}}$ é a soma das energias cinéticas iniciais de todas as partículas ionizantes eletricamente carregadas, liberadas pelas partículas ionizantes sem carga num material de massa dm,

$$
K=\frac{d E t r}{d m}\left(\mathrm{~J} \mathrm{~kg}^{-1}\right)
$$


tendo como unidade o Joule por quilograma, cujo nome especial é Gray (Gy);

- Exposição, X, é o quociente de dq por dm, onde dq é o valor absoluto de todas as cargas elétricas dos íns de um mesmo sinal produzidos no ar quando, todos os elétrons (négatrons e pósitrons) liberados por fótons num elemento de volume de ar, cuja massa é dm, são completamente freados no ar,

$$
X=\frac{d q}{d m}\left(\mathrm{C} \mathrm{kg}^{-1}\right),
$$

tendo como unidade o Coulomb por quilograma;

- Dose Absorvida, $D$, é a grandeza dosimétrica fundamental, é o quociente entre $\mathrm{d} \epsilon$ por $\mathrm{dm}$, onde $\mathrm{d} \epsilon$ é a energia média transmitida pela radiação ionizante para a matéria de massa $\mathrm{dm}$, logo

$$
D=\frac{d \epsilon}{d m} \quad\left(\mathrm{~J} \mathrm{~kg}^{-1}\right),
$$

tendo como unidade o Joule por quilograma, cujo nome especial é Gray (Gy);

- Energia Transmitida, $\epsilon$, pela radiação ionizante na matéria em um volume, em Joule (J), é

$$
\epsilon=R_{\text {in }}+R_{\text {out }}+\sum Q
$$

onde $R_{\text {in }}$ é a energia da radiação incidente no volume, ou seja, a soma das energias excluindo as massas de repouso de todas as partículas ionizantes carregadas ou não que entrem no volume de controle, $R_{\text {out }}$ é a energia da radiação que sai do volume de controle, ou seja, a soma das energias de todas as partículas ionizantes carregadas ou não que saem do volume de controle, e $\sum Q$ é o somatório de todas as mudanças (decréscimos: sinal positivo, acréscimos: sinal negativo) de estado energético e massa de repouso de cada núcleo e partícula elementar em cada interação que ocorra no volume de controle;

- Equivalente de Dose (Dose Equivalent), $\mathrm{H}$, é o produto de $\mathrm{Q}$ e $\mathrm{D}$ em um ponto do tecido, onde $D$ é a dose absorvida e $Q$ é o fator de qualidade no ponto, logo

$$
H=Q D=\int Q(L) D_{L} d L
$$


onde $Q(L)$ é o fator de qualidade para partículas com transferência linear de energia (Linear Energy Transfer, LET) L, e $D_{L}$ é a distribuição espectral em termos de $L$ da dose absorvida no ponto. A grandeza desta unidade é Joule por quilograma $\left(\mathrm{J} \mathrm{kg}^{-1}\right)$, cujo nome especial é Sievert (Sv). As grandezas operacionais resultam de pontos de interesse e condições de irradiação específicos.

A probabilidade de ocorrência de efeitos estocásticos não depende apenas da dose absorvida, mas também do tipo e da energia da radiação causadora da dose. Esta dependência é considerada ponderando-se com um fator de peso relacionado com o tipo e a energia da radiação. Para o equivalente de dose, este fator de peso é conhecido por fator de qualidade (quality factor), $Q$, e é aplicado ao valor de dose absorvida no ponto de interesse do tecido em questão, e sua dependência em relação à transferência linear de energia, L, de partículas carregadas em água é fornecida pelo relatório ICRP 60 (ICRP, 1991).

O fator de qualidade $Q$, é dado por:

$$
Q=D^{-1} \int Q(L) D_{L} d L
$$

onde $\mathrm{D}$ é a dose absorvida no ponto de interesse, $D_{L}$ é a distribuição de $\mathrm{D}$ em transferência linear de energia, $L$, no ponto de interesse, e $Q(L)$ é o fator de qualidade em função da transferência linear de energia, L, em água. A integração é realizada sobre a distribuição $D_{L}$, levando-se em conta todas as partículas carregadas, excluindo seus elétrons secundários (ICRU, 2001). Para fins deste trabalho, a dose absorvida a $10 \mathrm{~mm}$ de profundidade da esfera ICRU, sem qualquer fator de ponderação (quality-weighting) será denominada por dose ambiente, $D^{*}(10)$.

Entretanto, para a avaliação da grandeza equivalente de dose ambiente é necessário obter os valores do fator de qualidade (Q) para cada tipo de partícula, por meio da relação $Q(L)$ em função da transferência linear de energia (ICRU, 1970) de cada partícula, sendo que no caso de algumas partículas ainda variam seus valores para cada faixa de energia (bin) envolvida no processo.

O relatório ICRP 74 (ICRP, 1997) recomenda que seja utilizada a função representada nas Equações 12.a, 12.b e 12.c para o cálculo do $Q(L)$ : 


$$
\begin{aligned}
& Q(L)=1 \quad(L<10 \mathrm{keV} / \mu \mathrm{m}) \\
& Q(L)=0,32 L-2,2 \quad(10 \leq L \leq 100 \mathrm{keV} / \mu \mathrm{m}) \\
& Q(L)=300 / \sqrt{L} \quad(L>100 \mathrm{keV} / \mu \mathrm{m})
\end{aligned}
$$

É importante ressaltar que os coeficientes de conversão fornecidos pelo relatório ICRP 74 (ICRP, 1991) foram calculados para irradiações monoenergéticas. Na prática, os campos de radiação monoenergéticos são raros e geralmente as energias de suas partículas constituintes variam ao longo de diferentes faixas energéticas. Mesmo em laboratórios primários, os campos de referência usados para testes e calibrações de equipamentos são em sua maioria quase monoenergéticos (quasi-monoenergetic). Sendo assim, os coeficientes de conversão médios e efetivos aplicados ao espectro a ser analisado deverão ser determinados por integração sobre todo o espectro de energia da radiação presente. Outra consideração diz respeito aos campos de radiação importantes para a proteção radiológica (como o campo de RC objeto deste estudo, por exemplo) que geralmente consistem de mais de um tipo de radiação por causa das radiações secundárias geradas pelas interações das radiações primárias com a matéria, particularmente para nêutrons em qualquer faixa de energia e para a maioria das radiações de altas energias.

Por isso foi necessário realizar uma discretização dos tallies por faixas de energia (bin), de tal forma que os valores empregados do fator $Q$ fossem os mais próximos possíveis do valor real para cada quantidade de dose absorvida computada em cada bin de energia. Entretanto, os fatores de qualidade, por serem dependentes da transferência linear de energia, $L$, fornecidos pelos relatórios ICRU 49 (1993), 57 (1998) e 73 (2005) não podem ser utilizados pontualmente, porque o fator $L$ varia bruscamente durante a perda de energia (slowing-down) do próton ou íon. Com este propósito, foi definido um fator de qualidade médio $\left(Q_{m}\right)$ simulando a perda de energia da partícula. Para tanto, a dependência de $Q(L)$ em função do $L(E)$ foi integrada desde a energia inicial (Ei) até $E$ igual a zero $(E=0)$, ao longo de todas as energias compreendidas neste intervalo,

$$
\mathrm{Q}_{\mathrm{m}}(\mathrm{Ei})=\frac{\int_{E i}^{0} Q(L(E)) d E}{\int_{E i}^{0} d E}
$$


usando os valores de $L$ apresentados para prótons e partículas alfa (ICRU,1993) e íons pesados C, N e O (ICRU, 2005). Segundo Garny et al.(2009), a diferença entre o emprego do valor do fator $Q$ pontual e o fator $Q$ médio é mostrado na Figura 5 para prótons e partículas alfa.

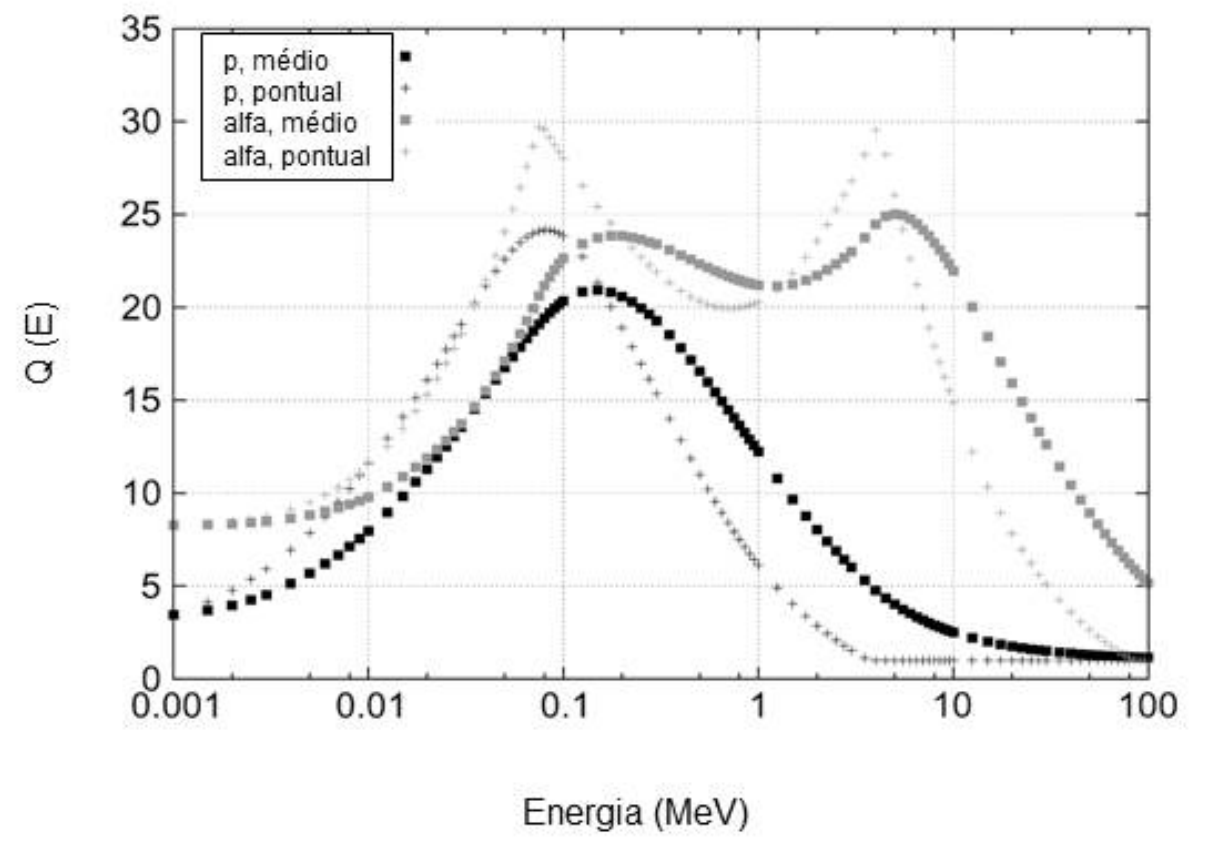

Figura 5 - Comparação entre os fatores de qualidade pontual (cruz) e médio (quadrado) para prótons (em preto) e partículas alfa (em cinza). Imagem extraída de Garny et al. (2009)

Pode-se observar um deslocamento da curva tanto para altas energias quanto um decréscimo para os valores máximos para ambas partículas. Logo, ao empregar os 121 bins (grupos) de energia (discretização dos intervalos) bem como o fator de qualidade médio para o cálculo do equivalente de dose ambiente, a seguinte equação será utilizada:

$$
H^{*}(10)=\sum_{\text {partículas }} \sum_{\text {grupos }} Q_{m}\left(E_{i}\right) \times D
$$

onde $Q_{m}$ é o fator de qualidade médio da partícula com energia inicial $E_{i}$ e $D$ é a dose absorvida depositada pela partícula no grupo. 
Os fatores de qualidade $Q$ para nêutrons ao sofrerem um ajuste de curva, transformam-se em fatores de ponderação de radiação W para nêutrons, conforme apresentado na Figura 6.

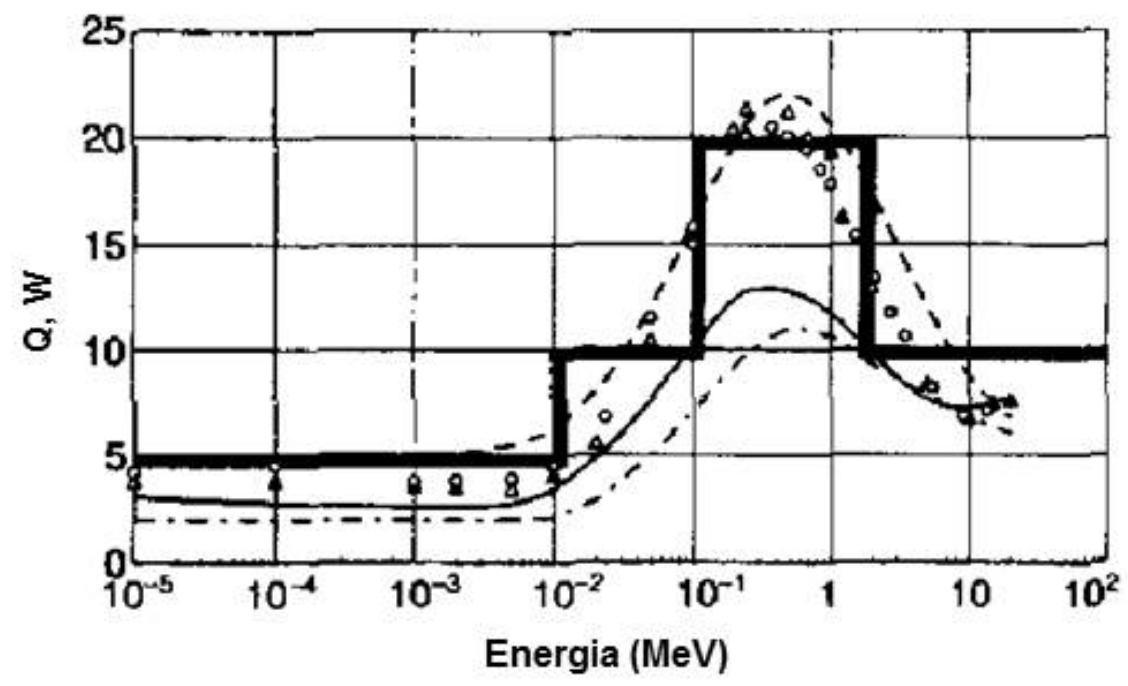

Figura 6 - Fatores de qualidade $Q$ e fatores de ponderação de radiação W para nêutrons em função da energia do nêutron. Valores de $W_{R}$ ( - - - -) oriundos de um ajuste de curva dos dados contidos no relatório ICRP 60; fator de qualidade efetivo $Q_{E F F}(-$. - . -) do relatório ICRP 21; fator de qualidade efetivo

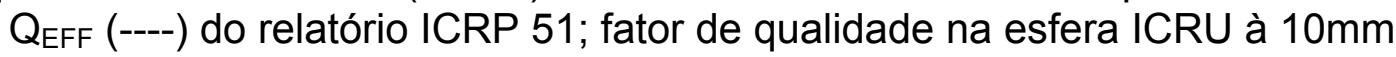
oriundos de Schuhmacher $(\Delta)$ e Leuthold $(\mathbf{O})$. Imagem extraída e adaptada (Portal e Dietze,1992).

Quando o espectro de nêutrons deve ser considerado na prática, $W_{R}$ pode ser deduzido pela relação matemática (ICRP, 1991):

$$
W_{R}=5+17 \exp \left[-(\ln (2 E))^{2} / 6\right]
$$

onde $\mathrm{E}$, em $\mathrm{MeV}$, fornece o ajuste da curva suave dos valores de $\mathrm{W}_{\mathrm{R}}$ para nêutrons em função da energia, como demostrado na Figura 7.

O relatório ICRP 60 (1991) recomenda ainda que seja utilizado um fator de ponderação para a radiação $W_{R}$ (radiation-weighting factor) indicado pela linha sólida e a aproximação pelo fator $W_{N}$ (neutron-weighting factor) pelo traçado pontilhado da Figura 7. 


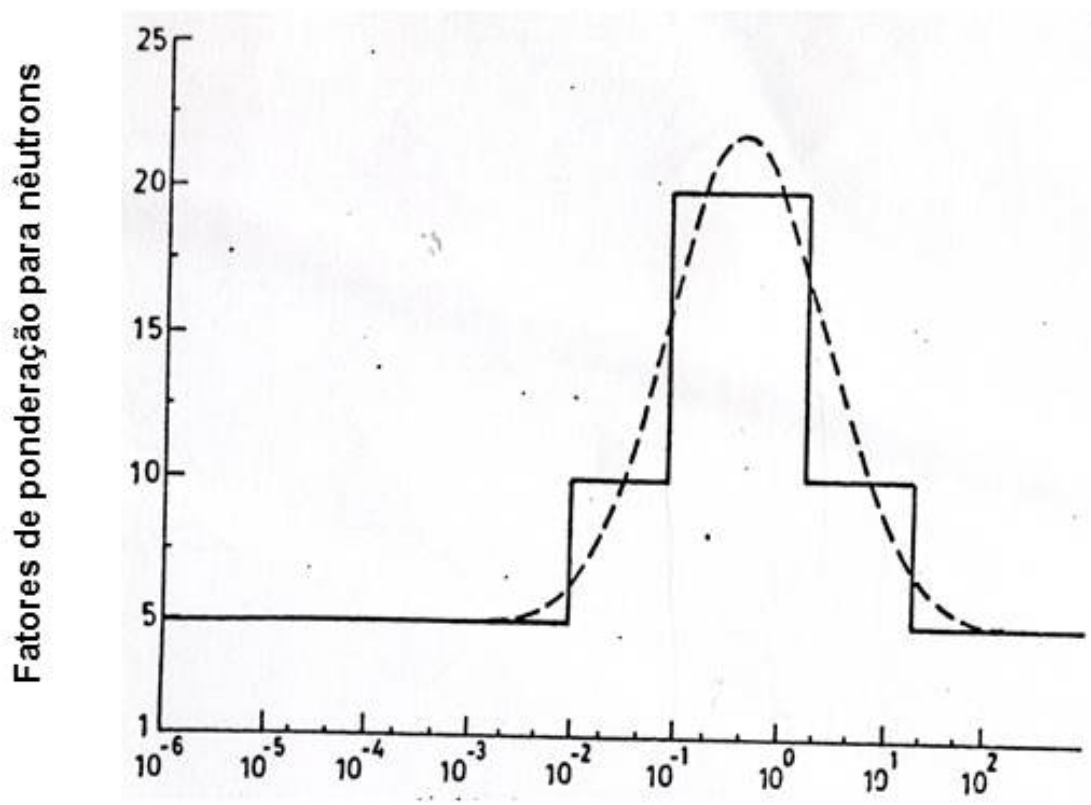

Energia do nêutron incidente (MeV)

Figura 7 - Fatores de ponderação para nêutrons, onde a linha sólida representa $W_{R}$ e o ajuste da curva é uma aproximação para $W_{N}(I C R P, 1991)$.

Conforme ainda as recomendações da ICRP, as alterações do poder de freamento (stopping power) afetam diretamente apenas as grandezas operacionais equivalente de dose pessoal $\left(H_{p}(d)\right)$ e equivalente de dose ambiente $\left(H^{*}(d)\right)$, pois as mesmas são calculadas com base no fator de qualidade $Q$, calculado em função do LET (L) da partícula incidente. Os valores numéricos das grandezas de proteção (dose equivalente $(H)$, dose efetiva $(E)$ ), pela definição não seriam diretamente afetados, pois são calculados por meio dos fatores de ponderação da radiação $W_{R}$, que são dependentes da energia e não do poder de freamento. Entretanto, os valores de $W_{N}$ recomendados pela ICRP para nêutrons são indiretamente dependentes de diversos parâmetros, tais como os valores do LET. A Figura 7 mostra que os valores estimados oriundos da Equação 13 e a relação $Q(L)$ - $L$ recomendada estão em concordância.

Torna-se necessário que o esforço seja contínuo na obtenção de fatores de ponderação para a radiação bem como na obtenção de fatores de qualidade e suas relações, tanto para dados avaliados na área física quanto para a área radiobiológica, e dessa forma melhorar a consistência entre as grandezas operacionais e de proteção. 


\subsubsection{Grandezas de proteção}

- Dose Equivalente $\left(\mathrm{H}_{\mathrm{T}}\right)$ (Equivalent Dose).

A grandeza física fundamental em dosimetria é a dose absorvida. Em proteção radiológica, a grandeza básica é a dose absorvida média no órgão ou no tecido humano. Para um mesmo valor de dose absorvida, observa-se que algumas radiações são mais efetivas que outras em causar efeitos estocásticos. Para considerar este fato, foi introduzida uma grandeza mais apropriada, a dose equivalente, $\mathrm{H}_{\mathrm{T}}$, onde

$$
H_{T}=D W_{R}
$$

tendo como unidade o Joule por quilograma $\left(\mathrm{J} \mathrm{kg}^{-1}\right)$, cujo nome especial é Sievert (Sv) e $W_{R}$ é o fator de ponderação para a radiação.

- Dose Efetiva (E) (Effective Dose): reflete o detrimento combinado dos efeitos estocásticos causados pelas doses equivalentes em todos os órgãos e tecidos do corpo; a dose equivalente em cada órgão e tecido é multiplicada pelo respectivo fator de ponderação do tecido $W_{T}$, sendo então feito o somatório desses produtos para se obter a dose efetiva, E:

$$
E=\Sigma H_{T} \times W_{T}
$$

tendo como unidade o Joule por quilograma $\left(\mathrm{J} \mathrm{kg}^{-1}\right)$, cujo nome especial é Sievert (Sv) e $W_{T}$ é o fator de ponderação para o tecido.

- Equivalente de Dose Efetiva $\left(\mathrm{H}_{\mathrm{E}}\right)$ (Effective Dose Equivalent), é a média ponderada dos equivalentes de dose no tecido,

$$
H_{E}=\Sigma H_{T} W_{T}
$$




\subsubsection{Grandezas operacionais}

As grandezas operacionais foram introduzidas no relatório ICRU 39 (1985) e posteriormente detalhadas nos relatórios 43 (1988), 47 (1992) e 51 (1993) da ICRU. O relatório ICRP 74 (ICRP,1997) recomenda sua utilização nas medições de proteção radiológica. As grandezas operacionais são baseadas na grandeza equivalente de dose (Dose Equivalent) e todas têm a mesma unidade, o Sievert (Sv). A descrição exata das grandezas operacionais para monitoramento de área e para calibração de dosimetros pessoais é conseguida por meio da definição de um objeto simulador substituindo o corpo e a definição de um ponto específico no objeto simulador, uma vez que o equivalente de dose é uma grandeza pontual.

O relatório ICRU 39 (1985) providenciou definições das grandezas operacionais em pontos a profundidades $d$ nos objetos simuladores de tecidoICRU (ICRU tissue). Considera-se a constituição material do tecido-ICRU sendo a de um material com densidade igual a $1 \mathrm{~g} / \mathrm{cm}^{-3}$ e composição mássica de $76,2 \%$ de oxigênio, 11,1\% de carbono, 10,1\% de hidrogênio e 2,6\% de nitrogênio (ICRU, 1980).

- Equivalente de dose ambiente $\left(\mathrm{H}^{*}(\mathrm{~d})\right)$ (Ambient Dose Equivalent)

Para monitoramento de área, a ICRU (2001) recomenda o uso da grandeza equivalente de dose ambiente, cujo símbolo $H^{*}(10)$ relaciona-se a uma estimativa conservadora de dose efetiva (effective dose). Esta grandeza é definida em um simples objeto simulador, a esfera ICRU, pelo equivalente de dose a $10 \mathrm{~mm}$ de profundidade, e fornece condições únicas de calibração para dosímetros de área.

A grandeza $H^{*}(10)$ é definida em um campo hipotético de radiação, chamado de campo expandido e alinhado, cuja fluência é unidirecional e sua distribuição angular e de energia possuem os mesmos valores em relação ao volume de controle. O equivalente de dose ambiente, em um ponto de um campo de radiação, é o equivalente de dose que seria produzido pelo correspondente campo expandido e alinhado na esfera ICRU a $10 \mathrm{~mm}$ de profundidade, no raio oposto ao sentido do campo alinhado. Este formato implica no $\mathrm{H}^{*}(10)$, embora calculado em termos da interação do campo da radiação na esfera ICRU, ser 
atribuído a um ponto do campo existente na ausência da esfera ou outro receptor (necessário para comparação entre as grandezas operacionais e de proteção).

- Equivalente de dose pessoal $\left(H_{P}(d)\right)$ (Personal Dose Equivalent)

É o equivalente de dose em um tecido a uma determinada profundidade $d$, em ponto específico do corpo, e sua unidade é Joule por quilograma, cujo nome especial é Sievert (Sv).

\subsection{DOSIMETRIA TERMOLUMINESCENTE}

Materiais luminescentes são materiais ou substâncias capazes de emitir luz. Esta luminescência pode ser de diferentes tipos, tais como a bioluminescência que ocorre em animais vivos (ex. Vaga-lume), com um comprimento de onda da luz emitida entre 520 e $590 \mathrm{~nm}$, resultante da oxidação de substâncias bioquímicas (CALDAS, 2012). Neste trabalho, o tipo de luminescência que será abordado é a termoluminescência, cujo mecanismo da luminescência consiste basicamente de uma excitação sobre o material luminescente, por meio de radiação induzida direta ou indiretamente ionizante e um posterior aquecimento, seja por corrente elétrica ou luz laser, de modo que a energia transmitida para o material se transforma em luz. Como exemplos de materiais termoluminescentes tem-se: $\mathrm{CaSO}_{4}: \mathrm{Dy}$; LiF:Mg, Ti e $\mathrm{MgB}_{4} \mathrm{O}_{7}$.

Os dosímetros termoluminescentes em uso no presente trabalho são de dois tipos, com diferentes proporções isotópicas de ${ }^{6} \mathrm{Li} \mathrm{e}{ }^{7} \mathrm{Li}$. As pastilhas de nome comercial TLD-600 possuem 95,6 \% de ${ }^{6} \mathrm{Li} \mathrm{e} \mathrm{4,4 \%} \mathrm{de}{ }^{7} \mathrm{Li}$, e as pastilhas de nome comercial TLD-700 possuem 99,99 \% de ${ }^{7} \mathrm{Li} \mathrm{e} 0,01 \%$ de ${ }^{6} \mathrm{Li}$ (CARNELL, 1998), de forma que as respostas dos dois tipos de pastilhas para nêutrons térmicos e epitérmicos são diferentes, permitindo efetuar a discriminação em campos mistos nêutron-gama, por meio do método dos pares. O intervalo de dose mensurável por este dosímetro é de $10 \mathrm{mGy}$ a 10 Gy e o desvanecimento térmico (fading) é da ordem de $5 \%$ ao ano, a $20^{\circ} \mathrm{C}$, de forma que a resposta pode ser facilmente corrigida.

O método dos pares consiste em se expor simultaneamente dosímetros do tipo TLD-600 e TLD-700 em campos mistos nêutron-gama. A diferença da leitura obtida nas curvas de termoluminescência do ${ }^{6} \mathrm{Li}$ e do ${ }^{7} \mathrm{Li}$ permite avaliar a contribuição de cada componente do campo por meio da 
subtração das curvas para cada conjunto (par) de pastilhas. Um exemplo comparativo das curvas de emissão termoluminescente do TLD-600 e do TLD700 expostos a um campo misto nêutron-gama, pode ser visto na Figura 8 (FEDERICO, 2011).

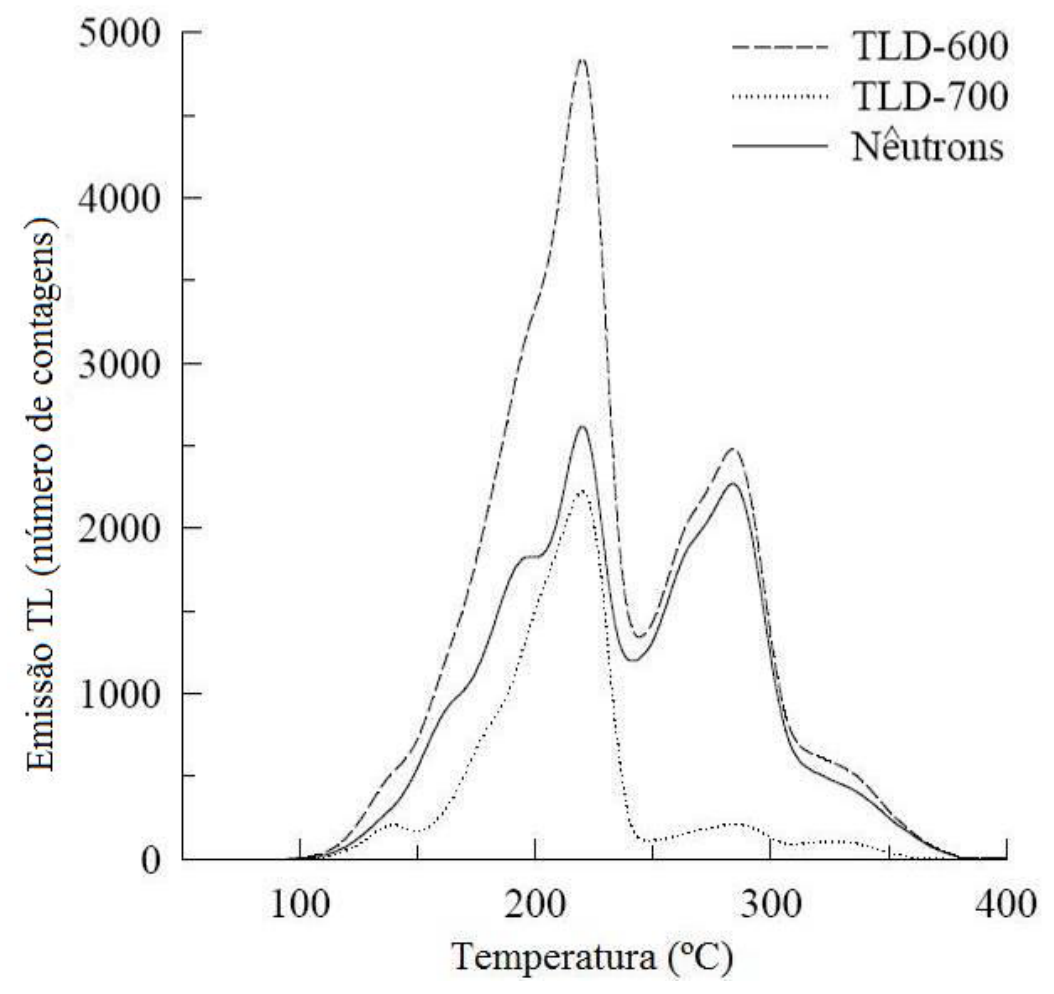

Figura 8 - Curvas de emissão termoluminescente de pastilhas de TLD600 e TLD-700 após exposição em um campo misto nêutron - gama, mostrando a curva resultante da subtração do sinal do TLD-700 no sinal do TLD -600, cujo resultado corresponde ao sinal referente a nêutrons (extraído e adaptado de Federico (2011)). 


\section{MATERIAIS E MÉTODOS}

Neste capitulo são apresentados os recursos computacionais empregados durante as simulações computacionais, os códigos e ambientes computacionais utilizados, bem como o detector de polimetilmetacrilato (PMMA) simulado ao longo deste trabalho.

\subsection{MÉTODO MONTE CARLO}

O Método Monte Carlo é um método estocástico que emprega uma sequência de números aleatórios para realizar uma simulação de um processo físico ou fenômeno.

\subsubsection{Breve histórico}

A utilização de números aleatórios, para simular problemas em estatística matemática, remonta ao início do século passado. O desenvolvimento inicial do Método Monte Carlo para estudar processos em Física e Química está diretamente relacionado com o trabalho de diversos físicos e matemáticos, entre os quais pode-se destacar Enrico Fermi, John Von Neumann e Nicholas Metropolis, que estudaram processos termonucleares relacionados com o Projeto Manhattan (MORGON e COUTINHO, 2007).

Este método estatístico destaca-se pela vantagem de ser um método em que a modelagem matemática tridimensional de objetos apresenta-se de maneira simplificada, evitando assim a resolução da equação de transporte de modo determinístico. Com o uso do Método Monte Carlo, os resultados obtidos são limitados apenas pela qualidade dos dados nucleares disponibilizados pela biblioteca utilizada. 


\subsubsection{Transporte de radiação}

O Método Monte Carlo quando utilizado para cálculos de transporte de radiação consiste basicamente de um conjunto de partículas geradas de acordo com a situação física do caso a ser simulado, cujas coordenadas de cada partícula individual mudam aleatoriamente em cada interação com a matéria (no caso específico deste trabalho, devido ao fato da análise do campo de RC ser restrita a sua componente neutrônica, as interações previstas serão espalhamento elástico ou inelástico, captura, captura radiativa, emissão de nêutrons ou fissão), de maneira que o comportamento médio destas partículas seja descrito em termos de grandezas macroscópicas como fluxo ou densidade de partículas. A partir dessas grandezas são obtidas outras específicas, tais como energia depositada ou dose absorvida (YORIYAZ, 2012).

Os códigos computacionais utilizados ao longo deste trabalho que são baseados no Método Monte Carlo são o MCNP5-1.60 e o MCNPX 2.7.0.

\subsubsection{Estrutura dos códigos computacionais MCNP5-1.60 e MCNPX} 2.7 .0

Os códigos MCNP5 e MCNPX permitem ao usuário realizar simulações em geometrias tridimensionais complexas, com especificações dos materiais empregados em cada região desta geometria, caracterização da fonte de radiação, tempo de simulação bem como os tipos de partículas a serem transportadas. O arquivo de entrada no formato ASCII é organizado em blocos de programação, por meio de cartões (cards) (POSSANI, 2012). A associação dos cards de superfície geram células, que são estruturas básicas da geometria a ser modelada. Nas células são vinculados contadores estatísticos chamados tallies que armazenam as informações que o usuário requisitou na simulação.

O objetivo de cada simulação de transporte de radiação na matéria é obter informação do sistema simulado, tais como fluxo de determinada partícula que atravessa uma determinada superfície, pulsos de energia num detector, energia depositada numa célula, dentre outras opções. Neste trabalho procura-se obter informações sobre a energia depositada em determinado volume de controle, para fins dosimétricos. 
Para cada informação (tally) que o usuário deseje é necessário confeccionar um card específico e inseri-lo no terceiro bloco do arquivo de entrada. Na Tabela 1 são mostrados diferentes tipos de tallies e suas funções.

Tabela 1 - Exemplos de tipos de tallies disponíveis.

\begin{tabular}{|c|c|c|}
\hline Cartão & Função do cartão & Unidade \\
\hline F1:pl & $\begin{array}{c}\text { Corrente integrada numa } \\
\text { superfície }\end{array}$ & Partículas \\
\hline $\mathrm{F} 2: p l$ & $\begin{array}{c}\text { Fluxo médio numa } \\
\text { superfície }\end{array}$ & Partículas $/ \mathrm{cm}^{2}$ \\
\hline F4:pl & Fluxo médio numa célula & Partículas $/ \mathrm{cm}^{2}$ \\
\hline F5:pl & $\begin{array}{c}\text { Fluxo num detector } \\
\text { pontual ou radial }\end{array}$ & Partículas $/ \mathrm{cm}^{2}$ \\
\hline F6:pl & $\begin{array}{c}\text { Energia média } \\
\text { depositada na célula }\end{array}$ & $\mathrm{MeV} / \mathrm{g}$ \\
\hline $\mathrm{F} 7: p l$ & $\begin{array}{l}\text { Energia de fissão } \\
\text { depositada }\end{array}$ & $\mathrm{MeV} / \mathrm{g}$ \\
\hline F8:pl & $\begin{array}{l}\text { Pulsos de energia num } \\
\text { detector }\end{array}$ & $\mathrm{MeV}$ \\
\hline
\end{tabular}

O termo $p /$ é o tipo de partícula da qual se deseja obter a informação. Dependendo do código, alguns tipos de partículas não são aceitos, como por exemplo o tally do tipo $\mathrm{F} 6: \mathrm{H}$, onde $\mathrm{H}$ é o designador de próton e existe no código MCNPX, mas este cartão não funciona quando aplicado ao arquivo de entrada para uso no código MCNP5.

\subsection{RECURSOS COMPUTACIONAIS}

Para as simulações computacionais envolvendo as esferas ICRU, (ICRU, 1980) bem como a avaliação da grandeza equivalente de dose ambiente, $\left(H^{*}(10)\right)$, a fim de se obter a curva referente ao equivalente de dose ambiente pela fluência $\left(H^{*}(10) / \Phi\right)$ na esfera ICRU (vide Figura 13), um computador marca Apple, modelo MacBookPro, contendo um processador de 2,4 GHz Intel Core 2 Duo, 
com memória de 4 GB de RAM 1067 MHz DDR3 e um computador Dell, com processador Intel 15 com 3,0 GHz, Quadcore e 16 GB de RAM foram utilizados tanto para a validação dos códigos computacionais empregados bem como para avaliar a metodologia a ser aplicada no decorrer do trabalho.

$\mathrm{Na}$ fase de avaliação do comportamento do detector de polimetilmetacrilato (PMMA), as simulações computacionais prévias foram realizadas no computador Dell mencionado. Os valores finais foram extraídos das simulações geradas pelo cluster existente no IEAv devido às fontes de radiação simuladas serem os espectros de fontes de ${ }^{241} \mathrm{Am} / \mathrm{Be}$ e ${ }^{252} \mathrm{Cf}$, e de radiação cósmica na atmosfera em altitude de voo, foi necessária uma capacidade computacional suficiente para que a estatística dos códigos computacionais utilizados se aproximasse dos valores esperados em termos de precisão e exatidão.

\subsection{CÓDIGOS COMPUTACIONAIS EMPREGADOS}

Os códigos computacionais empregados neste trabalho foram os seguintes:

- MCNP5 (Monte Carlo N Particles version 5) e MCNPX 2.7.0 (Monte Carlo $N^{\circ}$ Particles eXtended), cedidos pelo Radiation Safety Information Computational Center (RSICC), do Oak Ridge National Laboratory do governo dos Estados Unidos da América, sendo a licença concedida para uso pessoal e restrita para fins de pesquisa sobre dosimetria das radiações;

- Códigos computacionais "Star codes";

\subsubsection{Código computacional MCNP5-1.60}

O código Monte Carlo N-Particle 5 versão 1.60 é um código computacional baseado no Método Monte Carlo para simulação do transporte de radiação no meio que pode ser utilizado para nêutrons, fótons e elétrons em separado e em problemas acoplados envolvendo os três tipos de partículas ao mesmo tempo, incluindo a capacidade de gerar auto-valores para sistemas críticos (X-5 MONTE CARLO TEAM, 2008). 


\subsubsection{Código computacional MCNPX}

O código computacional Monte Carlo N-Particle eXtended (MCNPX), desenvolvido no Los Alamos National Laboratory (LANL) (PELOWITZ, 2011), é um código de simulação Monte Carlo em 3-D para o transporte de radiação na matéria, com uma variedade de opções de dados de entrada, capaz de processar a trajetória de 34 tipos diferentes de partículas e/ ou íons num determinado bin (grupo) de energia. O código emprega como bases de dados nucleares as bibliotecas avaliadas disponíveis bem como diferentes modelos físicos para suprir a ausência de dados avaliados.

A versão do MCNPX que foi utilizada no desenvolvimento deste trabalho é a 2.7.0., onde foi incorporada uma versão do código computacional FLUKA (PELOWITZ, 2011), para o intervalo de altas energias. Dessa forma no MCNPX foram utilizadas as bibliotecas de dados nucleares avaliadas para cada nuclídeo, complementadas pelos dados obtidos por modelos nucleares para faixas de energia, da ordem de $\mathrm{GeV}$, onde não se possui bibliotecas de seções de choque avaliadas, segundo Goldhagen (2000). O modelo nuclear utilizado neste trabalho foi o modelo de Bertini, default do código MCNPX (PAZIANOTTO, 2012).

Para os nêutrons com energia $k T$, neste estado energético existe um tratamento matemático específico, incorporado nos códigos computacionais MCNP5 e MCNPX, onde o material do meio onde se encontra o nêutron deve ser especificado em um cartão (card) de material, para que as seções de choque utilizadas pelo código empreguem as tabelas $S(\alpha, \beta)$, presentes em algumas bibliotecas de dados nucleares, tais como a ENDF5 (Evaluated Nuclear Data File) e a LANL89 (Los Alamos National Laboratory). A tabela $S(\alpha, \beta)$ (com transferência de momento a e transferência de energia $\beta$ ) é necessária para simular o espalhamento elástico de nêutrons térmicos em moléculas tais como água e polietileno. $\mathrm{Na}$ molécula de água $\mathrm{H}_{2} \mathrm{O}$, por exemplo, a ligação $\mathrm{O}-\mathrm{H}$ pode sofrer oscilação harmônica de torsão (impedindo rotações) e vibração interna à baixas energias. Sendo as vibrações e oscilações dependentes da temperatura, a seção de choque de espalhamento também é dependente da temperatura. Para levar em consideração este efeito, um conjunto especial de dados necessita ser 
incluído para nêutrons com energia menor que $4 \mathrm{eV}$, presentes nas tabelas $S(\alpha, \beta)$ (PELOWITZ, 2011).

Todas estas características fazem deste código uma poderosa ferramenta no campo da proteção radiológica, modelagem de dosímetros, blindagem de radiação, podendo ser empregado em aplicações aeroespaciais que envolvam radiações na região de energia de $\mathrm{GeV}$.

\subsubsection{Códigos computacionais "Star codes"}

Os "Star Codes", ESTAR, PSTAR e ASTAR, são usados para calcular o poder de freamento (stopping-power) e as tabelas de alcance para elétrons, prótons e íons de Hélio (partículas alfa), de acordo com as recomendações dos relatórios da International Commission on Radiation Units and Measurements (ICRU) de números 37 (ICRU,1984) e 49 (ICRU,1993), são disponibilizados pelo National Institute of Standards and Technology (NIST) (NIST, 2013).

\subsection{DETECTOR DE PMMA}

O arranjo dosimétrico que foi utilizado neste trabalho é baseado na esfera do ICRU (1980), com posições para acomodar as pastilhas de dosímetros termoluminescentes (TLD) distribuídas convenientemente no volume da esfera, de forma a facilitar a avaliação da grandeza $H^{*}(10)$ e a permitir a obtenção de informações adicionais sobre o campo de radiação ionizante incidente, como por exemplo sua direcionalidade e uma estimativa da profundidade de dose máxima. Este arranjo já foi utilizado anteriormente por Federico (2011) em medições preliminares dentro de aeronaves e é constituído de uma esfera de polimetilmetacrilato (PMMA), material obtido na reação de poliadição do monômero $\mathrm{C}_{5} \mathrm{H}_{8} \mathrm{O}_{2}$, (Fig. 9), e pastilhas dosimétricas de dois materiais termoluminescentes diferentes. 


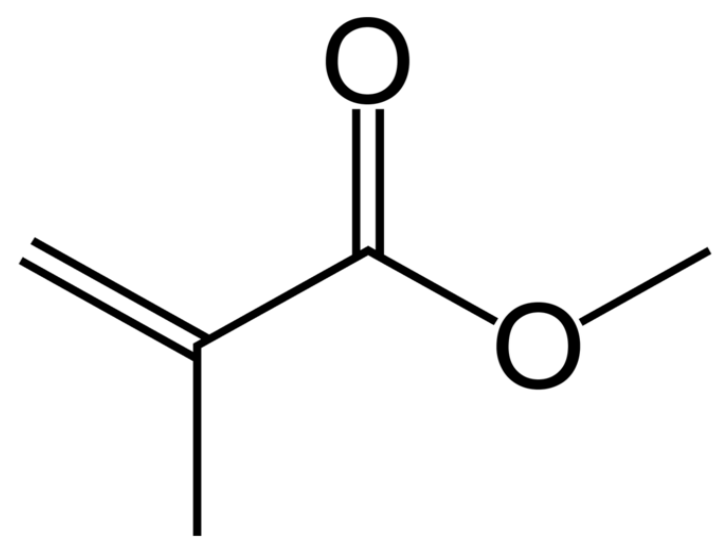

Figura 9 - Fórmula estrutural do monômero Metacrilato de Metila.

O detector de PMMA construído no IEAv consiste de uma esfera de raio 12,6 cm, projetada e construída por Federico (2011), com o intuito de detectar radiações ionizantes, possuindo em seu interior 43 cavidades no formato cilíndrico, para acomodação de pares de pastilhas dosimétricas termoluminescentes (TLD) da fabricante Harshaw Chem. Co., E.U.A. Cada par era constituído por uma pastilha modelo TLD-600 e outra TLD-700, para se mensurar a dose absorvida $\mathrm{D}$ (absorbed dose) devido a campos mistos de radiação, e consequentemente propiciar uma estimativa da grandeza equivalente de dose ambiente $\mathrm{H}^{*}(10)$, a fim de se obter informações sobre o campo de radiação ionizante incidente no detector.

A dosimetria termoluminescente foi desenvolvida utilizando-se dois lotes de 100 pastilhas termoluminescentes, constituídos de pastilhas na forma de disco com 0,9 mm de espessura e $4,5 \mathrm{~mm}$ de diâmetro. As pastilhas são compostas de LiF:Mg,Ti com diferentes concentrações isotópicas de ${ }^{6} \mathrm{Li}$, de forma que o TLD-600 (95,6\% de $\left.{ }^{6} \mathrm{Li} \mathrm{e} \mathrm{4,4 \%} \mathrm{de}{ }^{7} \mathrm{Li}\right)$ apresenta grande sensibilidade para a detecção de nêutrons térmicos enquanto o TLD-700 (0,1\% de ${ }^{6} \mathrm{Li}$ e $99,9 \%$ de $\left.{ }^{7} \mathrm{Li}\right)$ é praticamente insensível a eles. Ambos os dosímetros são sensíveis às radiações $\mathrm{X}$ e gama. As medições de dose são efetuadas por meio de uma combinação dos dosímetros do tipo TLD-600 e TLD-700, sendo que o método de análise já foi estabelecido por Federico (2011), sendo os valores experimentais utilizados neste trabalho, para fins de comparação com as simulações computacionais, fornecidos por Federico (2011). 
O posicionamento das pastilhas no interior do detector é apresentado conforme desenho esquemático mostrado na Figura 10.

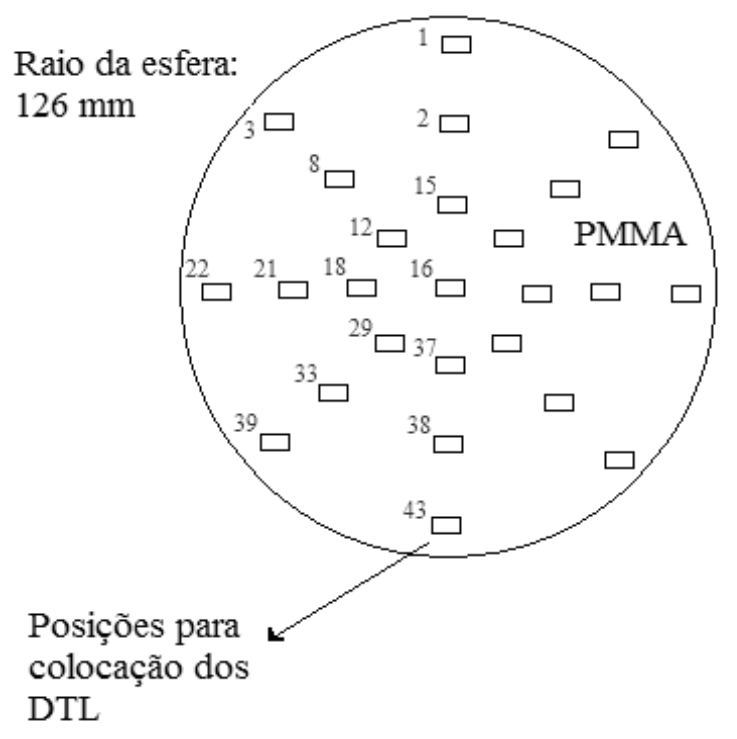

Profundidade das posições em relação à face exterior: $8,4 \mathrm{~mm}$; $42 \mathrm{~mm}$; $84 \mathrm{~mm}$ e $126 \mathrm{~mm}$.

Figura 10 - Desenho esquemático do detector de PMMA com algumas posições de TLD utilizadas (FEDERICO, 2011).

Como já citado anteriormente, um grande óbice no desenvolvimento da dosimetria para fins aeronáuticos situa-se no fato de que o acesso às instalações que possibilitam a calibração destes equipamentos para os campos de radiação de altas energias devido à $\mathrm{RC}$ é custoso e difícil. Uma alternativa mais viável e de custo relativamente baixo é a calibração e avaliação dos referidos sistemas dosimétricos em campos convencionais de baixas energias e sua extensão para altas energias por meio do Método Monte Carlo. Esse tipo de abordagem já foi utilizado com sucesso por Pazianotto (2012) na simulação de outro tipo de sistema detector. 


\section{RESULTADOS E DISCUSSÃO}

Neste capítulo serão apresentados e discutidos os resultados alcançados durante a pesquisa.

\subsection{DETERMINAÇÃO DO EQUIVALENTE DE DOSE AMBIENTE SIMULANDO A ESFERA ICRU}

Inicialmente foram feitas simulações da esfera ICRU, com a finalidade de se estudar os fatores iniciais do emprego do código computacional MCNP5, bem como analisar os diferentes tipos de tallies que pudessem vir a ser empregados.

Esferas (volumes de controle) de diferentes raios, com valores variando entre $0,05 \mathrm{~cm}$ a $0,01 \mathrm{~cm}$ foram utilizadas com a intenção de se verificar o volume de controle, cujo valor de dose absorvida tenderia ao valor definido pela International Commission on Radiological Protection (ICRP) (ICRP,1991), considerando-se um ponto (esfera de raio zero), posicionado a $10 \mathrm{~mm}$ da superfície da esfera ICRU, com a finalidade de se obter a grandeza operacional equivalente de dose ambiente, $\mathrm{H}^{*}(10)$. Foi utilizado um feixe de nêutrons monoenergético de $0,1 \mathrm{MeV}$, de uma fonte radial, de $15 \mathrm{~cm}$ de raio, centrada e alinhada com o centro da esfera ICRU (ICRU,1980), para produzir um campo expandido e alinhado, onde a fluência e a distribuição de energia são iguais às do campo expandido, mas onde a distribuição angular da fluência é unidirecional, conforme mostrado na Figura 11. 


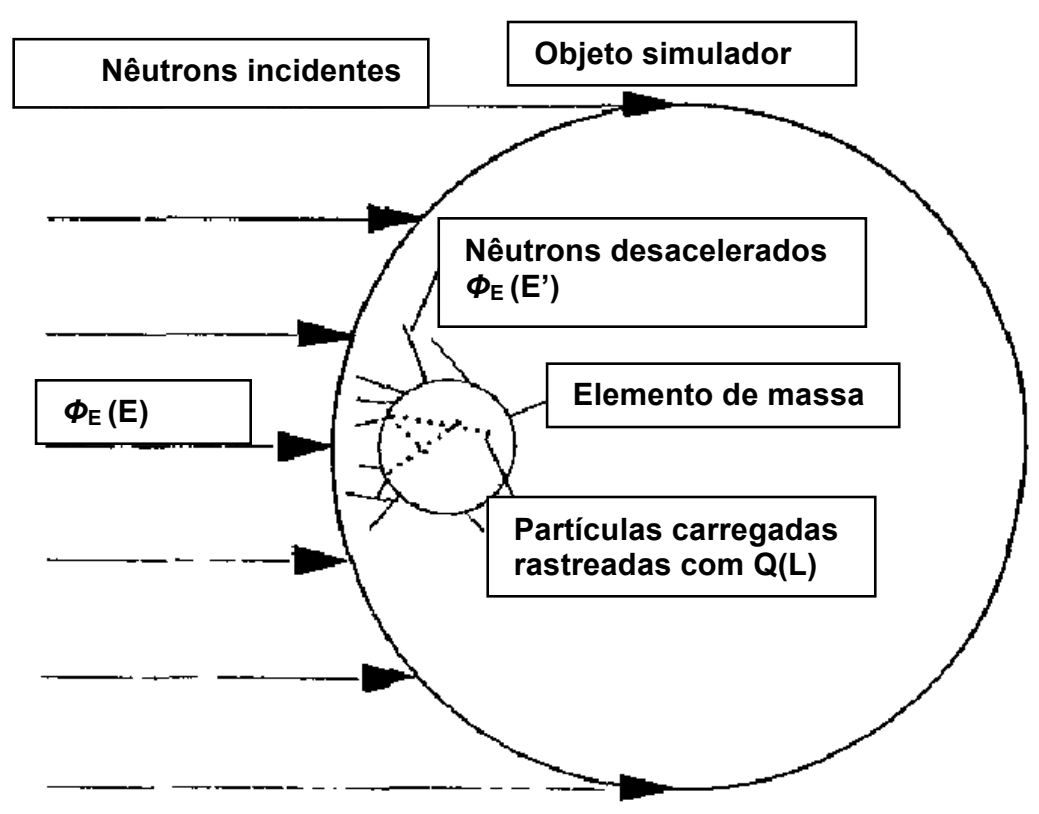

Figura 11 - Representação de um campo expandido e alinhado de nêutrons monoenergéticos incidentes na esfera ICRU (LEUTHOLD et al., 1992).

As esferas com raio entre 0,05 e $0,02 \mathrm{~cm}$ passaram pelos 10 (dez) testes estatísticos presentes no código MCNP5. Os valores obtidos nestas simulações são apresentados na Tabela 2.

Tabela 2 - Avaliação de volume de controle a ser empregado nas simulações computacionais.

\begin{tabular}{cccc}
\hline $\begin{array}{c}\text { Raio da } \\
\text { Esfera (cm) }\end{array}$ & Tally & $\begin{array}{c}\text { Energia } \\
\text { depositada } \\
\text { (MeV/g) }\end{array}$ & $\begin{array}{c}\text { Incerteza } \\
\text { Relativa }\end{array}$ \\
\hline 0,05 & F6:N,P & $6,03762 \mathrm{E}-05$ & 0,0299 \\
0,04 & F6:N,P & $6,05241 \mathrm{E}-05$ & 0,0365 \\
0,03 & F6:N,P & $6,15331 \mathrm{E}-05$ & 0,0480 \\
0,02 & F6:N,P & $6,08430 \mathrm{E}-05$ & 0,0719 \\
0,01 & F6:N,P & $5,99368 \mathrm{E}-05$ & 0,1482 \\
\hline
\end{tabular}

$\mathrm{Na}$ Tabela 2 observa-se que a medida que o raio da esfera que representa o volume de controle simulado aumenta, a incerteza relativa associada 
diminui (inversamente proporcional), devido a um maior cômputo de histórias no interior do volume de controle, conforme apresentado na Figura 12.

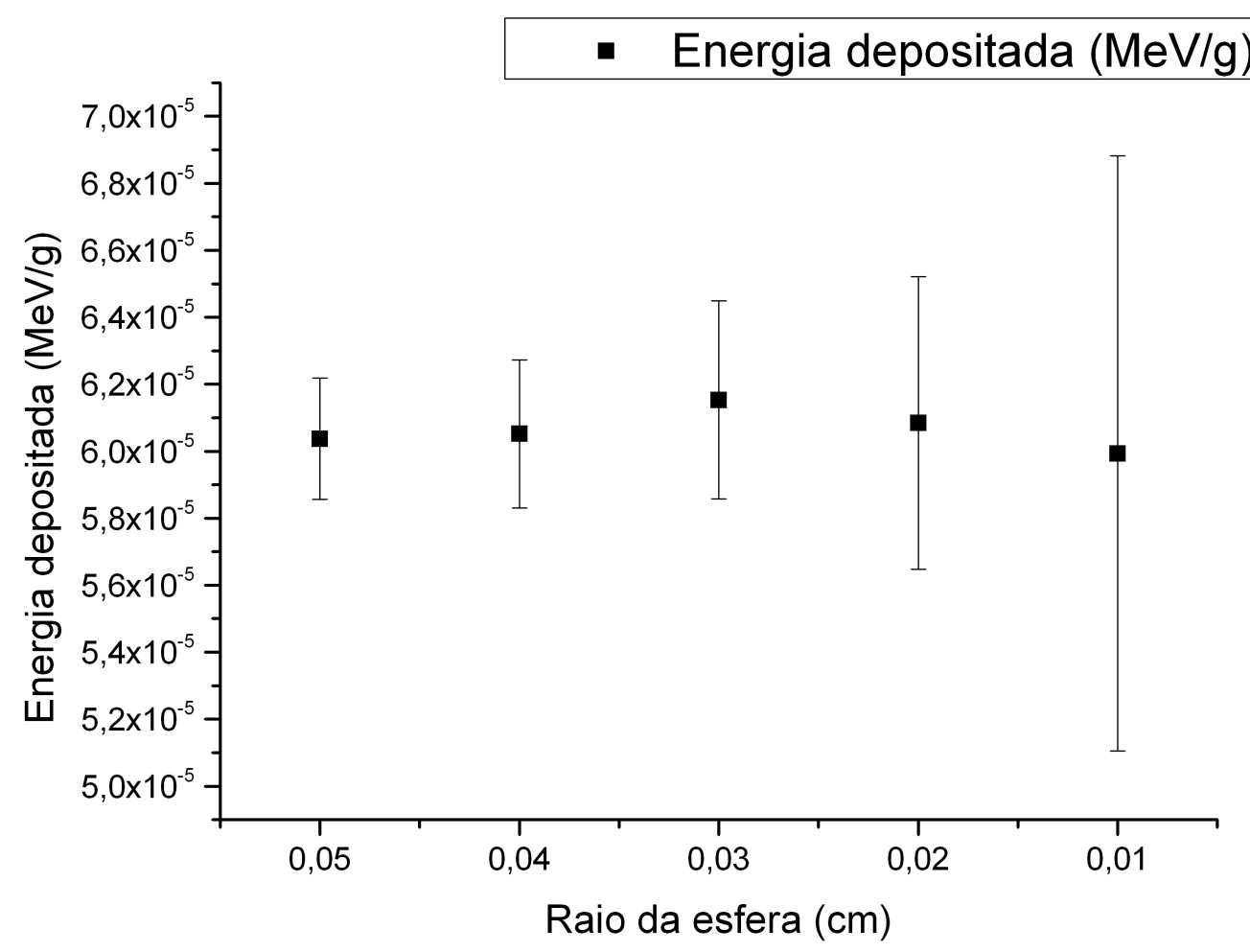

Figura 12 - Variação da energia depositada e sua incerteza associada em função do raio da esfera do volume de controle.

Conforme a Figura 12, pode-se visualizar que a incerteza associada à medição aumenta com a diminuição do raio da esfera do volume de controle (inversamente proporcional), sendo que os valores obtidos começam a tender para o que seria o resultado de uma esfera de raio zero (ponto).

Alguns pesquisadores (GARNY et al., 2009; SANTOS, 2013) optaram por trabalhar com um volume de controle cilíndrlco, com $10 \mathrm{~mm}$ de diâmetro e 5 $\mathrm{mm}$ de espessura, sendo o eixo do cilindro perpendicular à direção do feixe de nêutrons incidentes, com a finalidade de contabilizar um maior número de histórias durante o processamento dos códigos computacionais baseados no Método Monte Carlo, e consequentemente obter um resultado estatístico com uma incerteza associada menor. Ao longo deste trabalho, buscou-se nas simulações computacionais manter ao máximo as dimensões envolvidas na 
solução dos problemas, bem como o amplo uso de condições padrão (default) pré-estabelecidas pelos próprios códigos computacionais. Dessa forma, apesar da esfera de raio $0,02 \mathrm{~cm}$ representar melhor uma esfera de raio zero (ponto), optou-se, para efeitos de simulação, o volume de controle da esfera de raio 0,05 $\mathrm{cm}$, pois seu diâmetro é igual à espessura da pastilha TLD empregada no detector $(0,1 \mathrm{~cm})$ e a incerteza associada é menor do que a da esfera de raio 0,02 $\mathrm{cm}$.

Cada simulação nesta fase teve a duração de 1200 min computacionais para cada faixa de energia de nêutrons incidentes, tendo sido considerado em cada simulação não somente a importância dos nêutrons no sistema, mas também a contribuição dos fótons secundários (Bremsstrahlung) e os elétrons gerados para a dose absorvida no volume de controle.

Após a etapa de definição do volume de controle a ser usado (esfera de raio $0,05 \mathrm{~cm}$ ) e o tipo de tally empregado neste volume (tally $\mathrm{F} 6$ ), a metodologia aplicada neste trabalho buscou verificar os códigos computacionais MCNP5 e MCNPX, por meio da confecção da curva referente ao equivalente de dose ambiente pela unidade de fluência $\left(H^{*}(10) / \Phi\right)$ na esfera ICRU (Figura 13), em função da energia da radiação incidente, resultante da irradiação de nêutrons monoenergéticos de um campo expandido e alinhado na esfera ICRU (ICRP,1997). Conforme preconizado pela ICRP 74 (ICRP,1997) e ICRU 57 (ICRU,1998) foi simulada uma esfera ICRU, irradiada por um feixe de nêutrons monoenergéticos alinhados a fim de se obter a dose absorvida a $10 \mathrm{~mm}$ da superfície da esfera, que foi multiplicado pelo fator de qualidade apropriado (Q) e transformou-se no equivalente de dose ambiente, $H^{*}(10)$. Na Figura 13 também são apresentadas as curvas do equivalente de dose ambiente por unidade de fluência descrita no relatório ICRP 74 (1997) e a obtida por Leuthold et al. (1992). 


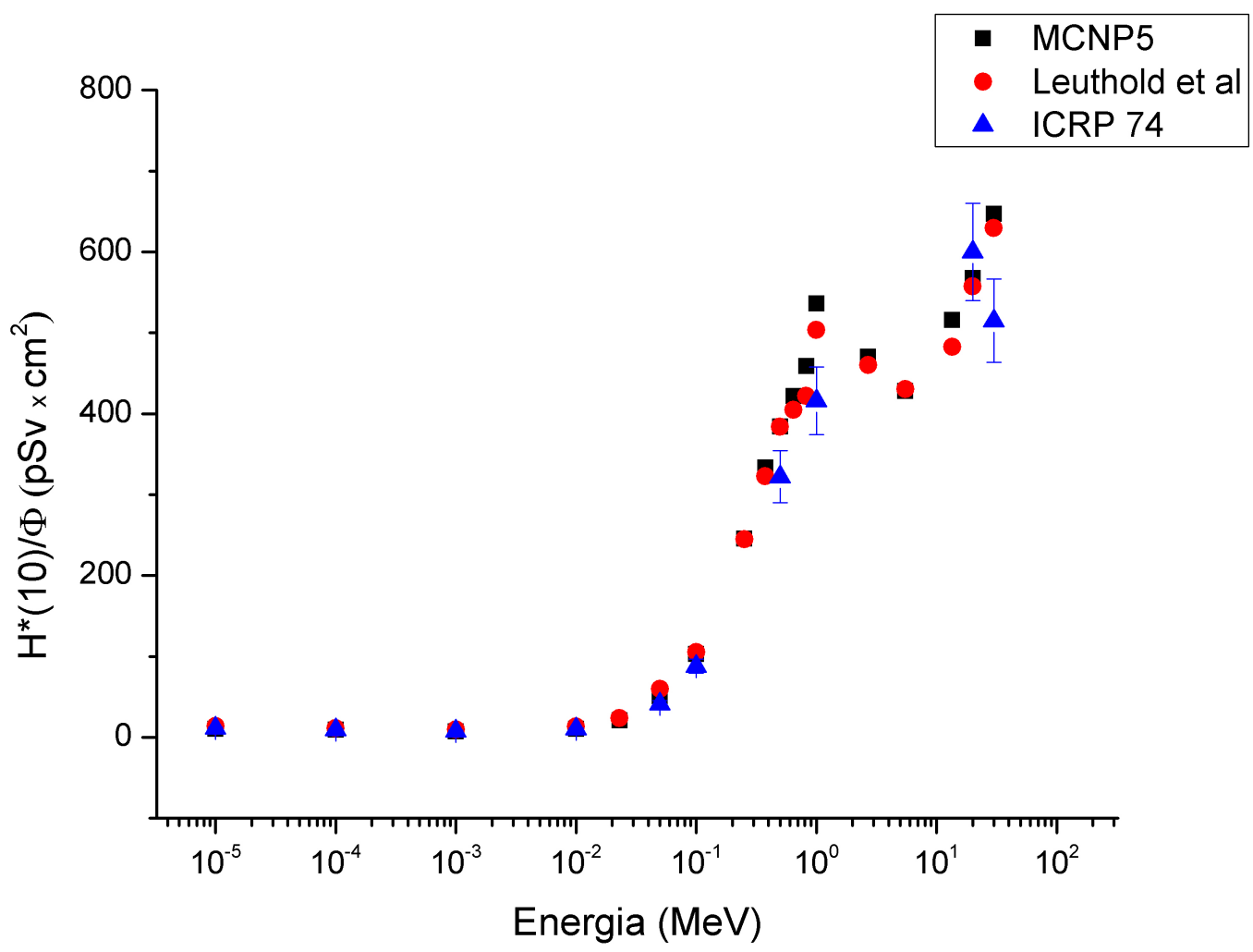

Figura 13 - Curvas do equivalente de dose ambiente por unidade de fluência do feixe de nêutrons $\left(H^{*}(10) / \Phi\right)$ na esfera ICRU (LEUTHOLD et al.,1992; ICRP,1997). A incerteza máxima dos dados foi de $10 \%$.

Conforme descrito anteriormente, para uma avaliação mais conservadora da dose absorvida à distância de $10 \mathrm{~mm}$ da superfície da esfera ICRU, optou-se por um volume de controle representado por uma esfera de raio $0,05 \mathrm{~cm}$, centrada no ponto específico em que se deseja determinar a dose absorvida. A intenção em se criar um volume de controle em torno do ponto onde será realizada a dosimetria da radiação é poder utilizar as opções disponibilizadas pelos códigos computacionais MCNP5 e MCNPX denominadas de tallies, que podem ser aplicadas por meio de superfícies (áreas) ou células (volumes).

Um grupo de dados de coeficientes de conversão de referência, em função da energia do nêutron incidente no intervalo entre nêutrons térmicos até $180 \mathrm{MeV}$ foi determinado por ajuste dos dados fornecidos pelos autores participantes do grupo de trabalho, composto pelo Institute of Radiation Protection of the Helmholtz Center (GSF), Institute of High Energy Physics (IHEP), Physikalisch-Technische Bundesansalt (PTB) e University of Texas, responsável pela definição de coeficientes de conversão de referência apresentados no 
relatório ICRP 74 (ICRP, 1997), por meio de uma curva de ajuste polinomial pelo método dos mínimos quadrados. Os dados primários são apresentados na Figura 14 .

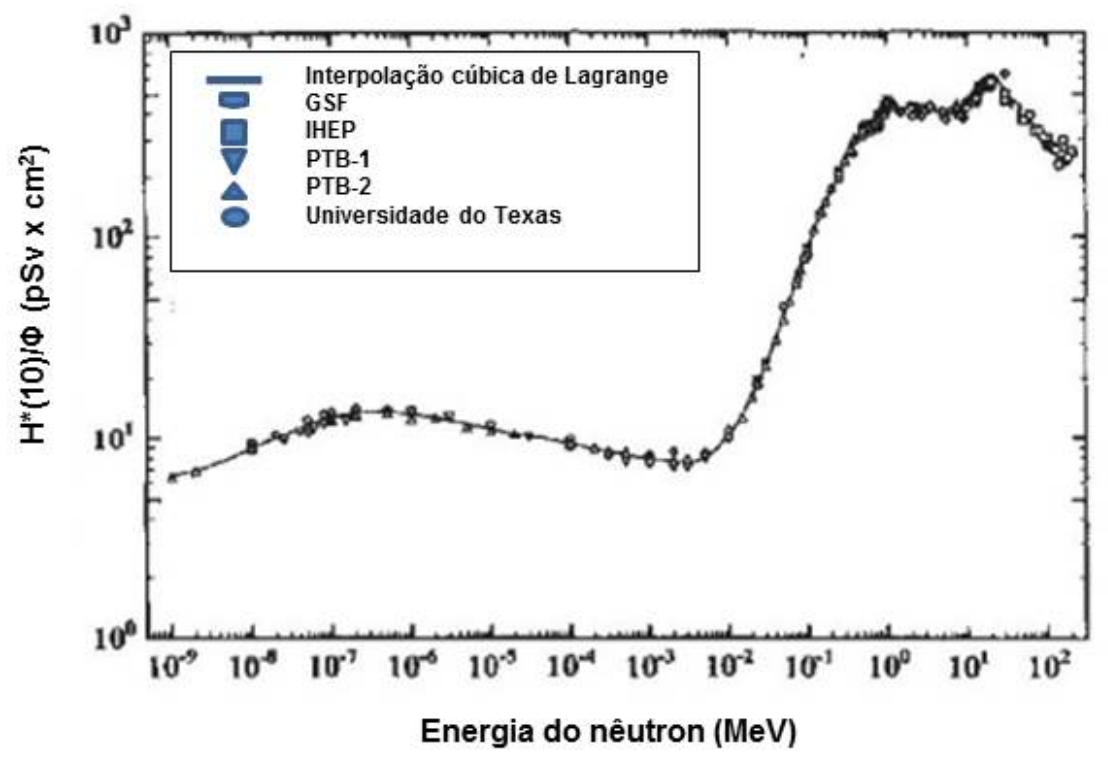

Figura 14 - Coeficientes de conversão de referência para equivalente de dose ambiente, em função da energia do nêutron, de institutos participantes do grupo de trabalho da ICRP 74 (1997).

A Figura 15 relaciona a razão entre os valores calculados de $H^{*}(10)$ pelo "melhor valor" ou "valor recomendado" obtido pelo ajuste de curva, incluindo as variações entre os dados dos diversos autores (ICRP, 1997). 


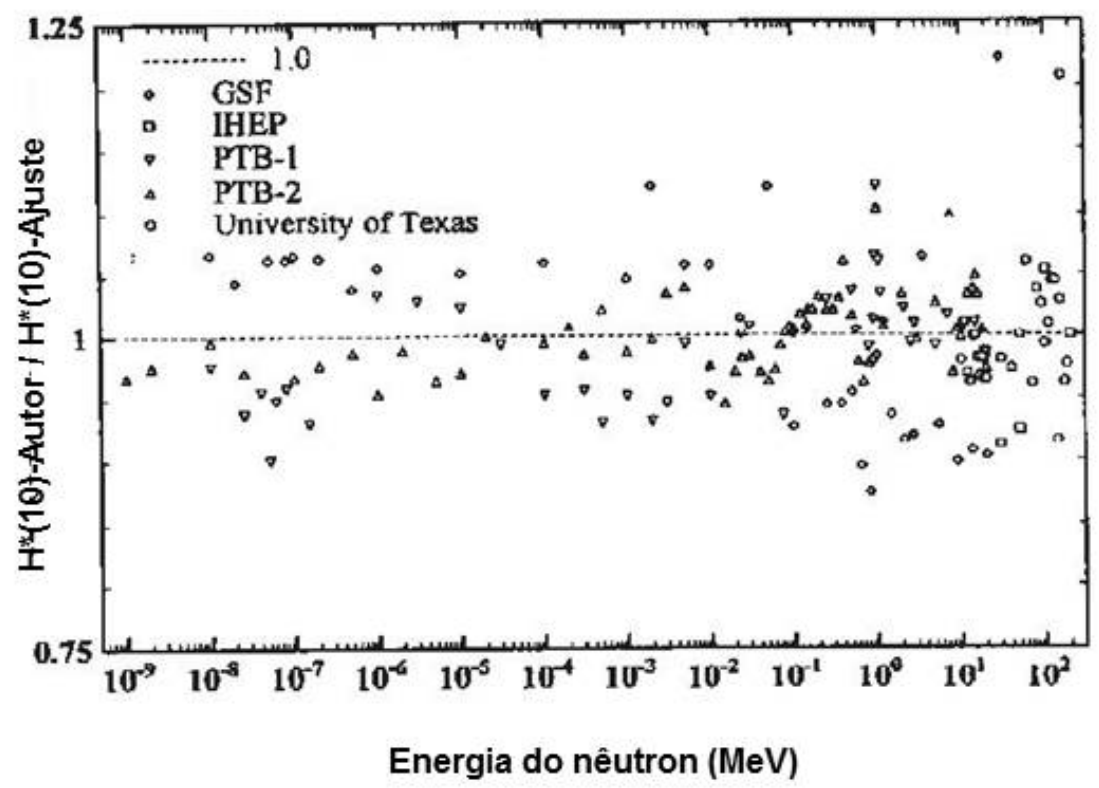

Figura 15 - Variação entre os coeficientes de conversão para equivalente de dose ambiente de diferentes institutos, $H^{*}(10) / \Phi$. A razão entre os dados obtidos por cada membro do grupo de trabalho e o melhor ajuste da curva avaliado pelo grupo é fornecido pela linha pontilhada, em função da energia do nêutron (ICRP,1997).

Com a finalidade de reproduzir a curva mencionada, observou-se a necessidade de definir o tipo de tally oferecido pelo código mais correto de se empregar. Como a intenção era de se obter a curva da Figura 13, para fins de certificação de que o processo definido era válido e a física do problema simulado estava correta, não foram empregados os tallies pré-estabelecidos de dosimetria presentes no código (tally F5) por "forçarem" a partícula a se dirigir ao volume de controle, bem como os valores de conversão definidos pela ICRP 103 (ICRP, 2007) de taxas de fluência para equivalente de dose ambiente. Dessa forma, o tally a ser escolhido deveria fornecer seus resultados de maneira que fosse facilmente correlacionado com a grandeza de dose absorvida, expressa em Gray (Gy).

Os tallies padrão de fluência são o tally F2 e F4. O tally F2 fornece a fluência média através de uma superfície previamente definida no bloco de superfícies do input, enquanto o tally F4 fornece a fluência média através de uma célula definida no bloco de células do input. Quando inseridos no input com um asterisco antes da letra $\mathrm{F}$, como por exemplo * $\mathrm{F} 4$, estes tallies irão fornecer valores em termos de energia por área $\left(\mathrm{MeV} / \mathrm{cm}^{2}\right)$. Os códigos MCNP5 e MCNPX 
são ideais para determinação de corrente ou grandezas baseadas em fluência. Fluência (partículas $/ \mathrm{cm}^{2}$ ) é de suma importância, pois pode ser convertida em dose absorvida ou equivalente de dose caso a distribuição diferencial de energia é conhecida. Como um dos objetivos específicos deste trabalho foi determinar os valores dos coeficientes de conversão de equivalente de dose ambiente por unidade de fluência, não se fez uso destes tallies.

O tally do tipo F5, conhecido como detector pontual, utiliza um estimador determinístico de fluência num ponto, em situações onde os percursos das partículas geradas aleatoriamente é ineficiente para um resultado estatístico satisfatório, sendo geralmente utilizados quando o tally F4 falha devido a pobreza dos dados amostrais selecionados no volume de controle. Importante ressaltar que este tipo de tally não foi empregado ao longo deste trabalho por "forçar" a partícula a se dirigir ao volume de controle, sendo comum neste tipo de tally aparecerem resultados com uma convergência falsa de valores.

O tally do tipo F8 é utilizado especificamente para transporte de elétrons e fótons. Este tipo de tally é importante quando ocorre transporte de elétrons em células de volume reduzido em conjunto com fótons de alta energia.

Para cálculo de dose existem três abordagens básicas:

- Avaliar a energia depositada ao longo da trajetória da partícula no volume de controle (célula) especificado (tally F6);

- Situações onde a aproximação Kerma não pode ser utilizada, emprega-se o tally F8 (apenas para fótons e elétrons);

- Inclusão dos cartões DE/DF para conversão da fluência em dose, tipicamente usado em irradiações de corpo inteiro.

A partir destas informações, optou-se pelo uso do tally F6, que na realidade é o resultado do valor obtido pelo tally F4 multiplicado por uma seção de choque, associado a uma energia média por interação, expressa em termos de energia por massa (MeV/g).

Logo, a conversão dos valores obtidos em MeV/g pelo tally F6 para $\mathrm{J} / \mathrm{kg}$, e consequentemente em Gray, facilita a mensuração da dose absorvida sem a utilização dos fatores de conversão estipulados pela ICRP 103 (ICRP, 2007).

Estatisticamente, o emprego do tally F6 tem como vantagem a sua padronização por história de partículas, enquanto o tally F8, por exemplo, realiza um balanço no volume de controle (total de partículas que entram menos o total 
de partículas que saíram), resultando em um método matemático menos preciso estatisticamente (SIQUEIRA, 2012).

Após a definição do tally F6 a ser utilizado, as simulações começaram a ser realizadas empregando o código MCNP5, que se limita a especificar os tipos de partículas apenas em termos de nêutrons, fótons e elétrons. Trabalhando em termos de dose absorvida, os valores obtidos de $D^{*}(10) / \Phi$ apresentaram na faixa de energia de $10^{-5} \mathrm{MeV}$ sua diferença máxima (30,89\%) e na faixa de energia de 0,5 MeV sua menor diferença $(0,05 \%)$ em relação aos apresentados por Leuthold et al. (1992), conforme Figura 16.

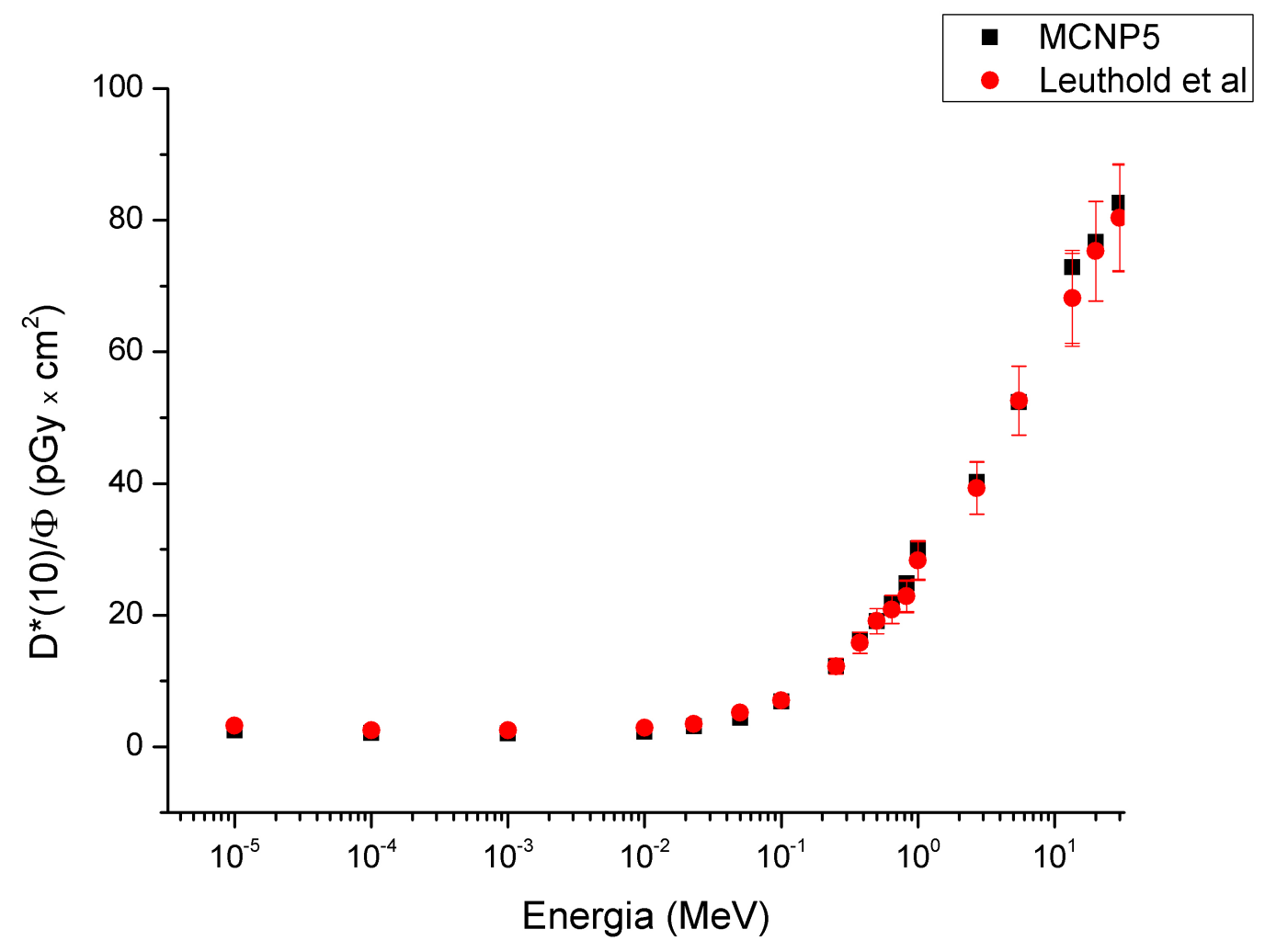

Figura 16 - Curvas da dose absorvida por unidade de fluência do feixe de nêutrons $\left(D^{*}(10) / \Phi\right)$ na esfera ICRU. 
O fato dos valores obtidos de $D^{*}(10) / \Phi$ apresentarem na faixa de energia de $10^{-5} \mathrm{MeV}$ sua diferença máxima (30,89 \%) foi observado em relação ao aumento da dose absorvida proveniente de radiação gama quando da simulação computacional de nêutrons lentos incidentes no volume de controle a ser mensurado.

As simulações iniciais realizadas com o código MCNP5 serviram para constatar a necessidade de ser empregado o card $\mathrm{E}$ em conjunto com o card F6 (não disponível no MCNP5), para que se conseguisse visualizar qual era a contribuição de cada partícula na dose absorvida e em que faixa de energia essa parcela se manifestava. Entretanto, mesmo sendo obtido o valor bruto da dose absorvida por feixe de nêutron monoenergético, constatou-se que a modelagem do problema estava no caminho certo, pois ao comparar os resultados obtidos com os apresentados por Leuthold et al. (1992), nota-se uma proximidade dos valores das doses absorvidas, conforme a Tabela 3. 
Tabela 3 - Comparação entre os valores obtidos com o código MCNP5.

\begin{tabular}{ccccccc}
\hline $\mathbf{A}$ & $\mathbf{B}$ & $\mathbf{C}$ & $\mathbf{D}$ & $\mathbf{E}$ & $\mathbf{F}$ & $\mathbf{G}$ \\
\hline $1,00 \times 10^{-5}$ & 2,46 & 3,22 & 10,37 & 4,22 & 13,59 & 11,3 \\
$1,00 \times 10^{-4}$ & 2,12 & 2,52 & 9,58 & 4,51 & 11,39 & 9,40 \\
$1,00 \times 10^{-3}$ & 2,02 & 2,53 & 7,52 & 3,73 & 9,45 & 7,90 \\
$1,00 \times 10^{-2}$ & 2,28 & 2,90 & 10,38 & 4,56 & 13,28 & 10,5 \\
$2,30 \times 10^{-2}$ & 3,08 & 3,48 & 20,85 & 6,77 & 23,57 & \\
$5,00 \times 10^{-2}$ & 4,38 & 5,19 & 50,54 & 11,5 & 59,92 & 41,1 \\
$1,00 \times 10^{-1}$ & 6,87 & 7,02 & 103,1 & 15,0 & 105,4 & 88,0 \\
$2,52 \times 10^{-1}$ & 12,3 & 12,2 & 245,5 & 20,0 & 244,8 & \\
$3,76 \times 10^{-1}$ & 16,3 & 15,8 & 333,5 & 20,4 & 322,9 & \\
$5,00 \times 10^{-1}$ & 19,1 & 19,1 & 384,0 & 20,1 & 383,7 & 322 \\
$6,46 \times 10^{-1}$ & 21,8 & 20,9 & 421,6 & 19,4 & 404,6 & \\
$8,25 \times 10^{-1}$ & 24,9 & 22,9 & 458,8 & 18,5 & 421,9 & \\
$1,00 \times 10^{0}$ & 30,2 & 28,3 & 536,1 & 17,8 & 503,6 & 416 \\
$2,70 \times 10^{0}$ & 40,2 & 39,3 & 470,5 & 11,7 & 460,0 & \\
$5,50 \times 10^{0}$ & 52,4 & 52,6 & 428,3 & 8,18 & 430,2 & \\
$1,35 \times 10^{1}$ & 72,9 & 68,2 & 515,8 & 7,08 & 482,5 & \\
$2,00 \times 10^{1}$ & 76,7 & 75,3 & 567,5 & 7,40 & 557,4 & 600 \\
$3,00 \times 10^{1}$ & 82,6 & 80,4 & 646,8 & 7,83 & 629,3 & 515 \\
\hline
\end{tabular}

onde:

- A representa a energia do nêutron incidente em MeV;

- B representa a dose absorvida pela unidade de fluência $\left(D^{*}(10) / \Phi\right)$ obtida neste trabalho em $p G y \times \mathrm{cm}^{2}$;

- C representa a dose absorvida pela unidade de fluência $\left(D^{*}(10) / \Phi\right)$ em pGy $\times \mathrm{cm}^{2}$ (LEUTHOLD et al., 1992);

- D representa o equivalente de dose ambiente pela unidade de fluência $\left(H^{*}(10) / \Phi\right)$ obtido neste trabalho em $\mathrm{pSv} \times \mathrm{cm}^{2}$;

- E representa o fator de qualidade efetivo (Qeff) em Sv/Gy (LEUTHOLD et al., 1992);

- $F$ representa o equivalente de dose ambiente pela unidade de fluência $\left(\mathrm{H}^{*}(10) / \Phi\right)$ em $\mathrm{pSv} \times \mathrm{cm}^{2}$ (LEUTHOLD et al., 1992);

- G representa o equivalente de dose ambiente pela unidade de fluência $\left(H^{\star}(10) / \Phi\right)$ em pSv $\times \mathrm{cm}^{2}$ (ICRP, 1997).

É importante ressaltar que todos os valores obtidos nas simulações com o código computacional MCNP5 apresentados na Tabela 3 passaram pelos 10 testes estatísticos pré-estabelecidos como rotina do código, sendo que um 
desses testes é referente ao erro relativo associado aos valores calculados (erro relativo menor que 0,01 ). Por isso as incertezas relativas não foram incluídas nas tabelas e nos gráficos apresentados com os valores obtidos pelo código MCNP5.

Os valores obtidos de $H^{*}(10) / \Phi$ não coincidem e apresentaram na faixa de energia de $10^{-5} \mathrm{MeV}$ sua diferença máxima (31,05 \%) e na faixa de energia de 0,5 MeV sua menor diferença $(0,08 \%)$ quando comparados com os apresentados por Leuthold et al. (1992), provavelmente pelo fato do autor ter confeccionado o trabalho no ano de 1992 (21 anos atrás) e utilizado uma versão anterior do código MCNP (MCNP3B), e uma biblioteca de dados nucleares (ENDF/B-IV) (GARBER et al., 1975) anterior à Evaluated Nuclear Data File B VII (ENDF/B-VII) (CHADWICK et al., 2006) presente na versão atual dos códigos MCNP5 e MCNPX. Isto significa que não utilizou seções de choque avaliadas mais recentes. Para fins de comprovação de que os resultados convergem para os mesmos valores, foram realizadas novas simulações com o código MCNP5, para verificar se apenas considerando nêutrons, fótons e elétrons seria possível alcançar os valores divulgados pelo relatório ICRP 74 (ICRP,1997). Os valores obtidos para os 10 grupos de energia estipulados para os feixes monoenergéticos da fonte usada durante as simulações envolvendo a esfera ICRU são apresentados na Tabela 4. 
Tabela 4 - Comparação entre os valores obtidos com o código MCNP5, utilizando diferentes capacidades computacionais.

\begin{tabular}{|c|c|c|c|c|}
\hline$(\mathrm{MeV})$ & $\begin{array}{c}\mathrm{H}^{*}(10) / \Phi \\
\text { Este } \\
\text { trabalho } \\
\left(\mathrm{pSv} \times \mathrm{cm}^{2}\right)\end{array}$ & $\begin{array}{c}\mathrm{H}^{*}(10) / \Phi \\
\text { Este } \\
\text { trabalho } \\
\left(\mathrm{pSv} \times \mathrm{cm}^{2}\right)\end{array}$ & $\begin{array}{c}H^{*}(10) / \Phi \\
\text { Leuthold } \\
\text { et al. } \\
(1992) \\
\left(p S v \times \mathrm{cm}^{2}\right)\end{array}$ & $\begin{array}{c}H^{*}(10) / \Phi \\
\text { ICRP } 74 \\
\\
(1997) \\
\left(p S v \times c^{2}\right)\end{array}$ \\
\hline $1.00 \times 10^{-4}$ & 4,37 & 9,58 & 11,39 & 9,40 \\
\hline $1.00 \times 10^{-3}$ & 4,06 & 7,52 & 9,45 & 7,90 \\
\hline $1.00 \times 10^{-2}$ & 6,86 & 10,4 & 13,28 & 10,5 \\
\hline $5.00 \times 10^{-2}$ & 33,5 & 50,5 & 59,92 & 41,1 \\
\hline $1.00 \times 10^{-1}$ & 80,4 & 103 & 105,4 & 88,0 \\
\hline $1.00 \times 10^{0}$ & 566 & 536 & 503,6 & 416 \\
\hline $5.00 \times 10^{0}$ & 616 & & & 405 \\
\hline $1.00 \times 10^{1}$ & 557 & & & 440 \\
\hline $2.00 \times 10^{1}$ & 518 & 567 & 557,4 & 600 \\
\hline $3.00 \times 10^{1}$ & 501 & 646 & 629,3 & 515 \\
\hline
\end{tabular}

A Tabela 4 serve como indicativo da convergência dos valores obtidos, mesmo empregando-se diferentes capacidades computacionais, ou seja, o ganho obtido ao se utilizar uma capacidade computacional maior é apenas em relação à velocidade de obtenção dos valores pesquisados, resultando em uma melhor produtividade da pesquisa.

Ressalta-se novamente que todos os valores obtidos nas simulações com o código MCNP5 apresentados na Tabela 4 passaram pelos 10 testes estatísticos pré-estabelecidos como rotina do código.

Os valores obtidos nesta etapa permaneceram distantes dos valores fornecidos pelo relatório ICRP 74 (1997) e apresentaram na faixa de energia de $10^{-4} \mathrm{MeV}$ sua diferença máxima $(215,10 \%)$ e na faixa de energia de $30 \mathrm{MeV}$ sua menor diferença $(2,79 \%)$, apesar da maior capacidade computacional envolvida.

O código MCNPX (Monte Carlo N Particles eXtended) difere do código MCNP5, pelo fato de se poder especificar os diversos tallies por tipo de partícula (nêutron, elétron, próton, fóton, dêuteron, alfa, etc.) e também pelo fato do código possuir modelos físicos em sua rotina que permitem simular partículas com altas energias (acima de $100 \mathrm{MeV}$, dependendo do isótopo).

Um detalhe do emprego do tally F6 precisa ser mencionado. Partículas ou fótons gerados por meio de reações no interior do volume de controle (célula) a ser mensurado são contabilizados em duplicidade, ou seja, um elétron que gera 
um fóton no interior do volume de controle irá contabilizar a energia liberada do elétron na geração do fóton no tally F6 E e a mesma energia também será contabilizada pelo tally F6 P referente aos fótons (PELOWITZ, 2011). Para evitar este tipo de erro no cômputo da dose absorvida no volume de controle, existe a opção de se calcular um tally F6 geral, ou seja, um tally que considere todo tipo de partícula existente, isto é, um tally no formato $+\mathrm{F} 6$, onde todas as energias são computadas, mas não em duplicidade. A partir desta informação, pode-se verificar em cada faixa de energia se existe esta duplicidade, realizando um simples balanço de energia entre o tally +F6 e os demais individuais, onde o valor total deverá ser igual ao somatório dos demais tallies individuais.

Durante esta etapa da pesquisa, cada simulação computacional teve a duração de 6000 min computacionais.

Os resultados alcançados na substituição do código computacional MCNP5 pelo código computacional MCNPX, na confecção da curva referente ao equivalente de dose ambiente pela fluência $\left(H^{*}(10) / \Phi\right)$ na esfera ICRU são apresentados na Tabela 5 e na Figura 17.

Tabela 5 - Valores obtidos para os 20 grupos de energia estipulados para os feixes monoenergéticos da fonte usada durante as simulações envolvendo a esfera ICRU.

\begin{tabular}{crrrrr}
\hline $\mathbf{A}$ & $\mathbf{B}$ & $\mathbf{C}$ & $\mathbf{D}$ & $\mathbf{E}$ & $\mathbf{F}$ \\
\hline $1,00 \times 10^{-5}$ & 2,43 & $3,20 \pm 0,60$ & 13,59 & 11,3 & $7,76 \pm 1,46$ \\
$1,00 \times 10^{-4}$ & 2,45 & $2,69 \pm 0,07$ & 11,39 & 9,40 & $6,58 \pm 0,18$ \\
$1,00 \times 10^{-3}$ & 2,00 & $3,63 \pm 1,06$ & 9,45 & 7,90 & $7,25 \pm 2,00$ \\
$1,00 \times 10^{-2}$ & 3,48 & $2,76 \pm 0,07$ & 13,28 & 10,5 & $9.61 \pm 0,25$ \\
$3,00 \times 10^{-2}$ & 5,15 & $3,92 \pm 0,80$ & & 23,7 & $20,2 \pm 4,10$ \\
$5,00 \times 10^{-2}$ & 6,81 & $5,71 \pm 1,20$ & 59,92 & 41,1 & $38,9 \pm 5,81$ \\
$1,00 \times 10^{-1}$ & 10,2 & $8,65 \pm 1,68$ & 105,4 & 88,0 & $88,5 \pm 7,20$ \\
$2,00 \times 10^{-1}$ & 15,9 & $11,2 \pm 0,60$ & & 170 & $178 \pm 9,77$ \\
$3,00 \times 10^{-1}$ & 17,3 & $14,6 \pm 0,60$ & & 233 & $253 \pm 11,2$ \\
$5,00 \times 10^{-1}$ & 17,7 & $18,5 \pm 0,10$ & 383,7 & 322 & $328 \pm 1,83$ \\
$7,00 \times 10^{-1}$ & 19,3 & $23,1 \pm 1,49$ & & 375 & $445 \pm 28,8$ \\
$1,00 \times 10^{0}$ & 18,1 & $29,6 \pm 0,66$ & 503,6 & 416 & $537 \pm 12,0$ \\
$2,00 \times 10^{0}$ & 15,7 & $35,5 \pm 0,70$ & & 420 & $557 \pm 11,7$ \\
$5,00 \times 10^{0}$ & 6,48 & $54,7 \pm 3,70$ & & 405 & $354 \pm 24,0$ \\
$1,00 \times 10^{1}$ & 6,43 & $67,9 \pm 3,24$ & & 440 & $437 \pm 20,8$ \\
$1,60 \times 10^{1}$ & 7,11 & $76,3 \pm 3,64$ & & 555 & $543 \pm 25,9$ \\
$2,00 \times 10^{1}$ & 7,42 & $81,8 \pm 8,23$ & 557,4 & 600 & $607 \pm 61,0$ \\
$3,00 \times 10^{1}$ & 4,90 & $81 \pm 13,3$ & & 515 & $453 \pm 74,1$ \\
$1,00 \times 10^{2}$ & 4,01 & $76,7 \pm 5,91$ & & 285 & $307 \pm 23,7$ \\
$2,01 \times 10^{2}$ & 5,35 & $35,5 \pm 5,48$ & & 260 & $190 \pm 29,3$ \\
\hline
\end{tabular}

onde: 
- A representa a energia do nêutron incidente em $\mathrm{MeV}$;

- B representa o fator de qualidade efetivo (Qeff) em Sv/Gy obtido neste trabalho;

- C representa a dose absorvida pela unidade de fluência $\left(D^{*}(10) / \Phi\right)$ obtida neste trabalho em $\mathrm{pGy} \times \mathrm{cm}^{2}$;

- D representa o equivalente de dose ambiente pela unidade de fluência $\left(H^{*}(10) / \Phi\right)$ em pSv× $\mathrm{cm}^{2}$ (LEUTHOLD et al., 1992);

- E representa o equivalente de dose ambiente pela unidade de fluência $\left(H^{*}(10) / \Phi\right)$ em pSv× $\mathrm{cm}^{2}($ ICRP, 1997);

- F representa o equivalente de dose ambiente pela unidade de fluência $\left(H^{*}(10) / \Phi\right)$ obtido neste trabalho em $\mathrm{pSv} \times \mathrm{cm}^{2}$.

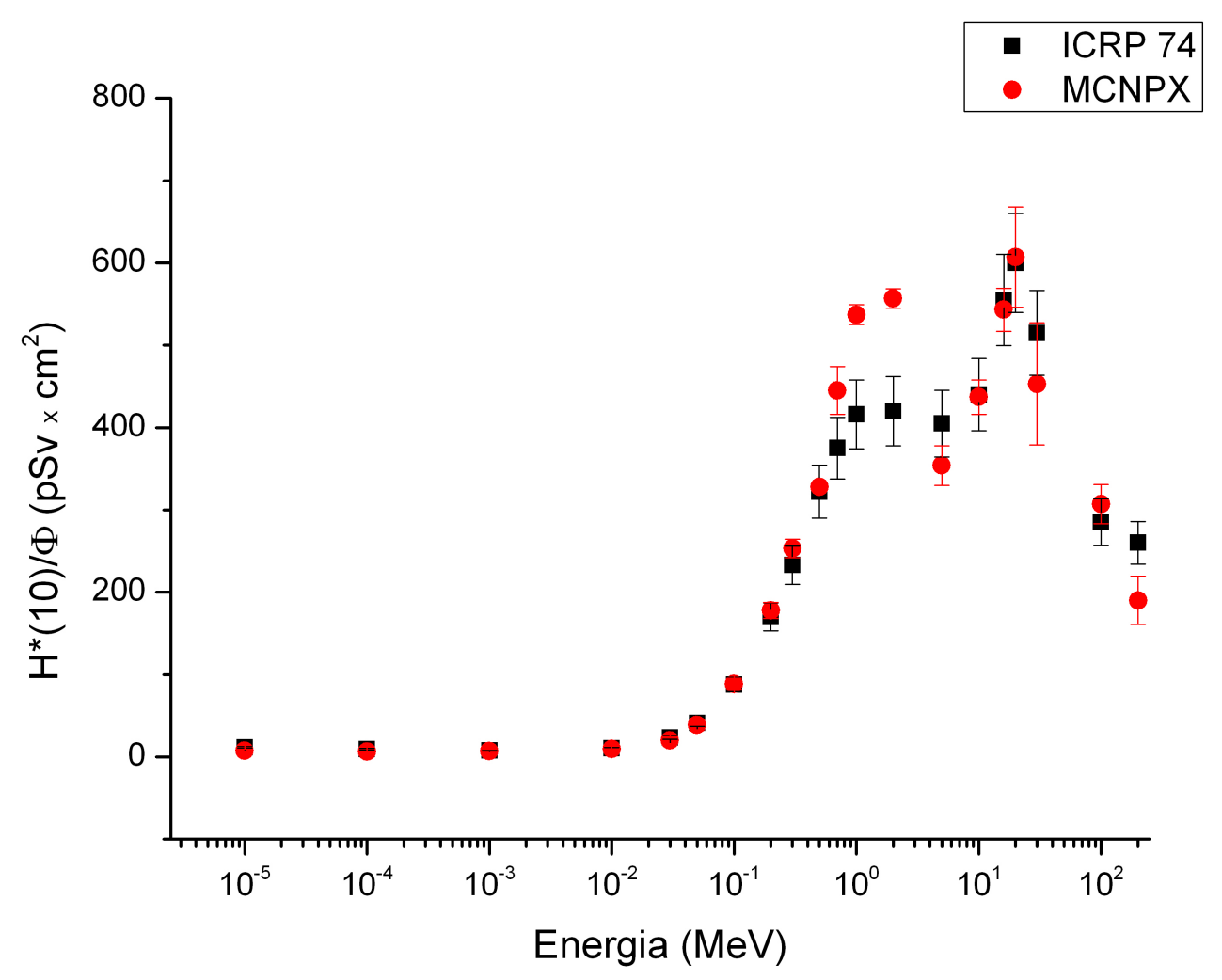

Figura 17 - Curvas do equivalente de dose ambiente por unidade de fluência do feixe de nêutrons $\left(H^{*}(10) / \Phi\right)$ na esfera ICRU.

O relatório ICRP 74 (ICRP, 1997) considera que a faixa de incerteza aceitável associada aos valores da grandeza dosimétrica equivalente de dose ambiente não deve passar de $10 \%$. 
Comparando os valores fornecidos pela ICRP (coluna E), inserida no valor a margem de incerteza máxima aceitável, com os valores e incertezas obtidos neste trabalho (coluna F), por meio do código computacional MCNPX, observa-se na faixa de energia de $10^{-5} \mathrm{MeV}$ sua diferença máxima (45,62 \%) e na faixa de energia de 0,1 MeV sua menor diferença (0,56 \%), conforme Figura 18.

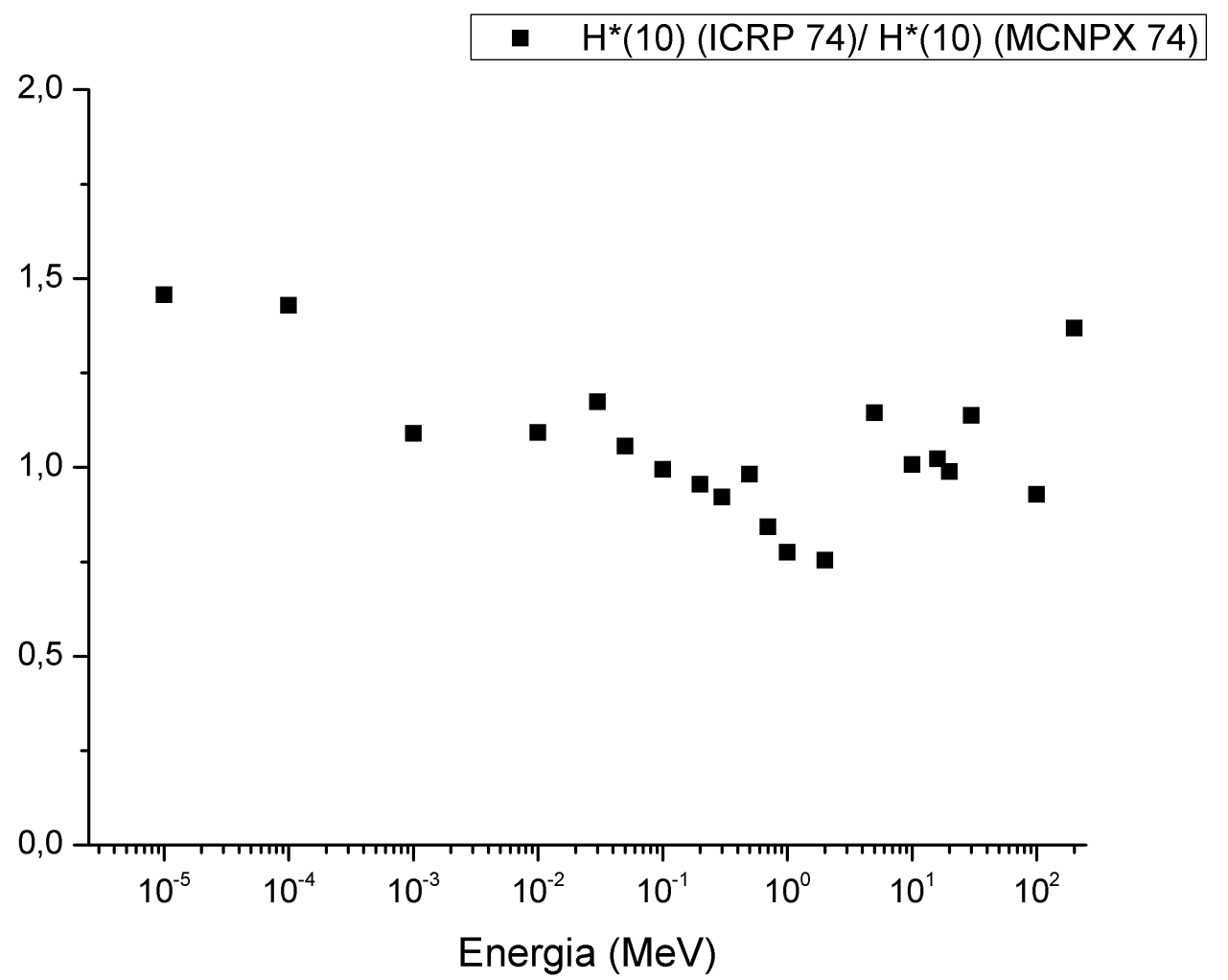

Figura 18 - Relação entre os coeficientes de conversão para equivalente de dose ambiente fornecido (ICRP 74) e calculado (MCNPX), $H^{*}(10) / \Phi$. A razão entre os dados é fornecida pelos pontos, em função da energia do nêutron.

Nota-se uma tendência de alargamento da faixa de valores obtidos em torno do intervalo de energia de 0,7 a $2 \mathrm{MeV}$ do feixe de nêutrons incidentes, em função da metodologia empregada neste trabalho diferir da metodologia utilizada pelo relatório ICRP 74 (ICRP,1997) no cômputo dos prótons de 0,6 MeV originados na reação ${ }^{14} \mathrm{~N}(n, p){ }^{14} \mathrm{C}$.

O Qeff é a razão entre o equivalente de dose ambiente $\left(H^{*}(10)\right)$ e a dose ambiente $\left(D^{*}(10)\right)$ e depende da energia do nêutron incidente. Na Tabela 5, na coluna B são apresentados os valores obtidos de Qeff neste trabalho, ao longo das simulações computacionais utilizando o codigo MCNPX. 
4.1.1 Determinação do equivalente de dose ambiente simulando a esfera ICRU com as sugestões da ICRP 103 para cálculo do fator $W_{R}$

O fator de ponderação para a radiação, $W_{R}$, foi definido para as grandezas dosimétricas de proteção relacionado com o fator de qualidade, $Q$, em função da transferência linear de energia $(L)$, sendo $Q(L)$ uma função definida pelo relatório ICRP 26 (ICRP,1977). No relatório ICRP 60 (ICRP,1991), o método de cálculo do fator de ponderação para a radiação foi modificado nos cálculos das grandezas dose equivalente e dose efetiva. Este fator $W_{R}$ deveria ser considerado nas aplicações envolvendo a área de proteção radiológica. Uma reavaliação dos valores de $W_{R}$ foi disponibilizada pelo relatório ICRP 103 (ICRP, 2007), onde os valores de $W_{R}$ para prótons e nêutrons diferem do relatório ICRP 60 (ICRP,1991). Os valores de $W_{R}$ passam a ser especificados em função do tipo e, no caso dos nêutrons em termos da energia da radiação incidente. Como um dos objetivos parciais deste trabalho era confeccionar a curva do equivalente de dose ambiente pela unidade de fluência na esfera ICRU e comparar os resultados obtidos com os valores presentes no relatório ICRP $74($ ICRP,1997) e no trabalho realizado por Leuthold et al. (1992), os fatores de ponderação para a radiação utilizados foram os definidos anteriormente, empregados tanto na realização do relatório ICRP 74 (ICRP,1997) quanto no trabalho de Leuthold e al. (1992), para que não houvesse discrepâncias na metodologia adotada.

Com a finalidade de estimar as alterações nos valores de equivalente de dose ambiente por unidade de fluência na esfera ICRU, utilizando os valores de $W_{R}$ sugeridos pelo relatório ICRP 103 (ICRP, 2007), que consiste do emprego das equações apresentadas a seguir para cálculo do $W_{R}$ em função da energia do nêutron incidente.

$$
\begin{aligned}
& W_{R}=2,5+18,2 e^{-\left[\ln \left(E_{n}\right)\right]^{2}} / 6, \quad E_{n}<1 \mathrm{MeV} \\
& W_{R}=5+17 e^{-\left[\ln \left(2 E_{n}\right)\right]^{2}} / 6,1 M e V \leq E_{n} \leq 50 \mathrm{MeV} \\
& W_{R}=2,5+3,25 e^{-\left[\ln \left(0,04 E_{n}\right)\right]^{2}} / 6, \quad E_{n}>50 \mathrm{MeV}
\end{aligned}
$$


As alterações mais significantes em comparação com o relatório ICRP 60 (ICRP,1991) ocorrem na faixa de energia abaixo de $1 \mathrm{MeV}$, que leva em conta a maior contribuição de fótons secundários na dose absorvida, e o decréscimo do fator de ponderação para nêutrons acima de $100 \mathrm{MeV}$ (ICRP,2007). Os resultados são apresentados na Tabela 6 e Figura 19.

Tabela 6 - Comparação dos valores da grandeza dosimétrica equivalente de dose ambiente utilizando os valores de $W_{R}$ apresentados na ICRP 74 e ICRP 103.

\begin{tabular}{crrrcc}
\hline $\mathbf{A}$ & $\mathbf{B}$ & \multicolumn{1}{c}{$\mathbf{C}$} & $\mathbf{D}$ & $\mathbf{E}$ & $\mathbf{F}$ \\
\hline $1,00 \times 10^{-5}$ & 2,03 & $3,20 \pm 0,60$ & 11,3 & $7,76 \pm 1,46$ & $6,48 \pm 1,22$ \\
$1,00 \times 10^{-4}$ & 2,07 & $2,69 \pm 0,07$ & 9,40 & $6,58 \pm 0,18$ & $5,55 \pm 0,15$ \\
$1,00 \times 10^{-3}$ & 1,77 & $3,63 \pm 1,06$ & 7,90 & $7,25 \pm 2,00$ & $6,41 \pm 1,88$ \\
$1,00 \times 10^{-2}$ & 2,60 & $2,76 \pm 0,07$ & 10,5 & $9.61 \pm 0,25$ & $7,18 \pm 0,18$ \\
$3,00 \times 10^{-2}$ & 3,07 & $3,92 \pm 0,80$ & 23,7 & $20,2 \pm 4,10$ & $12 \pm 2,44$ \\
$5,00 \times 10^{-2}$ & 4,00 & $5,71 \pm 1,20$ & 41,1 & $38,9 \pm 5,81$ & $22,9 \pm 4,81$ \\
$1,00 \times 10^{-1}$ & 6,62 & $8,65 \pm 1,68$ & 88,0 & $88,5 \pm 17,2$ & $57,2 \pm 11,1$ \\
$2,00 \times 10^{-1}$ & 11,2 & $11,2 \pm 0,60$ & 170 & $178 \pm 9,77$ & $126 \pm 6,91$ \\
$3,00 \times 10^{-1}$ & 13,4 & $14,6 \pm 0,60$ & 233 & $253 \pm 11,2$ & $195 \pm 8,66$ \\
$5,00 \times 10^{-1}$ & 18,5 & $18,5 \pm 0,10$ & 322 & $328 \pm 1,83$ & $342 \pm 1,92$ \\
$7,00 \times 10^{-1}$ & 17,7 & $23,1 \pm 1,49$ & 375 & $445 \pm 28,8$ & $409 \pm 26,4$ \\
$1,00 \times 10^{0}$ & 17,5 & $29,6 \pm 0,66$ & 416 & $537 \pm 12,0$ & $520 \pm 11,6$ \\
$2,00 \times 10^{0}$ & 15,4 & $35,5 \pm 0,70$ & 420 & $557 \pm 11,7$ & $548 \pm 11,6$ \\
$5,00 \times 10^{0}$ & 6,42 & $54,7 \pm 3,70$ & 405 & $354 \pm 24,0$ & $352 \pm 23,8$ \\
$1,00 \times 10^{1}$ & 6,40 & $67,9 \pm 3,24$ & 440 & $437 \pm 20,8$ & $434 \pm 20,7$ \\
$1,60 \times 10^{1}$ & 7,09 & $76,3 \pm 3,64$ & 555 & $543 \pm 25,9$ & $541 \pm 25,8$ \\
$2,00 \times 10^{1}$ & 7,41 & $81,8 \pm 8,23$ & 600 & $607 \pm 61,0$ & $606 \pm 61,0$ \\
$3,00 \times 10^{1}$ & 4,89 & $81 \pm 13,3$ & 515 & $453 \pm 74,1$ & $452 \pm 74$ \\
$1,00 \times 10^{2}$ & 3,74 & $76,7 \pm 5,91$ & 285 & $307 \pm 23,7$ & $287 \pm 22,1$ \\
$2,01 \times 10^{2}$ & 4,34 & $35,5 \pm 5,48$ & 260 & $190 \pm 29,3$ & $154 \pm 23,8$ \\
\hline
\end{tabular}

onde:

- A representa a energia do nêutron incidente em MeV;

- B representa o fator de qualidade efetivo (Qeff) em Sv/Gy obtido neste trabalho;

- C representa a dose absorvida pela unidade de fluência $\left(D^{*}(10) / \Phi\right)$ obtida neste trabalho em $\mathrm{pGy} \times \mathrm{cm}^{2}$;

- D representa o equivalente de dose ambiente pela unidade de fluência $\left(H^{*}(10) / \Phi\right)$ em pSv×cm${ }^{2}(I C R P, 1997)$; 
- E representa o equivalente de dose ambiente pela unidade de fluência $\left(H^{*}(10) / \Phi\right)$ obtido neste trabalho segundo as recomendações do relatório ICRP 74 (ICRP, 1997) em pSv× $\times \mathrm{cm}^{2}$;

- F representa o equivalente de dose ambiente pela unidade de fluência $\left(H^{*}(10) / \Phi\right)$ obtido neste trabalho segundo as recomendações do relatório ICRP 103 (ICRP, 2007) em pSv× $\mathrm{cm}^{2}$.

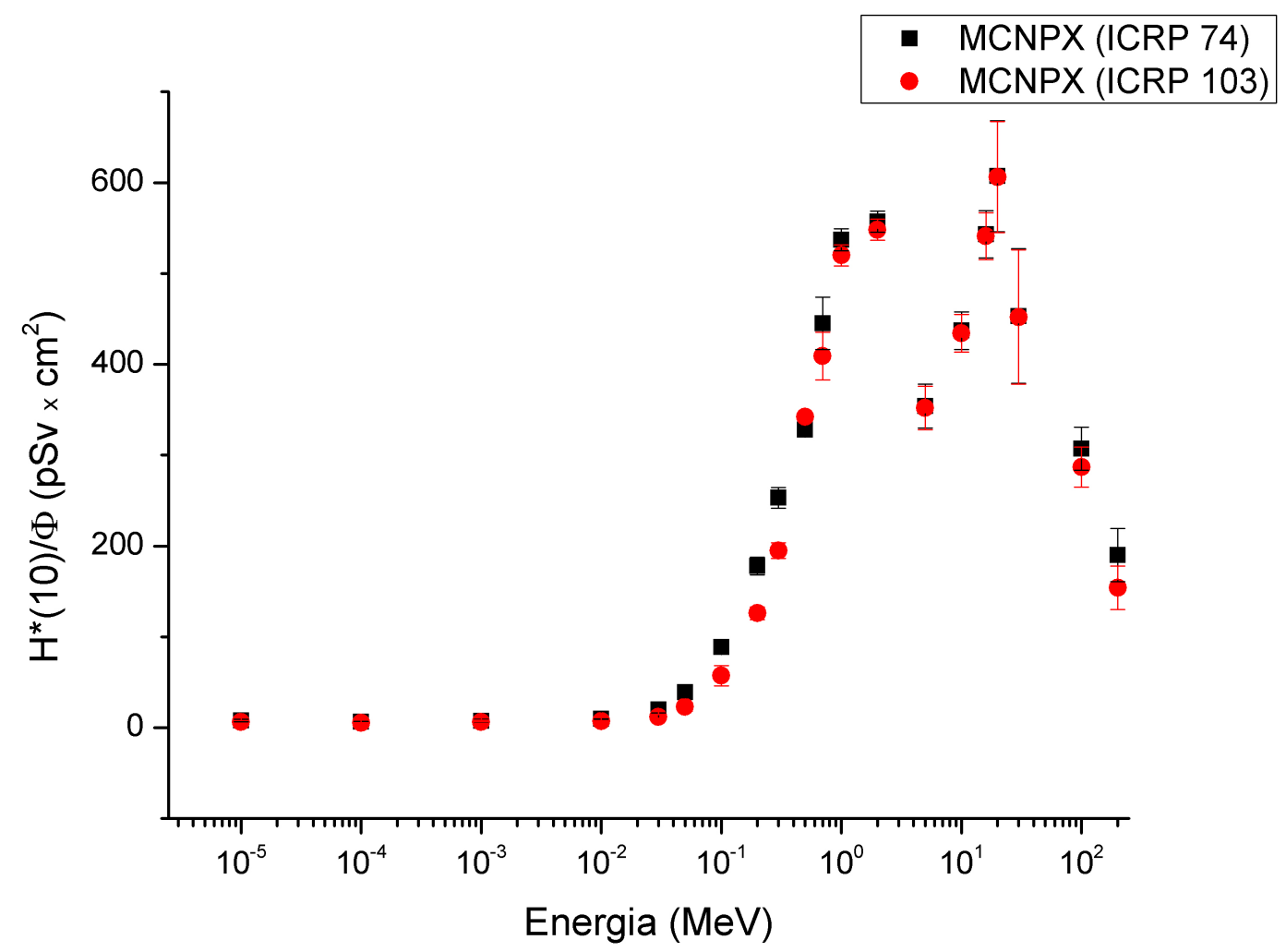

Figura 19 - Curvas do equivalente de dose ambiente por unidade de fluência do feixe de nêutrons $\left(H^{*}(10) / \Phi\right)$ na esfera ICRU em função da energia da radiação incidente, empregando-se os valores de fator de ponderação para nêutrons da ICRP 74 (ICRP,1997) e ICRP 103 (ICRP,2007).

A Figura 20 representa a variação entre os coeficientes de conversão para equivalente de dose ambiente em função da energia de radiação incidente, empregando-se os valores de fator de ponderação para nêutrons da ICRP 74 (ICRP,1997) e ICRP 103 (ICRP,2007). 


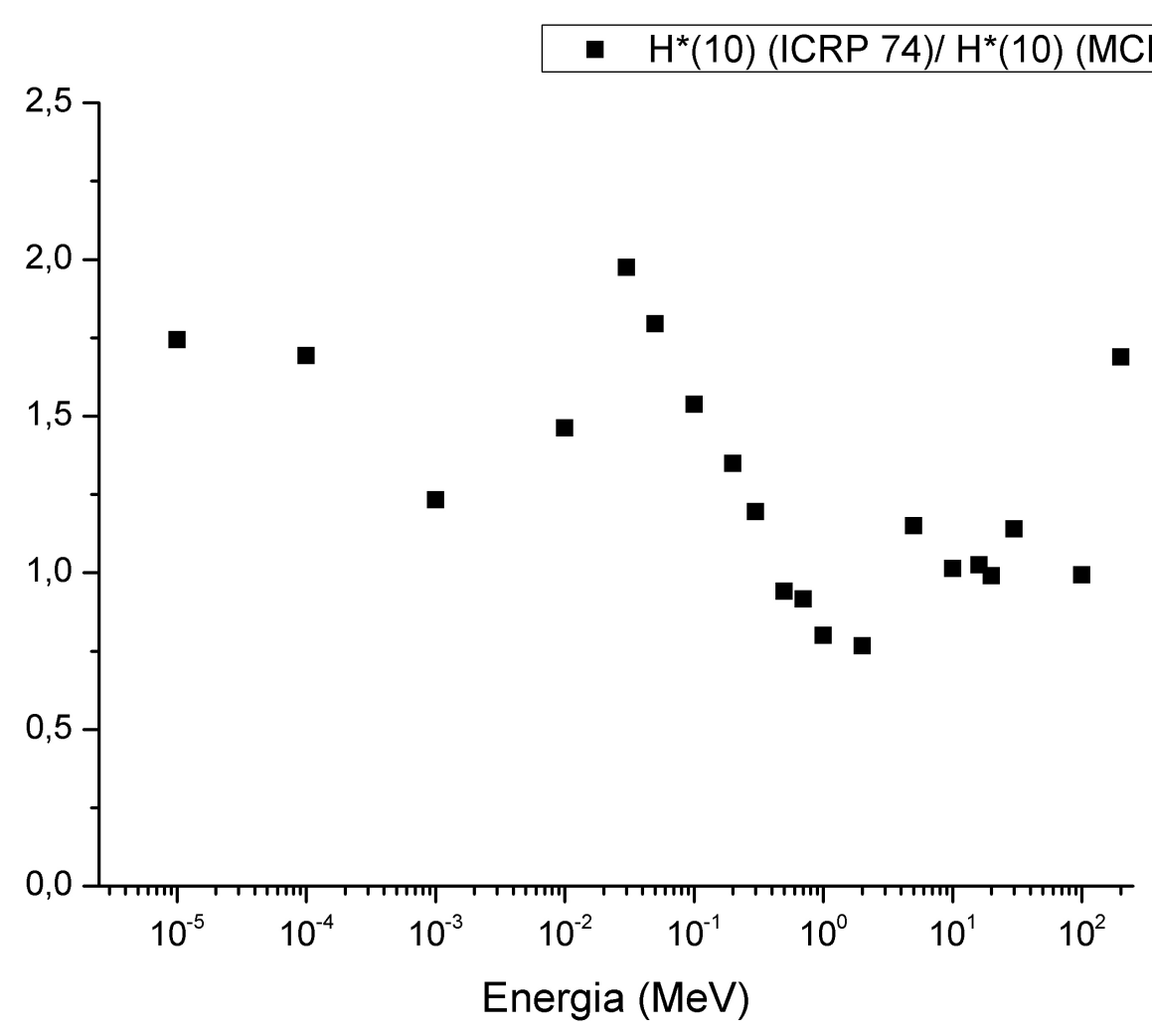

Figura 20 - Variação entre os coeficientes de conversão para equivalente de dose ambiente em função da energia da radiação incidente, empregando-se os valores de fator de ponderação para nêutrons da ICRP 74 (ICRP,1997) e ICRP 103 (ICRP,2007). A razão entre os dados é fornecida pelos pontos, em função da energia do nêutron.

$\mathrm{Na}$ Figura 21 pode-se observar as curvas do equivalente de dose ambiente por unidade de fluência do feixe de nêutrons $\left(H^{*}(10) / \Phi\right)$ na esfera ICRU em função da energia de radiação incidente, sendo os pontos em vermelho referentes aos valores sugeridos pelo relatório ICRP 74 (ICRP,1997) e os pontos em preto referentes aos valores obtidos utilizando o código computacional MCNPX em conjunto com os fatores de ponderação de radiação para nêutrons sugeridos pelo relatório ICRP 103 (ICRP,2007). 


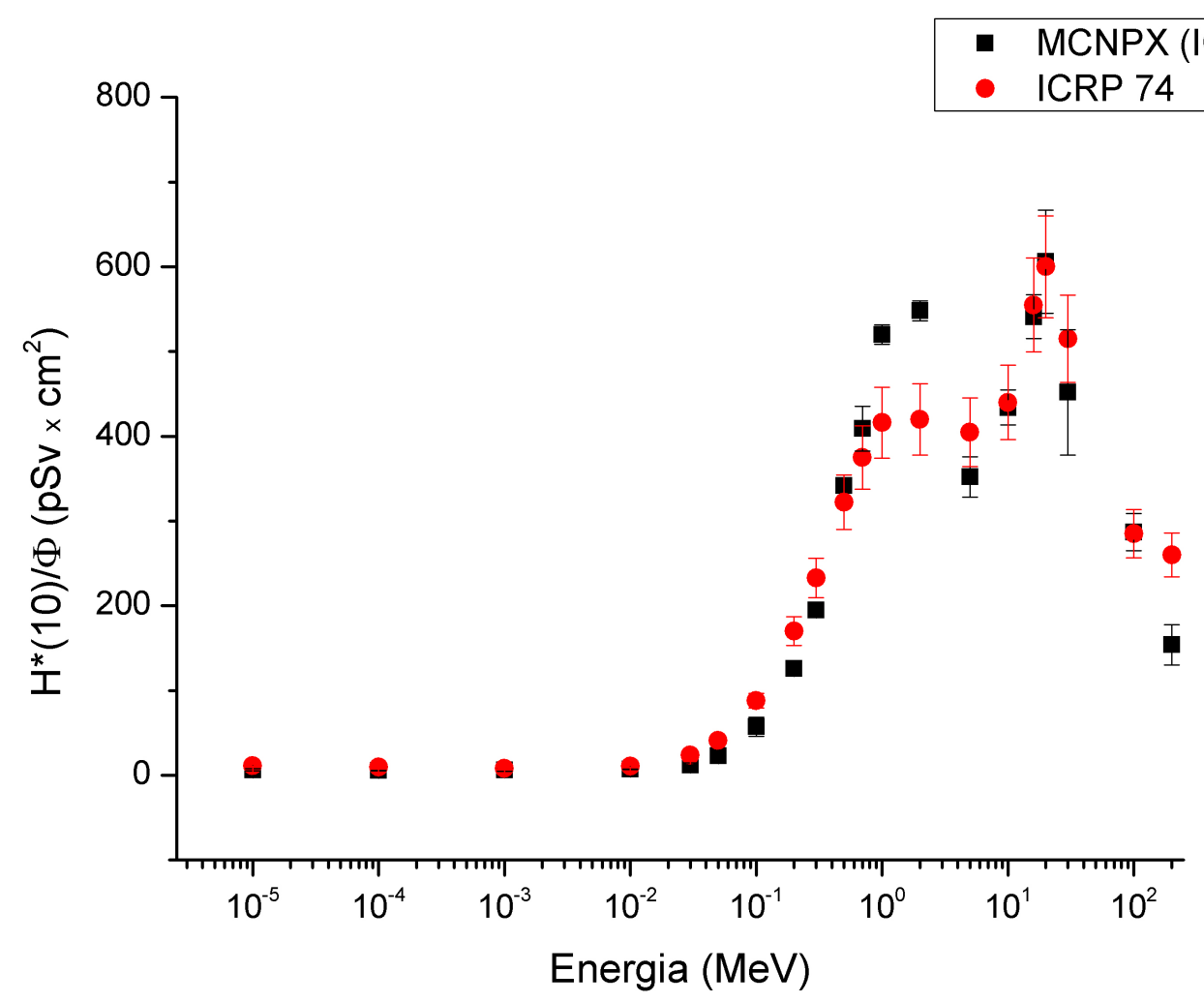

Figura 21 - Curvas do equivalente de dose ambiente por unidade de fluência do feixe de nêutrons $\left(H^{*}(10) / \Phi\right)$ na esfera ICRU.

\subsection{DETERMINAÇÃO DO EQUIVALENTE DE DOSE SIMULANDO O DETECTOR DE PMMA}

$\mathrm{Na}$ determinação do equivalente de dose do detector de PMMA, a metodologia aplicada é igual à aplicada na esfera ICRU, tendo sido necessário atentar para as características do objeto simulado, para fins de adequação das dimensões do campo alinhado e expandido ao qual o detector foi exposto, bem como a composição do material, que influenciou na escolha das bibliotecas de dados nucleares a serem usadas, assim como o poder de freamento das partículas no PMMA presentes no volume de controle, importantes para o cálculo do fator de qualidade no PMMA. Como exemplo, no caso de uma partícula que possui um poder de freamento de $47,23 \mathrm{MeV} \times \mathrm{cm}^{2} / \mathrm{g}$ para uma determinada energia, multiplicado pela densidade do material do detector $\left(1,19 \mathrm{~g} / \mathrm{cm}^{3}\right)$, obtémse o valor de 5,62 keV/ $\mu \mathrm{m}$, cujo valor é menor que $10 \mathrm{keV} / \mu \mathrm{m}$ (Eq. 2), logo o $\mathrm{Q}(\mathrm{L})$ desta partícula é igual a 1. Os valores do poder de freamento utilizados nas 
tabelas de cálculo para obtenção dos valores de $Q$, foram recomendados pelos relatórios 37 (ICRU, 1984), 49 (prótons e alfa) (ICRU, 1993) e 73 (íons mais pesados que Hélio) (ICRU, 2005). Para os valores não especificados nas tabelas dos relatórios citados, fez-se uso do pacote de programas "STAR CODES" (NIST, 2013), sendo que na realidade estes programas realizam uma interpolação entre os valores existentes nas tabelas presentes nas normas da ICRU. Estes códigos possuem algumas restrições, tais como considerar a energia mínima de $1 \mathrm{keV}$ para cálculos envolvendo prótons e íons de Hélio (partículas alfa) e $10 \mathrm{keV}$ para elétrons, e a energia máxima para cálculos em $1 \mathrm{GeV}$.

Para fótons e elétrons, neste estudo considerou-se o valor de $Q$ igual a 1 para todas as energias. No caso dos nêutrons, os fatores de ponderação que foram empregados são os sugeridos pelo relatório ICRP 60 (ICRP, 1991), pois os valores utilizados como referência neste trabalho (ICRP, 1997; LEUTHOLD et al., 1992; GARNY et al., 2009) foram calculados com os fatores de ponderação anteriores aos das modificações propostas pelo relatório ICRP 103 (ICRP, 2007).

É importante ressaltar que nas simulações computacionais não foi observada a geração de partículas alfa, dêuterons e prótons no interior do volume de controle, até a energia de $20 \mathrm{MeV}$, como observado ao longo das simulações envolvendo a esfera ICRU, em função da falta do elemento nitrogênio na composição do polimetilmetacrilato. Acima de $20 \mathrm{MeV}$, nota-se a geração de prótons, dêuterons e partículas alfa. Segundo o relatório ICRU 66 (ICRU, 2001), dois efeitos necessitam ser considerados: o espalhamento e a moderação de nêutrons rápidos na esfera ICRU, que elevam a dose absorvida no ponto de interesse e à participação dos prótons de $0,6 \mathrm{MeV}$ da reação induzida por nêutrons $\left({ }^{14} \mathrm{~N}(n, p){ }^{14} \mathrm{C}\right)$ na faixa de energia entre os nêutrons térmicos e de poucos $\mathrm{keV}$, conforme ilustrado na Figura 4, que mostra os valores de seção de choque (em barns) do nitrogênio para a reação mencionada (IAEA, 2013).

Para fins de verificação da participação dos prótons de 0,6 MeV da reação induzida por nêutrons $\left({ }^{14} \mathrm{~N}(n, p){ }^{14} \mathrm{C}\right)$, foi simulada a esfera ICRU retirando o elemento nitrogênio de sua composição mássica, sendo seu percentual redistribuído de forma proporcional para os elementos carbono, oxigênio e hidrogênio. Esta esfera ICRU modificada foi submetida a 3 campos expandidos e alinhados de nêutrons incidentes com energias de 5, 0,5 e 0,05 MeV, em que na simulação da esfera inicial foi observado a produção de prótons nestas faixas de 
energias. Sem o elemento nitrogênio presente, nenhum próton foi observado no volume de controle, confirmando a importância desta reação nuclear nos resultados envolvendo a esfera ICRU.

Os resultados referentes ao detector de PMMA são apresentados na Tabela 7 e na Figura 22

Tabela 7 - Resultados das simulações envolvendo o detector de PMMA.

\begin{tabular}{|c|c|c|c|}
\hline $\begin{array}{c}\mathrm{E} \\
(\mathrm{MeV}) \\
\end{array}$ & $\begin{array}{l}\mathrm{D}(10) / \phi \\
M C N P X \\
\left(p G y \times \mathrm{cm}^{2}\right)\end{array}$ & $\begin{array}{c}\mathrm{H}(10) / \phi \\
\mathrm{MCNPX} \\
\left(\mathrm{pSv} \times \mathrm{cm}^{2}\right)\end{array}$ & $\begin{array}{c}\text { Qeff } \\
\text { (Sv/Gy) }\end{array}$ \\
\hline $1,00 \times 10^{-5}$ & $2,40 \pm 0,59$ & $5,21 \pm 0,60$ & 2,17 \\
\hline $1,00 \times 10^{-4}$ & $2,35 \pm 0,73$ & $4,86 \pm 0,75$ & 2,07 \\
\hline $1,00 \times 10^{-3}$ & $1,21 \pm 0,71$ & $3,31 \pm 0,72$ & 2,75 \\
\hline $1,00 \times 10^{-2}$ & $0,90 \pm 0,90$ & $6,15 \pm 0,39$ & 6,83 \\
\hline $3,00 \times 10^{-2}$ & $4,45 \pm 0,78$ & $21,3 \pm 0,9$ & 4,79 \\
\hline $5,00 \times 10^{-2}$ & $5,12 \pm 0,73$ & $40,0 \pm 1,3$ & 7,82 \\
\hline $1,00 \times 10^{-1}$ & $7,87 \pm 0,75$ & $97,1 \pm 2,6$ & 12,3 \\
\hline $2,00 \times 10^{-1}$ & $11,5 \pm 0,6$ & $196 \pm 4$ & 17,0 \\
\hline $3,00 \times 10^{-1}$ & $15,8 \pm 0,5$ & $296 \pm 6$ & 18,8 \\
\hline $5,00 \times 10^{-1}$ & $21,8 \pm 0,6$ & $395 \pm 7$ & 18,1 \\
\hline $7,00 \times 10^{-1}$ & $24,9 \pm 0,5$ & $500 \pm 7$ & 20,1 \\
\hline $1,00 \times 10^{0}$ & $34 \pm 1$ & $664 \pm 17$ & 19,5 \\
\hline $2,00 \times 10^{0}$ & $42,4 \pm 0,9$ & $690 \pm 12$ & 16,3 \\
\hline $5,00 \times 10^{0}$ & $57,9 \pm 1,0$ & $700 \pm 12$ & 12,1 \\
\hline $1,00 \times 10^{1}$ & $73,6 \pm 1,4$ & $613 \pm 11$ & 8,33 \\
\hline $1,60 \times 10^{1}$ & $92,6 \pm 1,5$ & $678 \pm 11$ & 7,33 \\
\hline $2,00 \times 10^{1}$ & $99,5 \pm 2,1$ & $668 \pm 13$ & 6,71 \\
\hline $3,00 \times 10^{1}$ & $98,0 \pm 14,8$ & $856 \pm 129$ & 8,74 \\
\hline $1,00 \times 10^{2}$ & $80,4 \pm 7,04$ & $386 \pm 33,8$ & 4,81 \\
\hline $2,01 \times 10^{2}$ & $48,6 \pm 6,86$ & $209 \pm 29,5$ & 4,30 \\
\hline
\end{tabular}




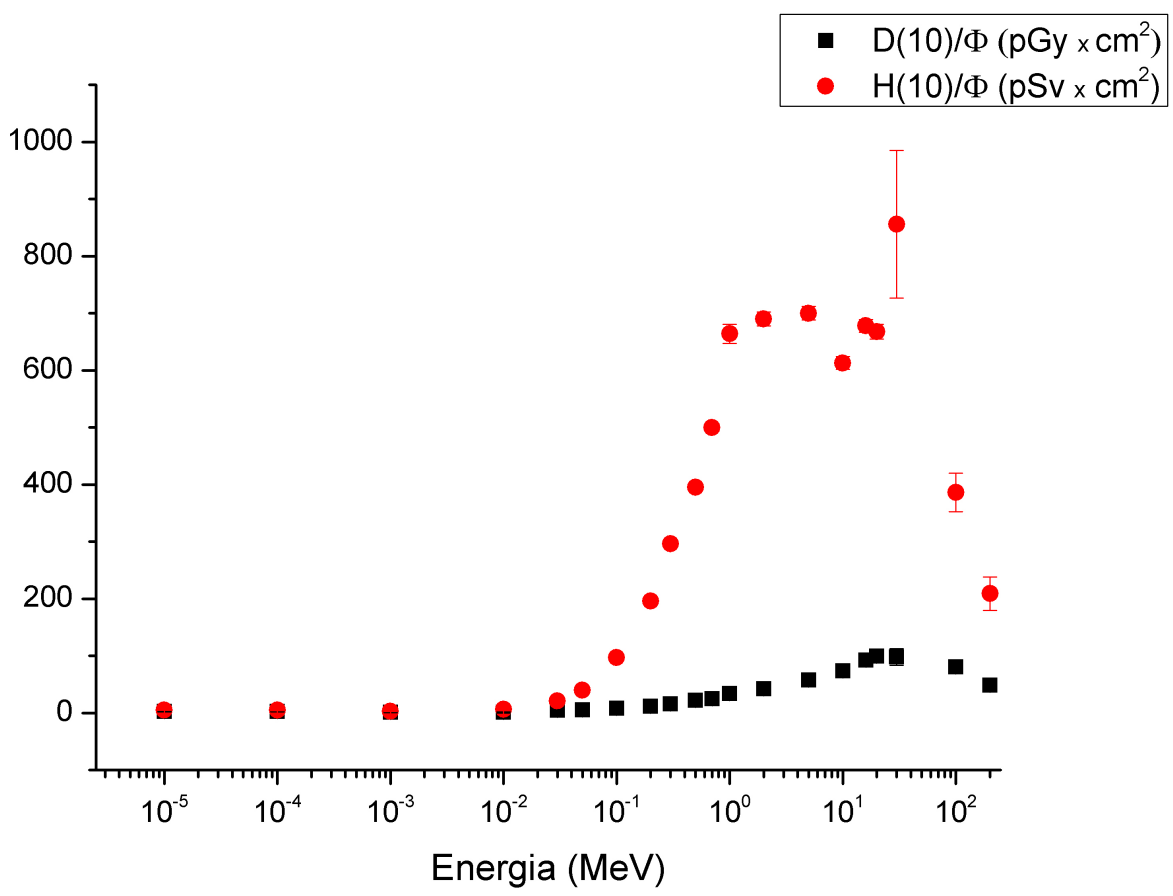

Figura 22 - Resultados das simulações envolvendo o detector de PMMA.

Observando-se a Tabela 6 bem como a Figura 23, nota-se que o detector apresenta comportamento semelhante ao da esfera ICRU (Fig.17) à medida que os valores do feixe de nêutrons incidentes aumenta, tanto em relação à dose absorvida por unidade de fluência (D/\$) (Fig.23) quanto ao equivalente de dose por unidade de fluência (H/\$) (Fig.24). 


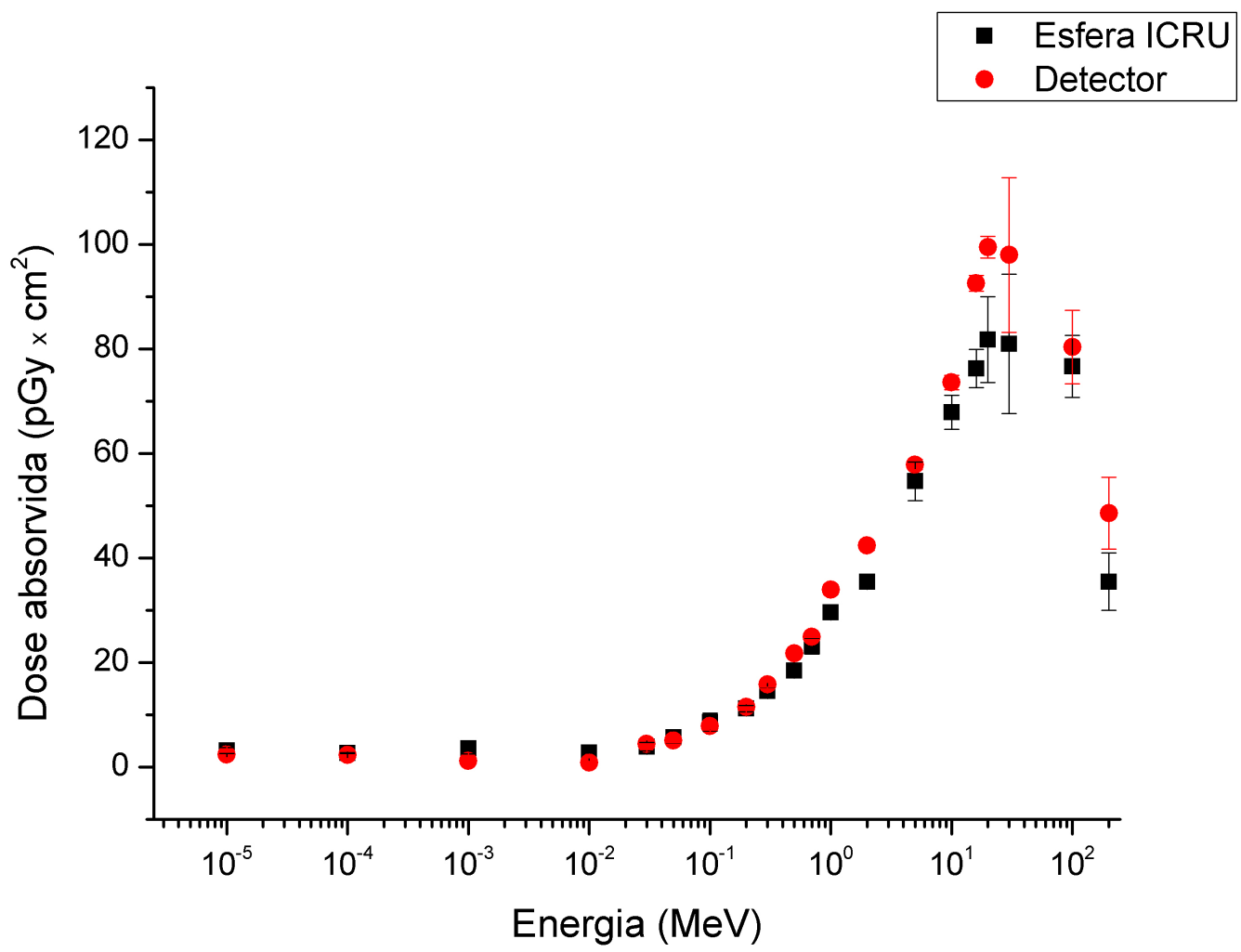

Figura 23 - Comparação dos resultados das simulações envolvendo o detector de PMMA e a esfera ICRU, em pGy x $\mathrm{cm}^{2}$.

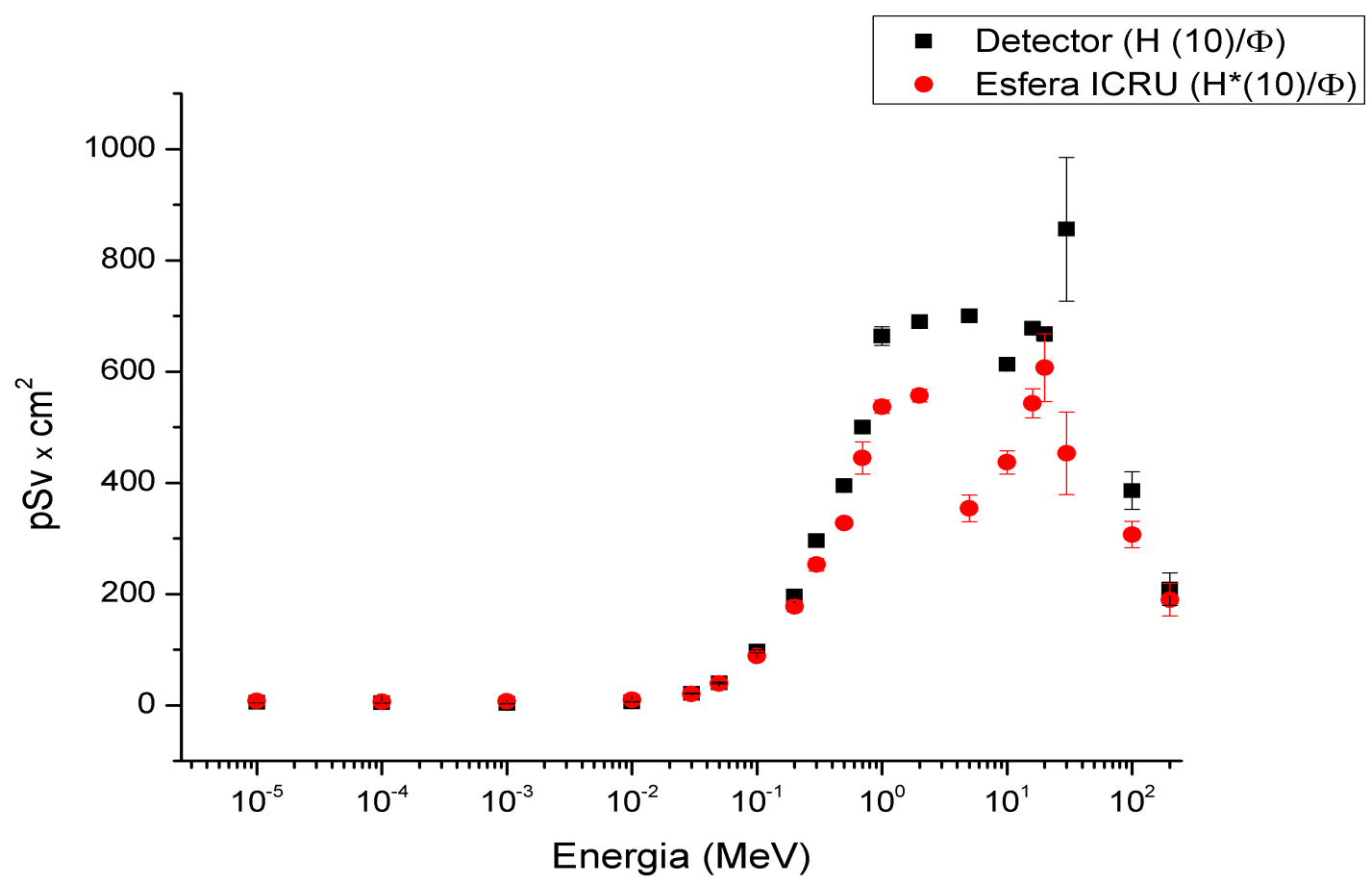

Figura 24 - Comparação dos resultados das simulações envolvendo o detector de PMMA e a esfera ICRU, em pSv x $\mathrm{cm}^{2}$. 
Segundo os resultados apresentados, para verificar se existe alguma proporcionalidade entre o detector e a esfera ICRU, em termos de dose absorvida, foi obtida a curva de calibração da Figura 25.

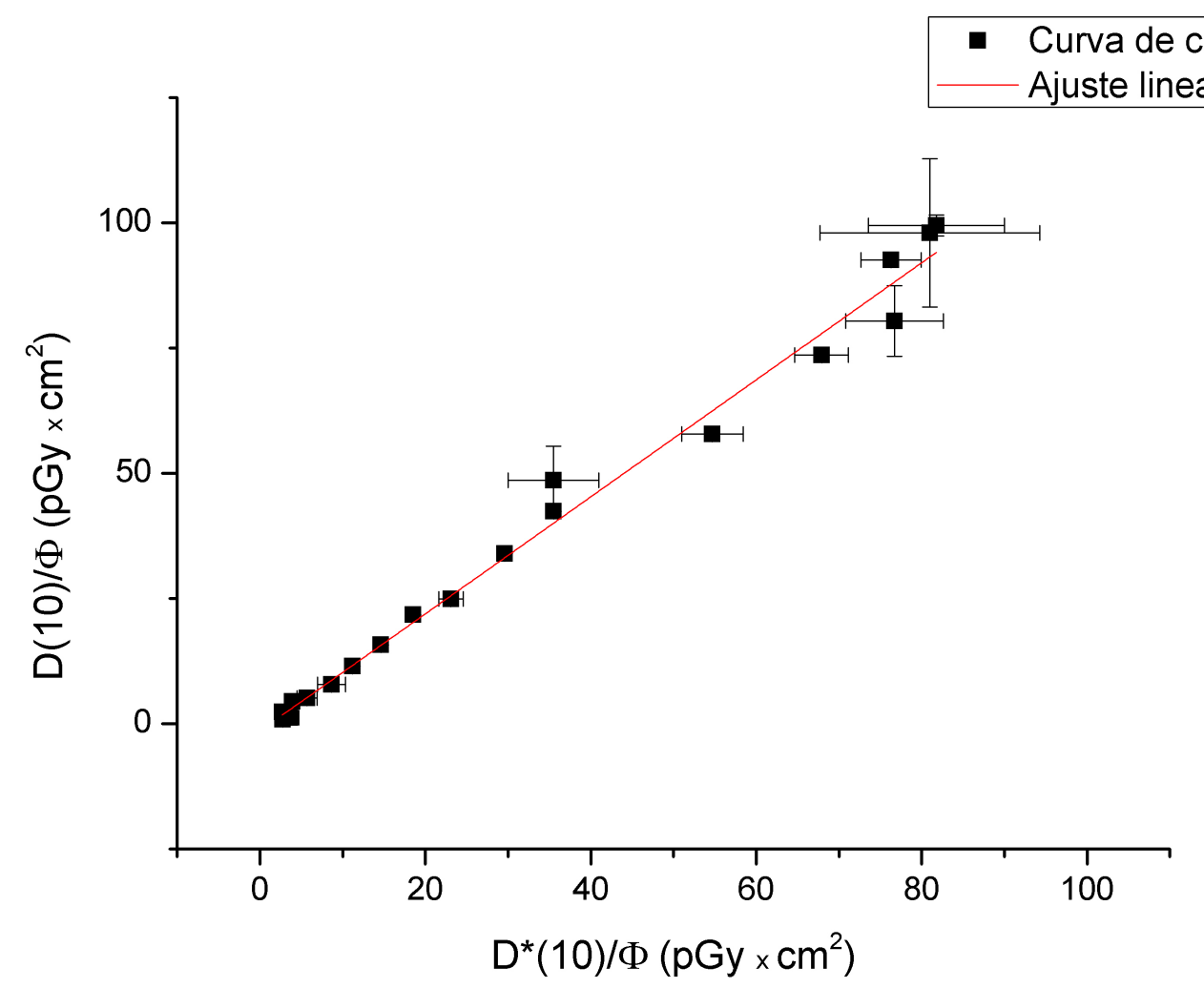

Figura 25 - Curva de calibração do detector em termos de dose absorvida em relação à esfera ICRU.

Sendo o coeficiente de correlação $\left(R^{2}\right)$ do ajuste linear representado igual a 0,9929, pode-se considerar a existência de uma proporcionalidade em termos de dose absorvida.

A Figura 26 representa a relação entre as doses absorvidas na esfera ICRU e no detector $\left(D^{*}(10) / D(10)\right)$ em função da energia do nêutron incidente, empregando-se os valores obtidos utilizando o código computacional MCNPX. 


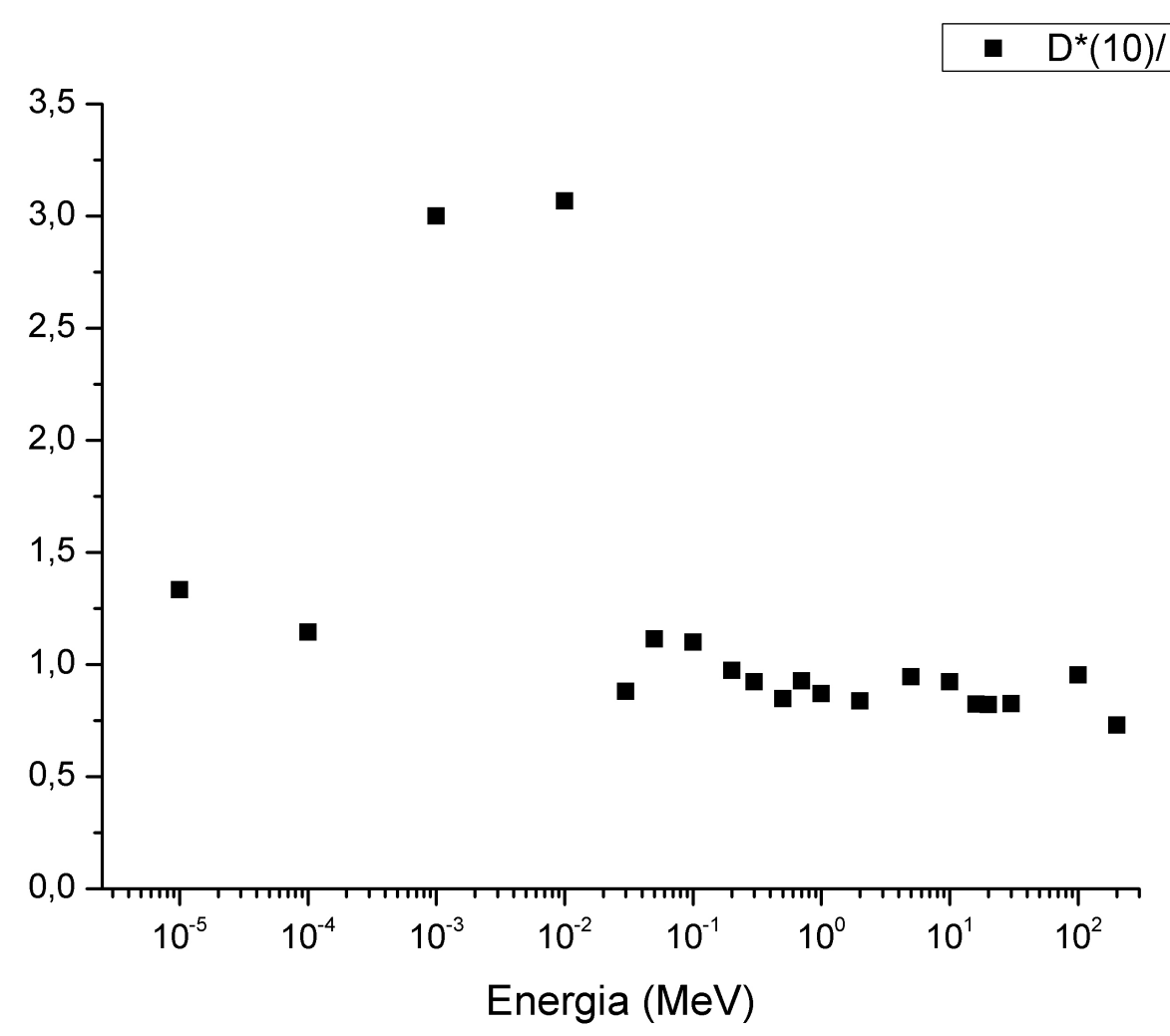

Figura 26 - Relação entre as doses absorvidas na esfera ICRU e no detector $\left(D^{*}(10) / D(10)\right)$ em função da energia do nêutron incidente.

Com relação à comparação entre o equivalente de dose por fluência do detector $(H)$ e o equivalente de dose ambiente por fluência $\left(H^{*}(10)\right)$, obteve-se a curva da Figura 24, sendo que conforme os resultados apresentados, para verificar se existe alguma proporcionalidade entre o detector e a esfera ICRU, em termos de equivalente de dose, foi obtida a curva de calibração da Figura 27. 


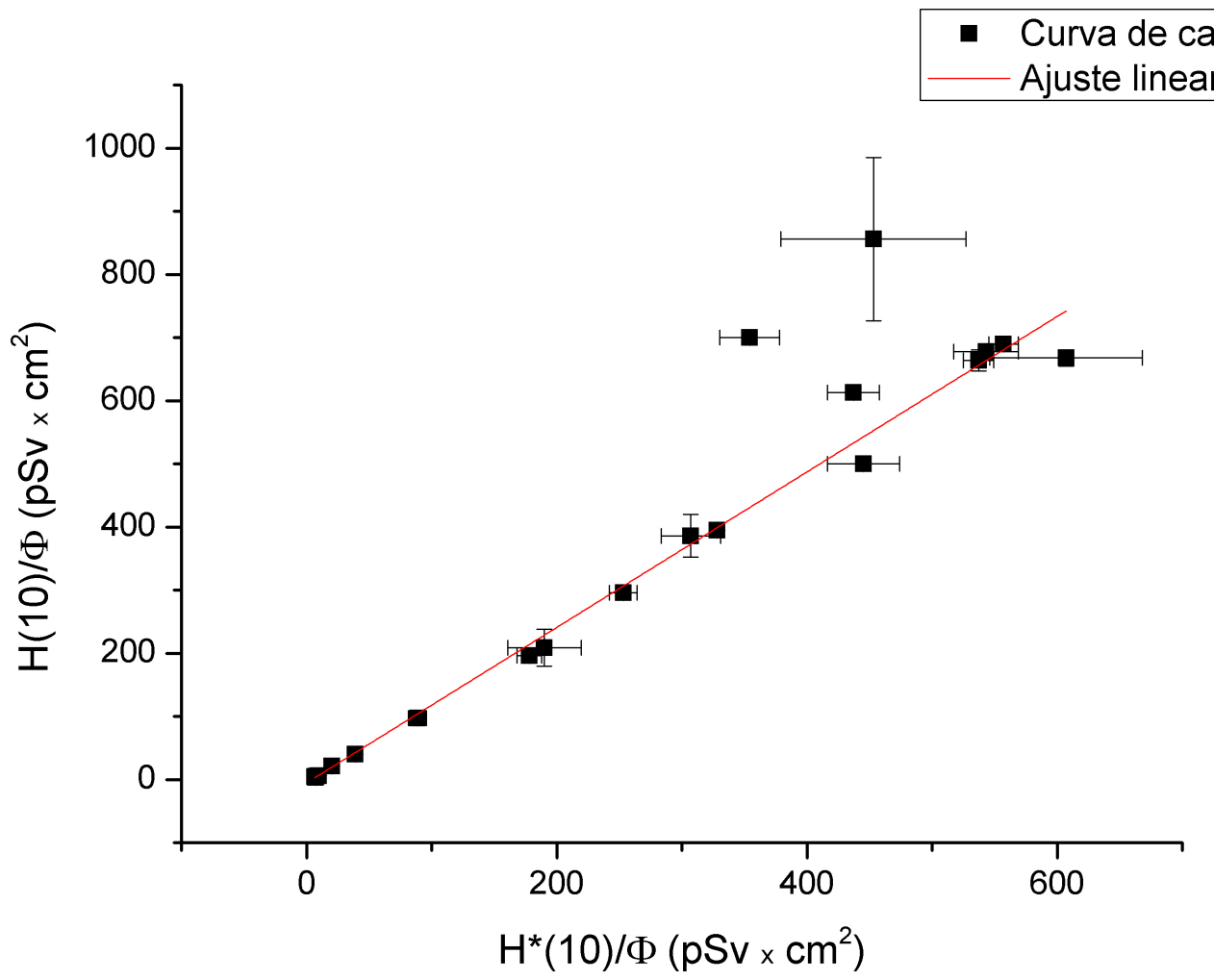

Figura 27 - Curva de calibração do detector em termos de equivalente de dose por unidade de fluência $(\mathrm{H}(10) / \phi)$ em relação ao equivalente de dose ambiente por unidade de fluência $\left(H^{*}(10) / \phi\right)$.

Como as duas curvas $\left(H^{*}(10) / \phi\right.$ e $\left.H / \phi\right)$ possuem pontos de máximo em faixas de energia diferentes (entre 1 e $5 \mathrm{MeV}$ ), optou-se por confeccionar uma curva de calibração no intervalo de energia de $10 \mathrm{eV}$ a $700 \mathrm{keV}$, conforme apresentado na Figura 28. 


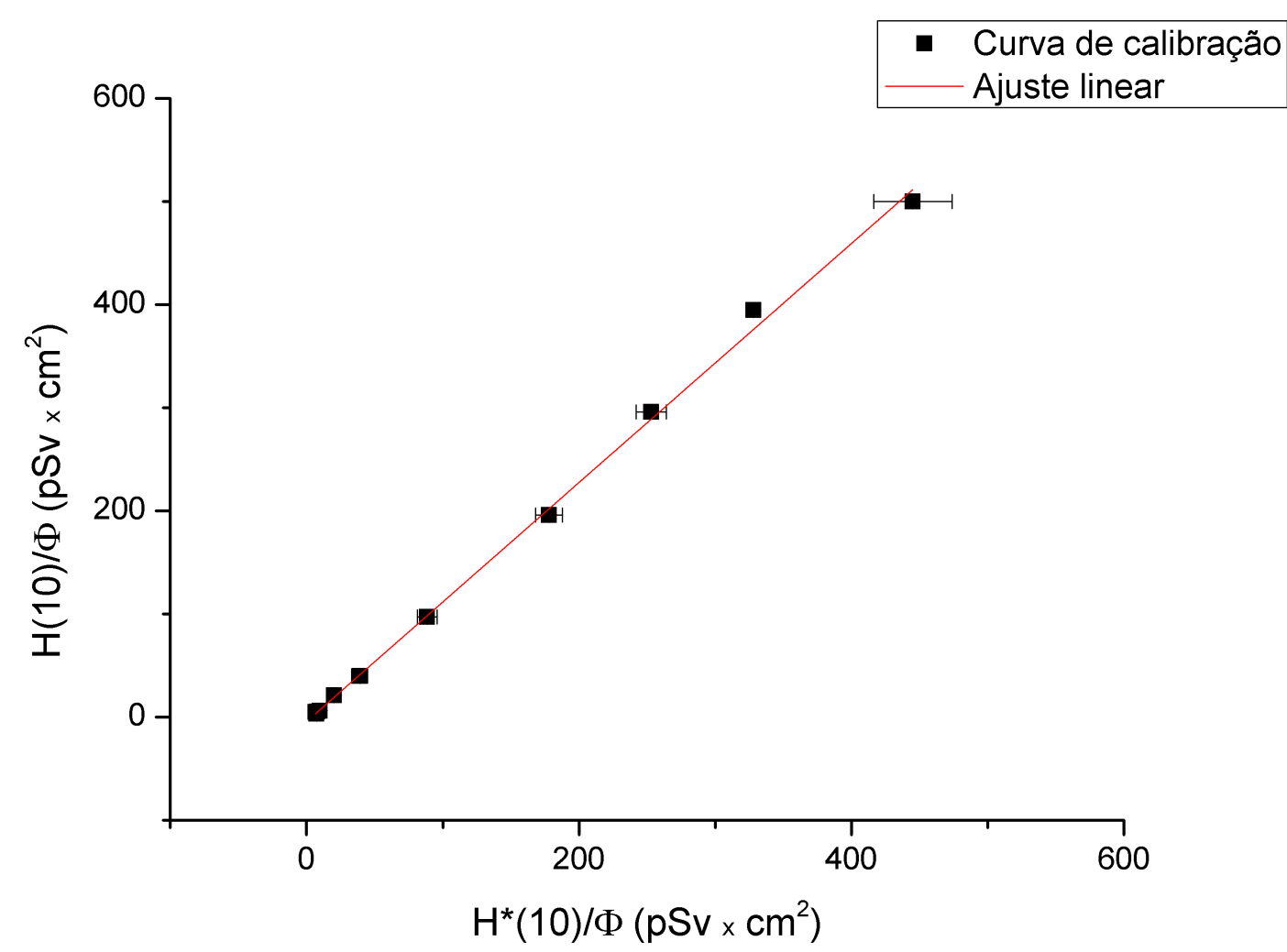

Figura 28 - Curva de calibração do detector em termos de equivalente de dose por fluência em relação ao equivalente de dose ambiente por fluência.

Sendo o coeficiente de correlação $\left(R^{2}\right)$ do ajuste linear da curva da Figura 28 igual a 0,9977, pode-se considerar a existência de uma proporcionalidade em termos de equivalente de dose no intervalo de energia de $10 \mathrm{eV}$ a $700 \mathrm{keV}$.

Com relação aos fatores de qualidade efetivos (Qeff) da esfera ICRU e do detector de PMMA, nota-se que as curvas possuem o mesmo comportamento ao longo de cada faixa de energia, conforme mostrado nas Figuras 29 e 30. 


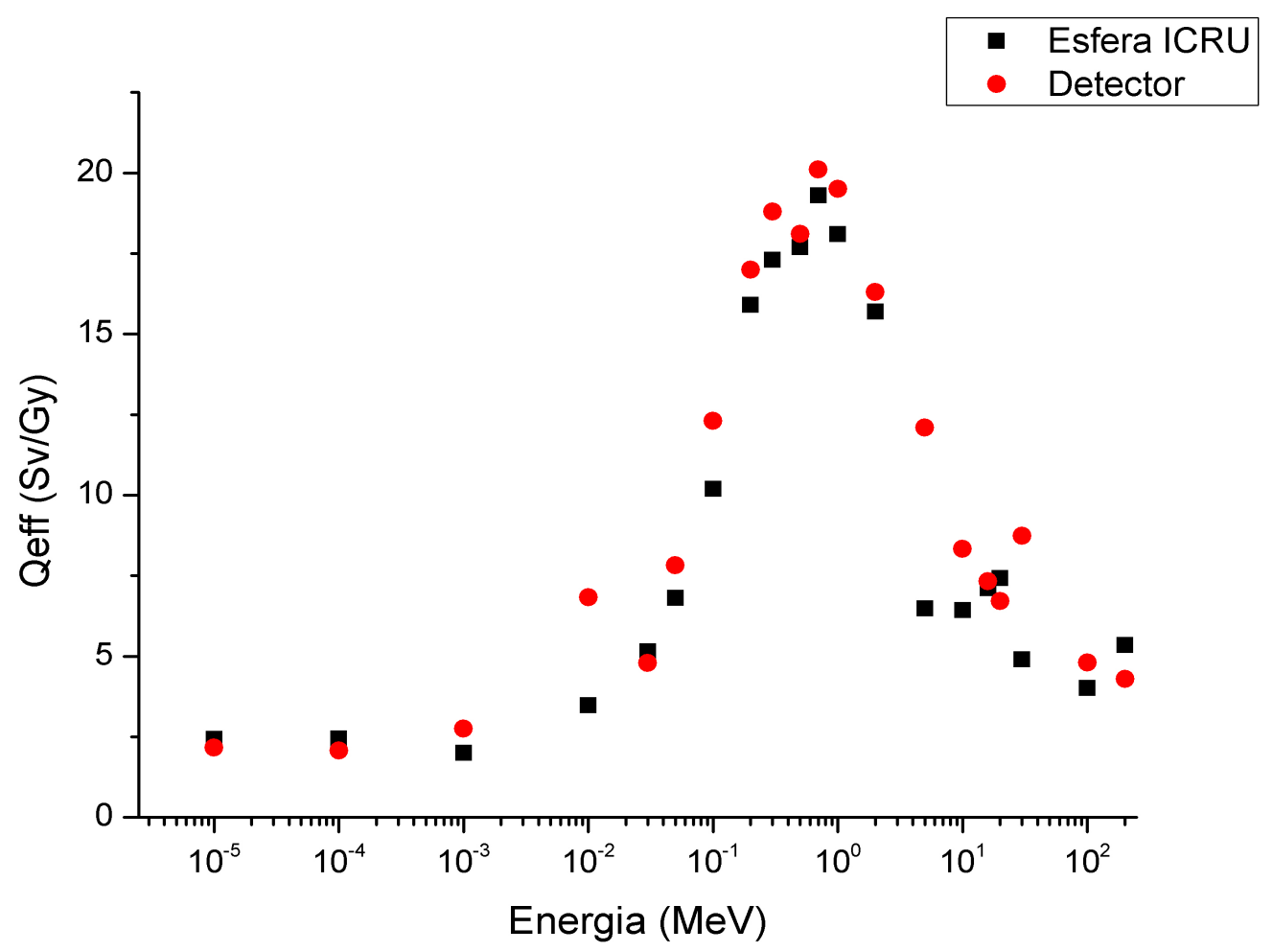

Figura 29 - Curvas dos fatores de qualidade efetivos (Qeff) do detector e da esfera ICRU em função da energia incidente.

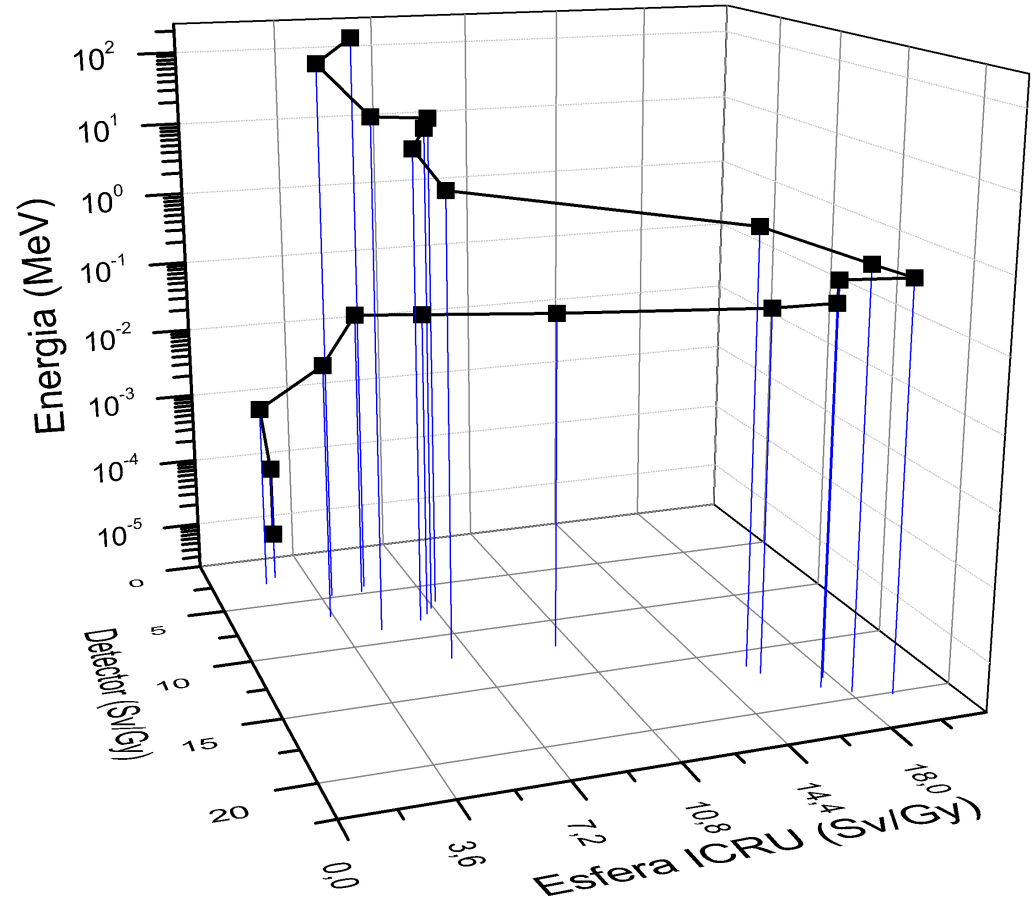

Figura 30 - Curva dos fatores de qualidade efetivos (Qeff) do detector e da esfera ICRU em função da energia, em formato tridimensional. 


\subsection{DETECTOR SUBMETIDO AO ESPECTRO DE ${ }^{241} \mathrm{Am} / \mathrm{Be}$}

A simulação computacional envolvendo uma fonte pontual, a uma distância de $86,5 \mathrm{~cm}$ da superfície do detector, alinhada com o centro do detector, cujo card de energia teve como distribuição o espectro de nêutrons normalizados de uma fonte de ${ }^{241} \mathrm{Am} / \mathrm{Be}$ conforme a Figura 31 (IAEA, 2001), teve por objetivo simular o detector com as pastilhas de fluoreto de lítio inseridas nas posições 4 , $15,16,19,23,24,37,38,40$ e 43, visando o fornecimento de dados para posterior comparação com os dados experimentais obtidos por Federico (2011), quando da irradiação do detector de PMMA por este tipo de fonte.

Os espectros de nêutrons emitidos das fontes citadas são apresentados em sua forma gráfica na Figura 31.

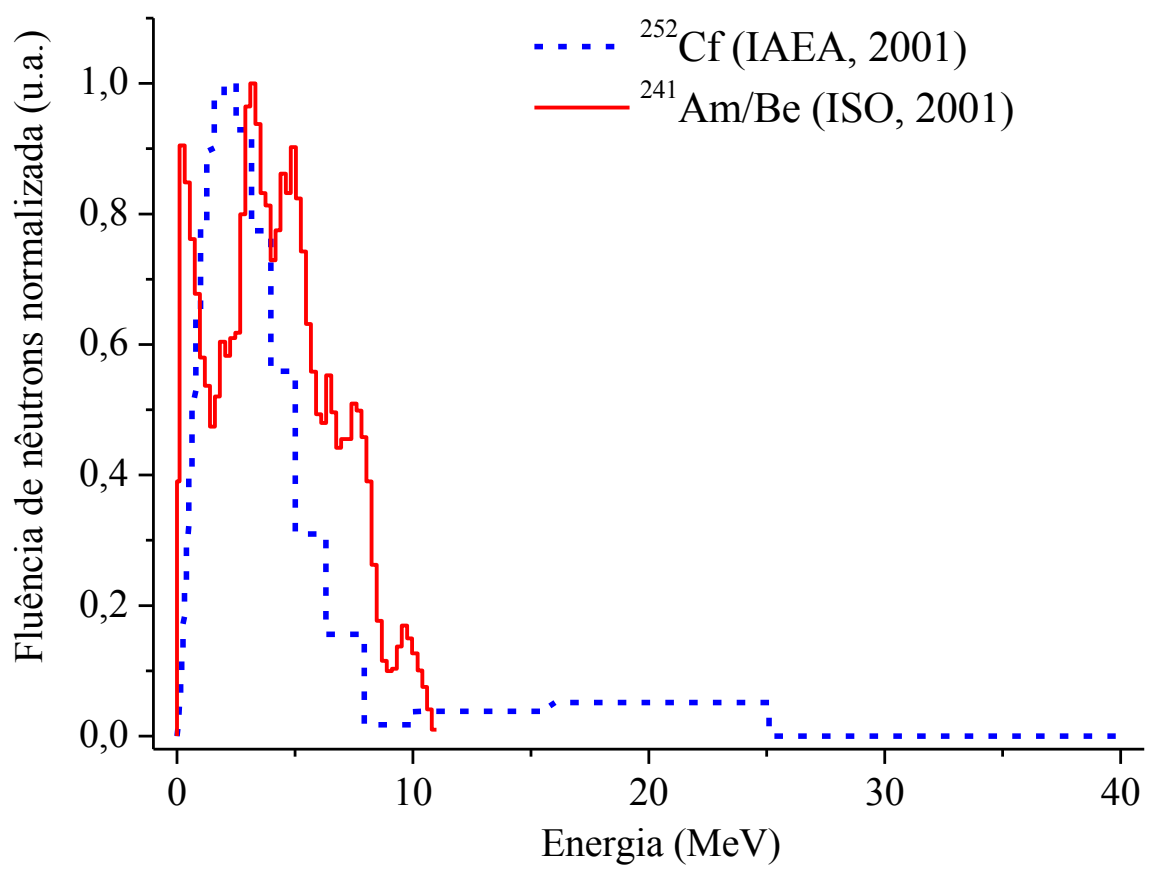

Figura 31 - Espectro de nêutrons normalizados emitidos por fontes de ${ }^{241} \mathrm{Am} / \mathrm{Be}$ e ${ }^{252} \mathrm{Cf}$ (IAEA,2001; ISO,2001). 


\subsubsection{Simulação computacional}

Os resultados obtidos durante a simulação computacional envolvendo a fonte de ${ }^{241} \mathrm{Am} / \mathrm{Be}$, cuja intenção era reproduzir as condições experimentais utilizadas por Federico (2011) são apresentados na Tabela 8.

Tabela 8 - Valores da simulação computacional empregando o espectro de emissão de nêutrons do ${ }^{241} \mathrm{Am} / \mathrm{Be}$.

\begin{tabular}{ccccc}
\hline Posição & $\begin{array}{c}\text { Dose } \\
\text { absorvida } \\
\text { TLD-600 } \\
\text { (pGy) }\end{array}$ & Incerteza & $\begin{array}{c}\text { Dose } \\
\text { absorvida } \\
\text { TLD-700 } \\
\text { (pGy) }\end{array}$ & $\begin{array}{c}\text { Incerteza } \\
\text { (pGy) }\end{array}$ \\
\hline 4 & $2,01 \mathrm{E}-01$ & $2,60 \mathrm{E}-02$ & $1,50 \mathrm{E}-01$ & $3,29 \mathrm{E}-03$ \\
15 & $1,08 \mathrm{E}-01$ & $4,01 \mathrm{E}-02$ & $8,64 \mathrm{E}-02$ & $3,19 \mathrm{E}-03$ \\
16 & $1,04 \mathrm{E}-01$ & $4,09 \mathrm{E}-02$ & $8,36 \mathrm{E}-02$ & $3,11 \mathrm{E}-03$ \\
19 & $1,49 \mathrm{E}-01$ & $1,95 \mathrm{E}-02$ & $1,28 \mathrm{E}-01$ & $2,04 \mathrm{E}-03$ \\
23 & $1,89 \mathrm{E}-01$ & $1,79 \mathrm{E}-02$ & $1,63 \mathrm{E}-01$ & $2,08 \mathrm{E}-03$ \\
24 & $1,95 \mathrm{E}-01$ & $1,14 \mathrm{E}-02$ & $1,60 \mathrm{E}-01$ & $1,78 \mathrm{E}-03$ \\
37 & $6,25 \mathrm{E}-02$ & $3,96 \mathrm{E}-02$ & $9,14 \mathrm{E}-02$ & $3,12 \mathrm{E}-03$ \\
40 & $1,34 \mathrm{E}-01$ & $2,74 \mathrm{E}-02$ & $1,40 \mathrm{E}-01$ & $3,22 \mathrm{E}-03$ \\
38 & $1,08 \mathrm{E}-01$ & $3,48 \mathrm{E}-02$ & $7,97 \mathrm{E}-02$ & $2,79 \mathrm{E}-03$ \\
43 & $9,91 \mathrm{E}-02$ & $2,01 \mathrm{E}-02$ & $6,38 \mathrm{E}-02$ & $2,07 \mathrm{E}-03$ \\
\hline
\end{tabular}

\subsubsection{Dados experimentais}

Os dados experimentais utilizados para realizar uma comparação com os valores simulados computacionalmente foram fornecidos por Federico (2011), valores estes obtidos em irradiações do detector com uma fonte de ${ }^{241} \mathrm{Am} / \mathrm{Be}$, em 15 de dezembro 2010, no Laboratório de Metrologia de Nêutrons (LN) situado no Instituto de Radioproteção e Dosimetria (IRD), localizado na cidade do Rio de Janeiro, R.J.

Os valores dos dados experimentais são apresentados na Tabela 9 e a comparação com os valores obtidos por meio da simulação computacional são apresentados na Figura 32 (TLD-600) e Figura 33 (TLD-700). 
Tabela 9 - Valores experimentais obtidos da irradiação do detector passivo com uma fonte de ${ }^{241} \mathrm{Am} / \mathrm{Be}$.

\begin{tabular}{ccc}
\hline & & \\
\hline Posição & TLD 600 $(p C)$ & TLD 700 $(p C)$ \\
4 & $5,10 \mathrm{E}+05$ & $9,47 \mathrm{E}+04$ \\
15 & $1,40 \mathrm{E}+06$ & $5,57 \mathrm{E}+04$ \\
16 & $1,49 \mathrm{E}+06$ & $6,00 \mathrm{E}+04$ \\
19 & $1,92 \mathrm{E}+06$ & $8,32 \mathrm{E}+04$ \\
23 & $1,73 \mathrm{E}+06$ & $1,08 \mathrm{E}+05$ \\
24 & $6,14 \mathrm{E}+05$ & $1,22 \mathrm{E}+05$ \\
37 & $1,51 \mathrm{E}+06$ & $5,87 \mathrm{E}+04$ \\
40 & $6,26 \mathrm{E}+05$ & $1,04 \mathrm{E}+05$ \\
38 & $1,16 \mathrm{E}+06$ & $5,72 \mathrm{E}+04$ \\
43 & $5,12 \mathrm{E}+05$ & $5,96 \mathrm{E}+04$ \\
\hline
\end{tabular}

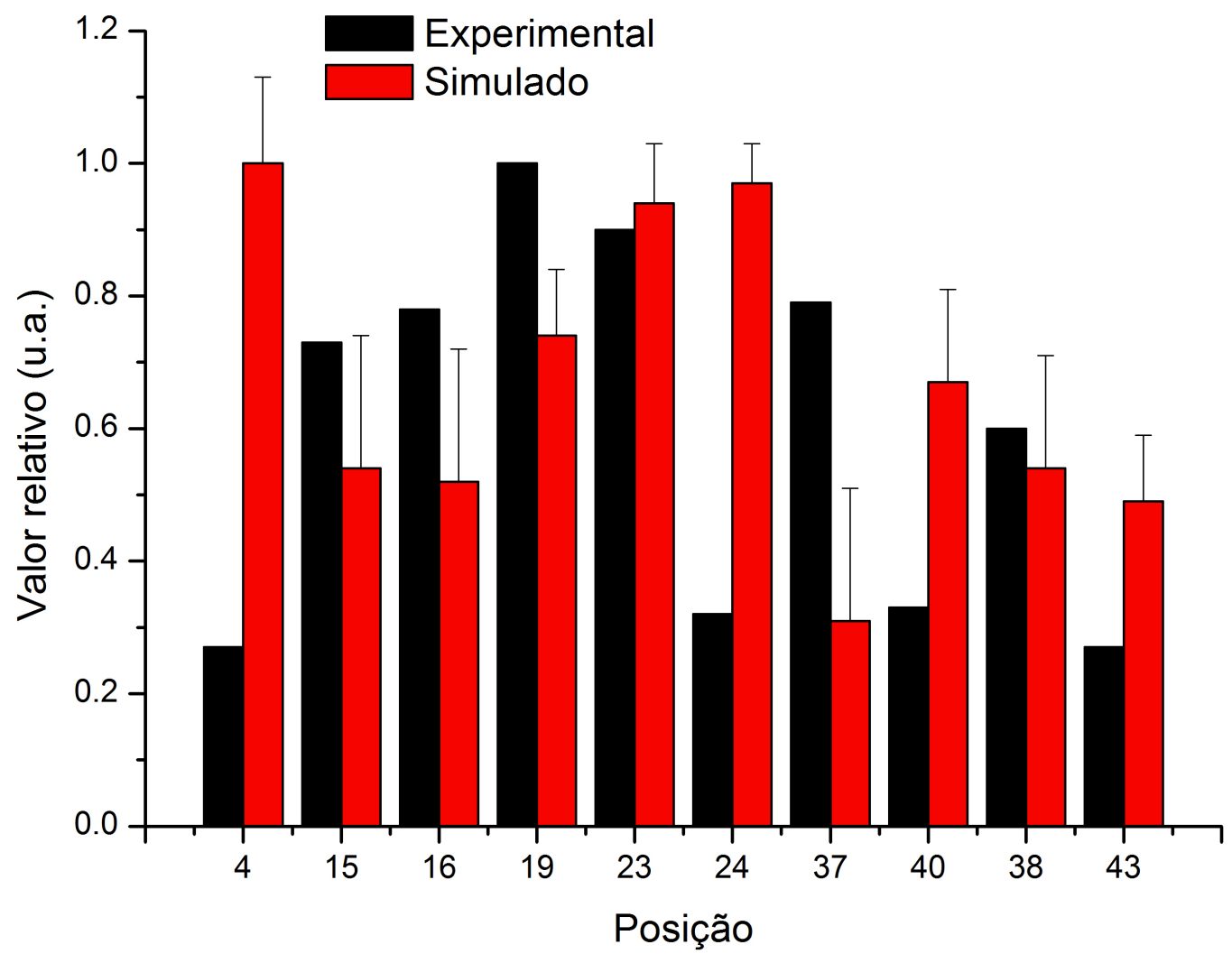

Figura 32 - Comparação dos valores experimentais com os valores simulados computacionalmente das pastilhas do tipo TLD 600, irradiadas com uma fonte de ${ }^{241} \mathrm{Am} / \mathrm{Be}$. 


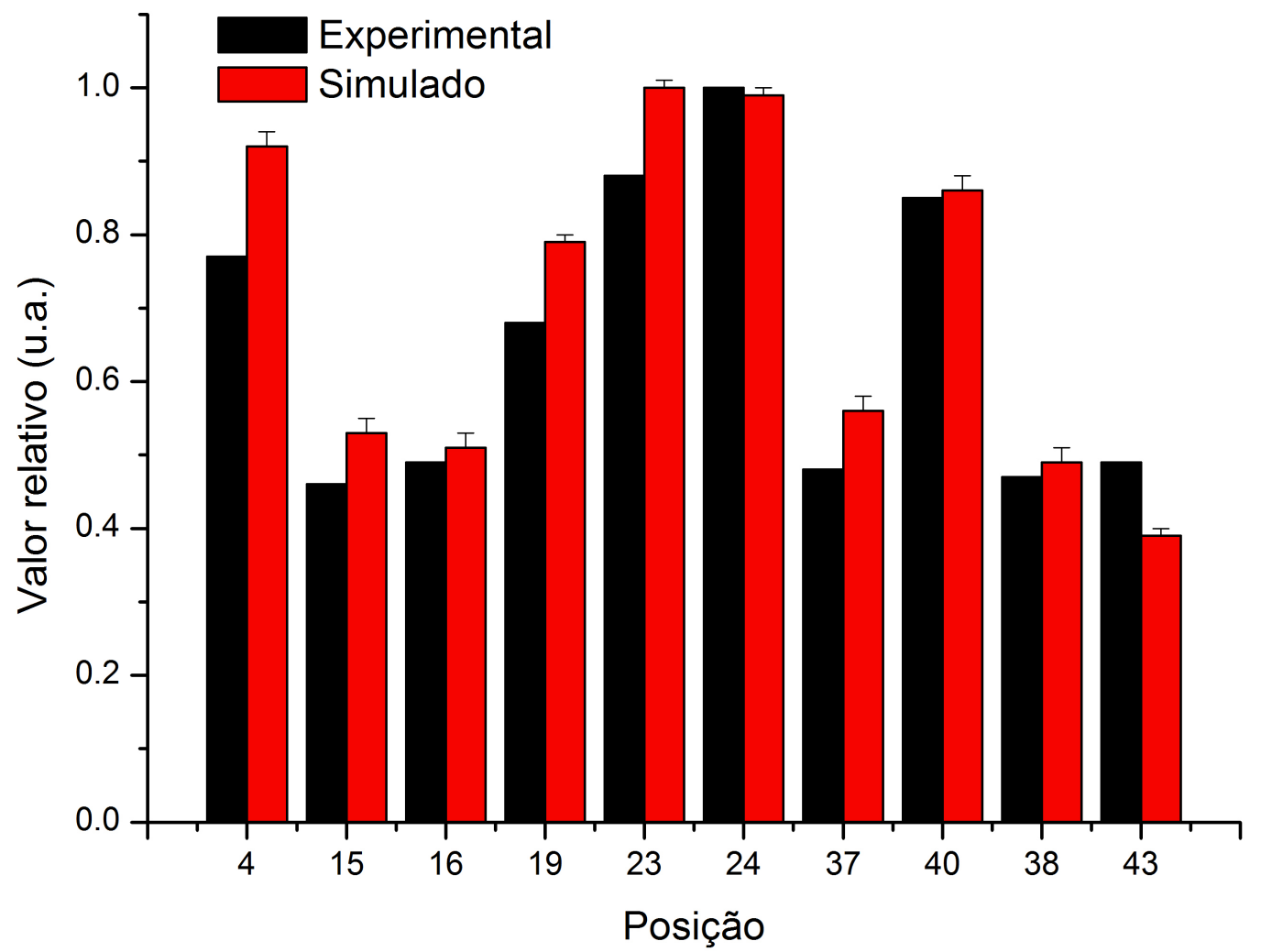

Figura 33 - Comparação dos valores experimentais com os valores simulados computacionalmente das pastilhas do tipo TLD 700, irradiadas com uma fonte de ${ }^{241} \mathrm{Am} / \mathrm{Be}$.

Para fins de observação do comportamento do detector quando irradiado por uma fonte de ${ }^{241} \mathrm{Am} / \mathrm{Be}$, os valores dos dados experimentais com os valores obtidos por meio da simulação computacional são apresentados apenas em suas posições na direção radial em relação à fonte, conforme mostrado nas Figuras 34 e 35 . 


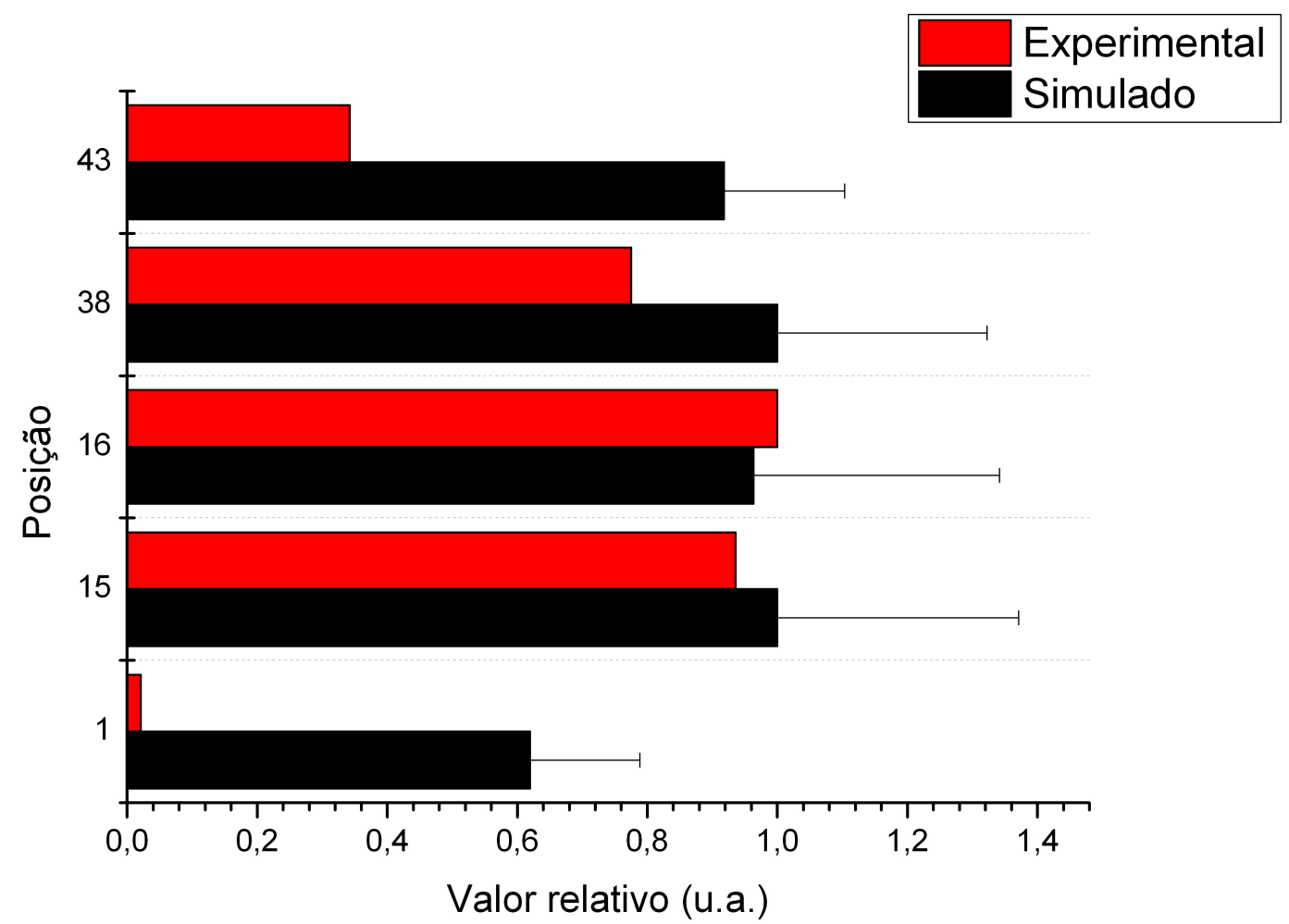

Figura 34 - Comparação dos valores experimentais com os valores simulados computacionalmente das pastilhas do tipo TLD 600, irradiadas com uma fonte de ${ }^{241} \mathrm{Am} / \mathrm{Be}$, nas posições na direção radial do detector em relação à fonte. 


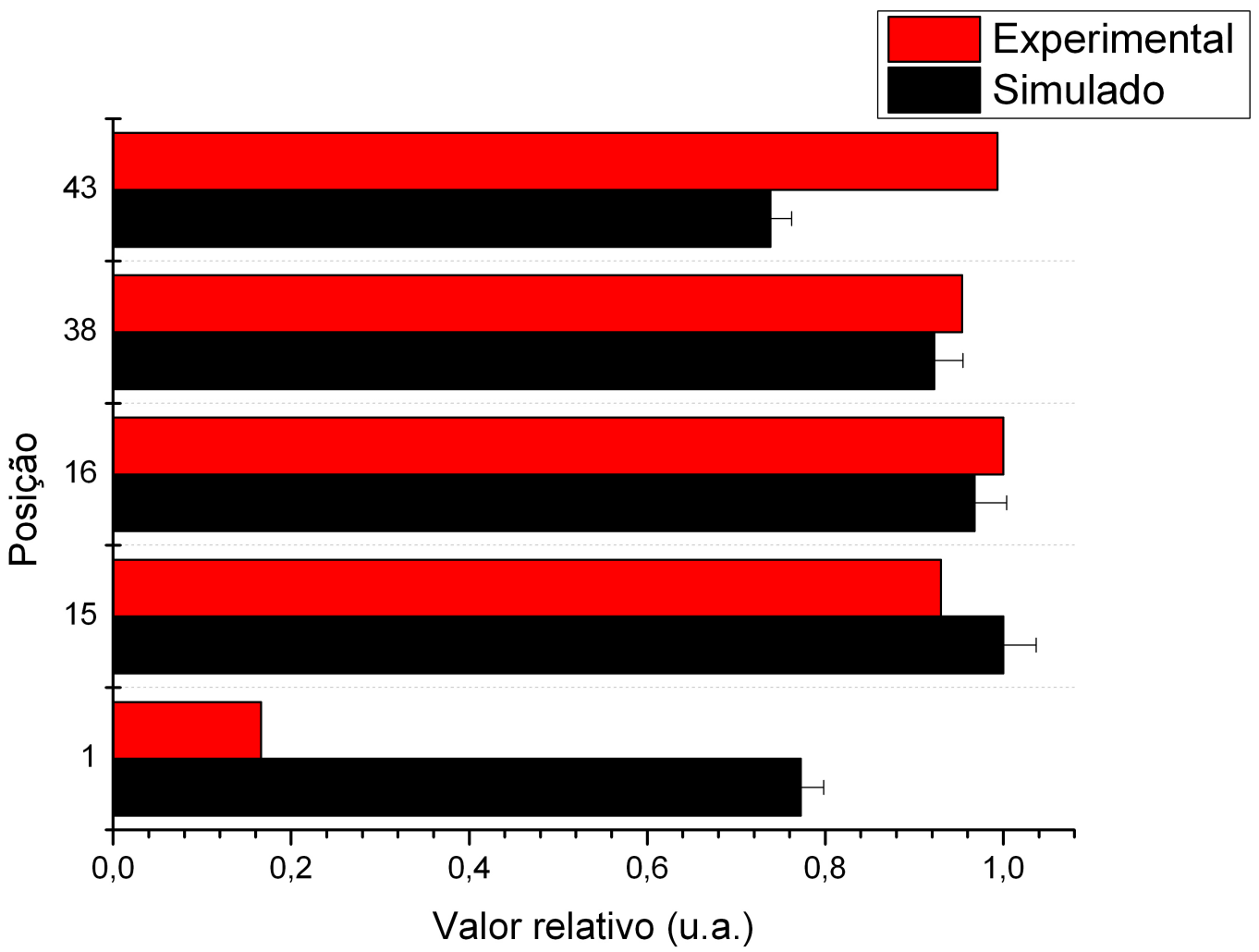

Figura 35 - Comparação dos valores experimentais com os valores simulados computacionalmente das pastilhas do tipo TLD 700, irradiadas com uma fonte de ${ }^{241} \mathrm{Am} / \mathrm{Be}$, nas posições na direção radial do detector em relação à fonte.

\subsection{DETECTOR SUBMETIDO AO ESPECTRO DE ${ }^{252} \mathrm{Cf}$}

A simulação computacional envolvendo uma fonte pontual, a uma distância de $100 \mathrm{~cm}$ da superfície do detector, alinhada com o centro do detector, cujo card de energia teve como distribuição o espectro de nêutrons normalizados de uma fonte de ${ }^{252} \mathrm{Cf}$ conforme (IAEA, 2001), teve por objetivo simular o detector com as pastilhas de fluoreto de lítio inseridas nas posições 1, 2, 4, 6, 15, 16, 17, 23, 24, 27 e 28, visando o fornecimento de dados para posterior comparação com os dados experimentais obtidos por Federico (2011), quando da irradiação do detector de PMMA por este tipo de fonte. 


\subsubsection{Simulação computacional}

Os resultados obtidos durante a simulação computacional envolvendo a fonte de ${ }^{252} \mathrm{Cf}$, cuja intenção era reproduzir as condições experimentais utilizadas por Federico (2011) são apresentados na Tabela 10.

Tabela 10 - Valores da simulação computacional empregando o espectro de emissão de nêutrons do ${ }^{252} \mathrm{Cf}$.

\begin{tabular}{ccccc}
\hline Posição & $\begin{array}{c}\text { Dose } \\
\text { absorvida } \\
\text { TLD-600 } \\
(\mathbf{p G y})\end{array}$ & Incerteza & $\begin{array}{c}\text { Dose } \\
\text { absorvida } \\
\text { TLD-700 } \\
(\mathbf{p G y})\end{array}$ & $\begin{array}{c}\text { Incerteza } \\
(\mathbf{p G y})\end{array}$ \\
\hline $\mathbf{1}$ & $4,06 \mathrm{E}-02$ & $2,18 \mathrm{E}-02$ & $4,96 \mathrm{E}-02$ & $2,40 \mathrm{E}-03$ \\
$\mathbf{2}$ & $2,39 \mathrm{E}-02$ & $2,39 \mathrm{E}-02$ & $6,80 \mathrm{E}-02$ & $3,20 \mathrm{E}-03$ \\
$\mathbf{4}$ & $1,65 \mathrm{E}-01$ & $3,38 \mathrm{E}-02$ & $1,37 \mathrm{E}-01$ & $3,96 \mathrm{E}-03$ \\
$\mathbf{6}$ & $2,60 \mathrm{E}-02$ & $1,29 \mathrm{E}-02$ & $1,06 \mathrm{E}-02$ & $1,17 \mathrm{E}-03$ \\
$\mathbf{1 5}$ & $2,33 \mathrm{E}-02$ & $2,33 \mathrm{E}-02$ & $7,21 \mathrm{E}-02$ & $3,30 \mathrm{E}-03$ \\
$\mathbf{1 6}$ & $1,21 \mathrm{E}-01$ & $4,61 \mathrm{E}-02$ & $7,56 \mathrm{E}-02$ & $3,40 \mathrm{E}-03$ \\
$\mathbf{1 7}$ & $2,97 \mathrm{E}-02$ & $2,97 \mathrm{E}-02$ & $4,01 \mathrm{E}-02$ & $2,41 \mathrm{E}-03$ \\
$\mathbf{2 3}$ & $1,60 \mathrm{E}-01$ & $2,33 \mathrm{E}-02$ & $1,68 \mathrm{E}-01$ & $2,57 \mathrm{E}-03$ \\
$\mathbf{2 4}$ & $1,81 \mathrm{E}-01$ & $1,51 \mathrm{E}-0$ & $1,56 \mathrm{E}-01$ & $2,22 \mathrm{E}-03$ \\
$\mathbf{2 7}$ & $1,87 \mathrm{E}-02$ & $1,87 \mathrm{E}-02$ & $1,58 \mathrm{E}-02$ & $1,55 \mathrm{E}-03$ \\
$\mathbf{2 8}$ & $1,18 \mathrm{E}-02$ & $1,00 \mathrm{E}-02$ & $5,45 \mathrm{E}-03$ & $9,07 \mathrm{E}-04$ \\
\hline
\end{tabular}

\subsubsection{Dados experimentais}

Os dados experimentais utilizados para realizar uma comparação com os valores simulados computacionalmente foram fornecidos pelo Dr. Claudio A. Federico, valores estes obtidos em irradiações do detector com uma fonte de ${ }^{252} \mathrm{Cf}$, em 18 de abril de 2002, no Laboratório de Metrologia de Nêutrons (LN) situado no Instituto de Radioproteção e Dosimetria (IRD), localizado na cidade do Rio de Janeiro, R.J.

Os valores dos dados experimentais são apresentados na Tabela $11 \mathrm{e}$ a comparação com os valores obtidos por meio da simulação computacional são apresentados na Figura 36 (TLD-600) e Figura 37 (TLD-700). 
Tabela 11 - Valores experimentais obtidos da irradiação do detector passivo com uma fonte de ${ }^{252} \mathrm{Cf}$.

\begin{tabular}{ccccccc}
\hline Posição & \multicolumn{2}{c}{ Com cone } & \multicolumn{2}{c}{ Sem cone } & \multicolumn{2}{c}{ Diferença } \\
\hline & $\begin{array}{c}\text { TLD 700 } \\
(p C)\end{array}$ & $\begin{array}{c}\text { TLD 600 } \\
(\mathrm{pC})\end{array}$ & $\begin{array}{c}\text { TLD 700 } \\
(\mathrm{pC})\end{array}$ & $\begin{array}{c}\text { TLD 600 } \\
(\mathrm{pC})\end{array}$ & $\begin{array}{c}\text { TLD 700 } \\
(\mathrm{pC})\end{array}$ & $\begin{array}{c}\text { TLD 600 } \\
(\mathrm{pC})\end{array}$ \\
$\mathbf{1}$ & $1,03 \mathrm{E}+04$ & $3,19 \mathrm{E}+04$ & $2,10 \mathrm{E}+04$ & $1,17 \mathrm{E}+05$ & $1,06 \mathrm{E}+04$ & $8,47 \mathrm{E}+04$ \\
$\mathbf{2}$ & $1,05 \mathrm{E}+04$ & $5,66 \mathrm{E}+04$ & $2,11 \mathrm{E}+04$ & $4,32 \mathrm{E}+05$ & $1,06 \mathrm{E}+04$ & $3,75 \mathrm{E}+05$ \\
$\mathbf{4}$ & $1,03 \mathrm{E}+04$ & $3,83 \mathrm{E}+04$ & $2,76 \mathrm{E}+04$ & $2,93 \mathrm{E}+05$ & $1,73 \mathrm{E}+04$ & $2,55 \mathrm{E}+05$ \\
$\mathbf{6}$ & $1,00 \mathrm{E}+04$ & $3,24 \mathrm{E}+04$ & $1,74 \mathrm{E}+04$ & $9,03 \mathrm{E}+04$ & $7,40 \mathrm{E}+03$ & $5,78 \mathrm{E}+04$ \\
$\mathbf{1 5}$ & $9,88 \mathrm{E}+03$ & $6,15 \mathrm{E}+04$ & $2,07 \mathrm{E}+04$ & $5,89 \mathrm{E}+05$ & $1,08 \mathrm{E}+04$ & $5,28 \mathrm{E}+05$ \\
$\mathbf{1 6}$ & $8,96 \mathrm{E}+03$ & $6,94 \mathrm{E}+04$ & $2,01 \mathrm{E}+04$ & $6,53 \mathrm{E}+05$ & $1,11 \mathrm{E}+04$ & $5,83 \mathrm{E}+05$ \\
$\mathbf{1 7}$ & $9,09 \mathrm{E}+03$ & $5,86 \mathrm{E}+04$ & $1,76 \mathrm{E}+04$ & $4,06 \mathrm{E}+05$ & $8,54 \mathrm{E}+03$ & $3,48 \mathrm{E}+05$ \\
$\mathbf{2 3}$ & $1,05 \mathrm{E}+04$ & $7,77 \mathrm{E}+04$ & $2,73 \mathrm{E}+04$ & $8,29 \mathrm{E}+05$ & $1,69 \mathrm{E}+04$ & $7,51 \mathrm{E}+05$ \\
$\mathbf{2 4}$ & $9,96 \mathrm{E}+03$ & $4,71 \mathrm{E}+04$ & $2,86 \mathrm{E}+04$ & $3,33 \mathrm{E}+05$ & $1,86 \mathrm{E}+04$ & $2,86 \mathrm{E}+05$ \\
$\mathbf{2 7}$ & $9,28 \mathrm{E}+03$ & $4,67 \mathrm{E}+04$ & $1,50 \mathrm{E}+04$ & $1,91 \mathrm{E}+05$ & $5,75 \mathrm{E}+03$ & $1,44 \mathrm{E}+05$ \\
$\mathbf{2 8}$ & $9,71 \mathrm{E}+03$ & $3,49 \mathrm{E}+04$ & $1,22 \mathrm{E}+04$ & $6,03 \mathrm{E}+04$ & $2,48 \mathrm{E}+03$ & $2,54 \mathrm{E}+04$ \\
\hline
\end{tabular}

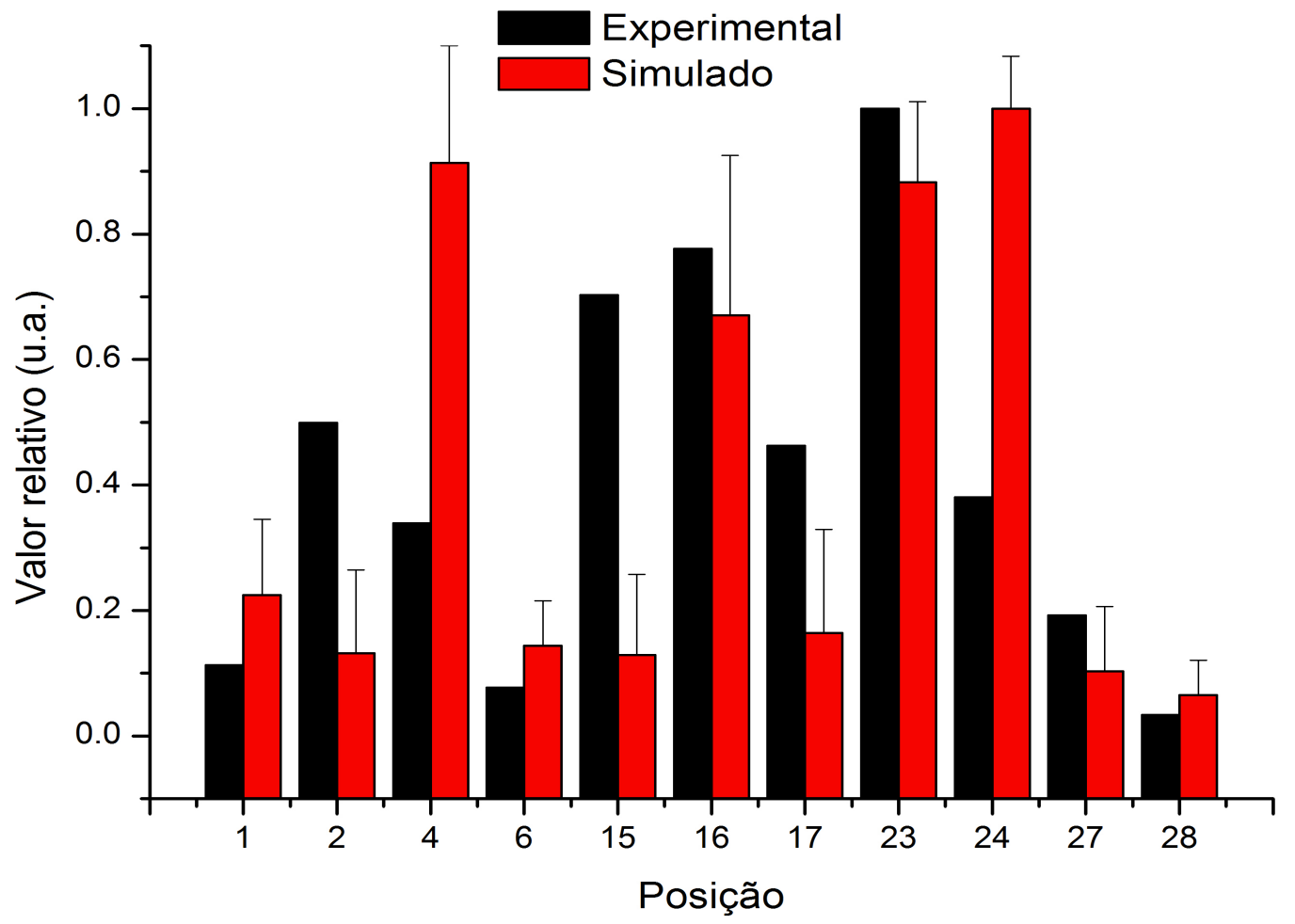

Figura 36 - Comparação dos valores experimentais com os valores simulados computacionalmente das pastilhas do tipo TLD 600, irradiadas com uma fonte de ${ }^{252} \mathrm{Cf}$. 


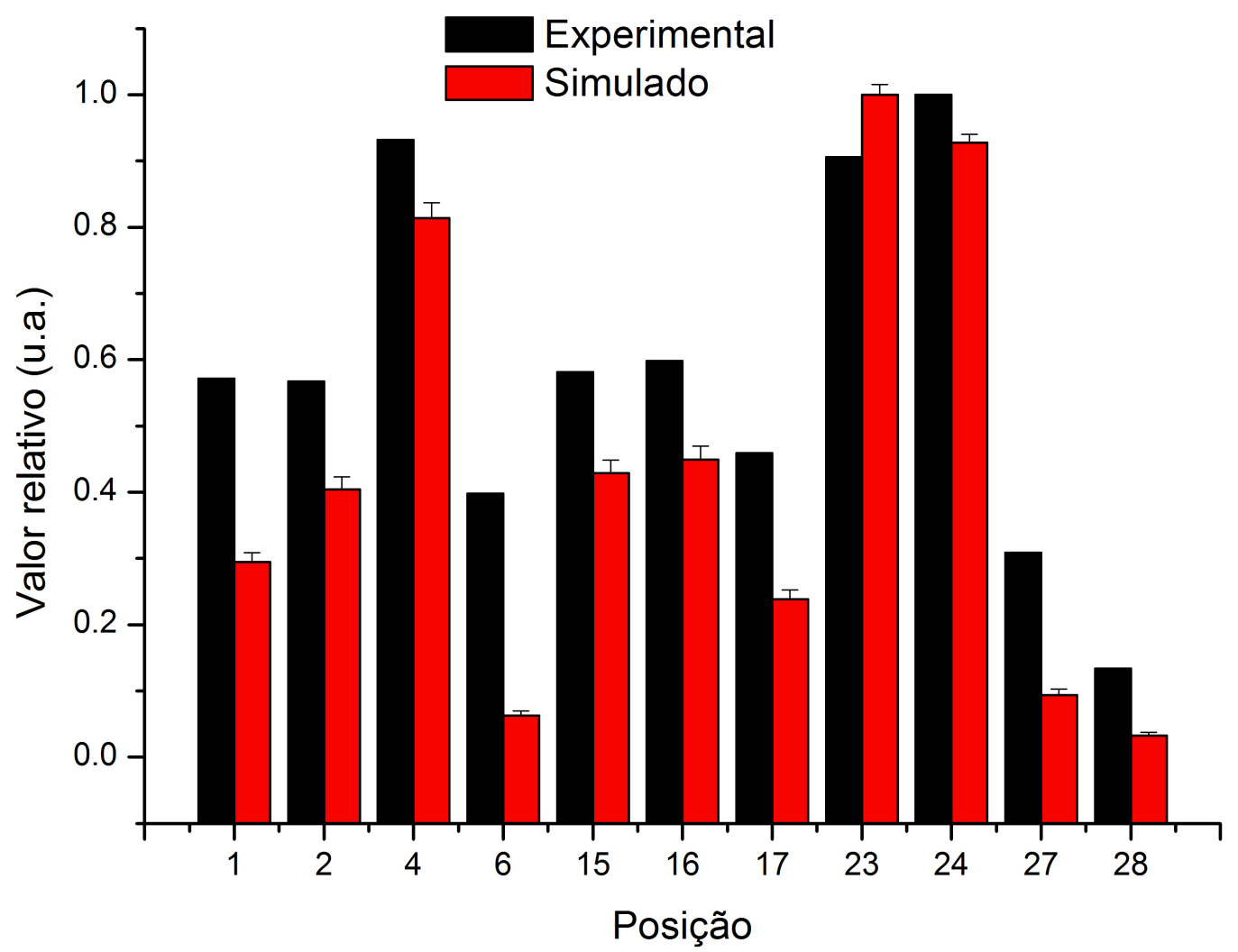

Figura 37 - Comparação dos valores experimentais com os valores simulados computacionalmente das pastilhas do tipo TLD 700, irradiadas com uma fonte de ${ }^{252} \mathrm{Cf}$.

Para fins de observação do comportamento do detector quando irradiado por uma fonte de ${ }^{252} \mathrm{Cf}$, os valores dos dados experimentais com os valores obtidos por meio da simulação computacional são apresentados apenas em suas posições na direção longitudinal em relação à fonte, conforme mostrado nas Figuras 38 e 39. 


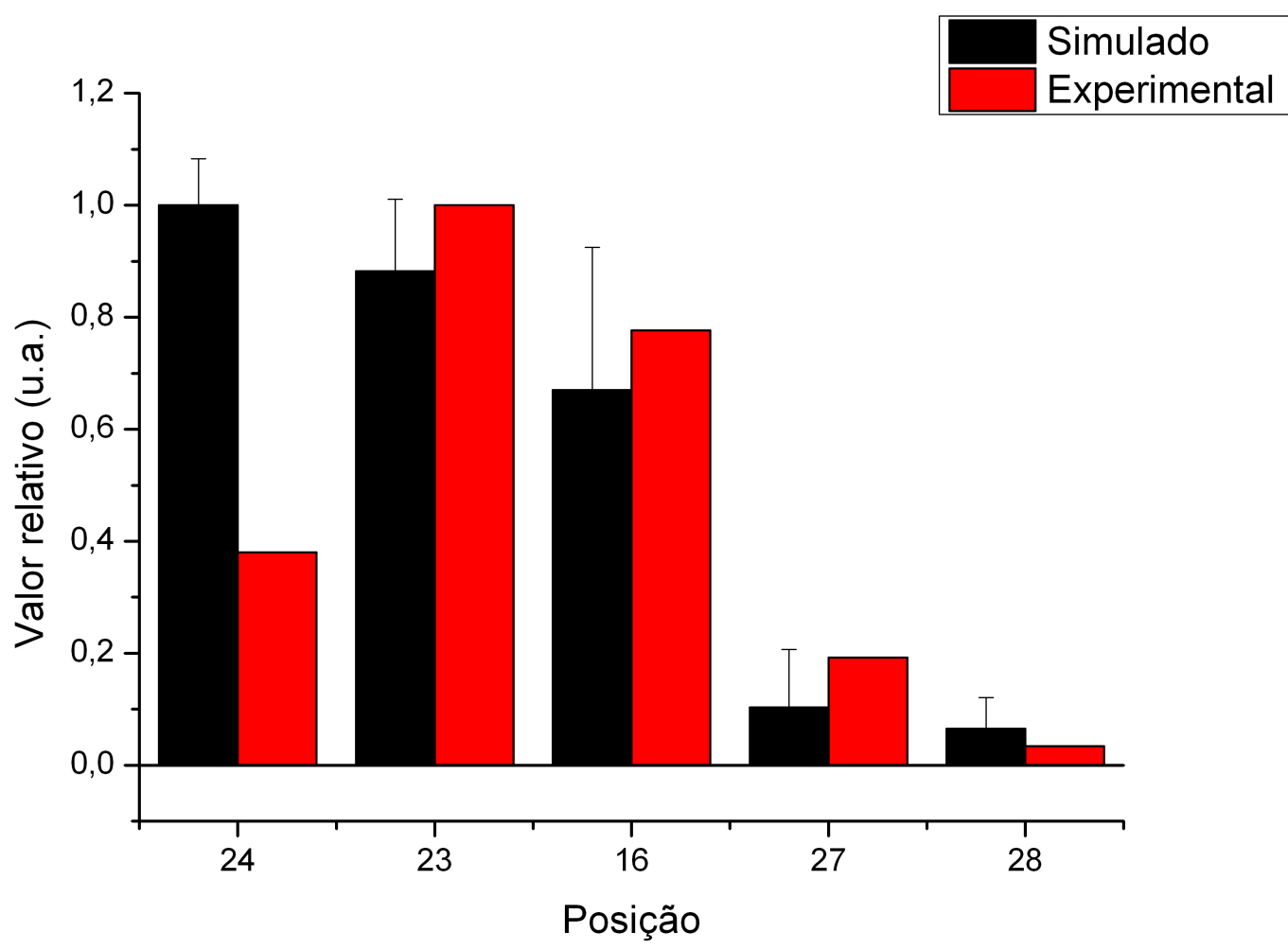

Figura 38 - Comparação dos valores experimentais com os valores simulados computacionalmente das pastilhas do tipo TLD 600, irradiadas com uma fonte de ${ }^{252} \mathrm{Cf}$, nas posições na direção longitudinal do detector em relação à fonte. 


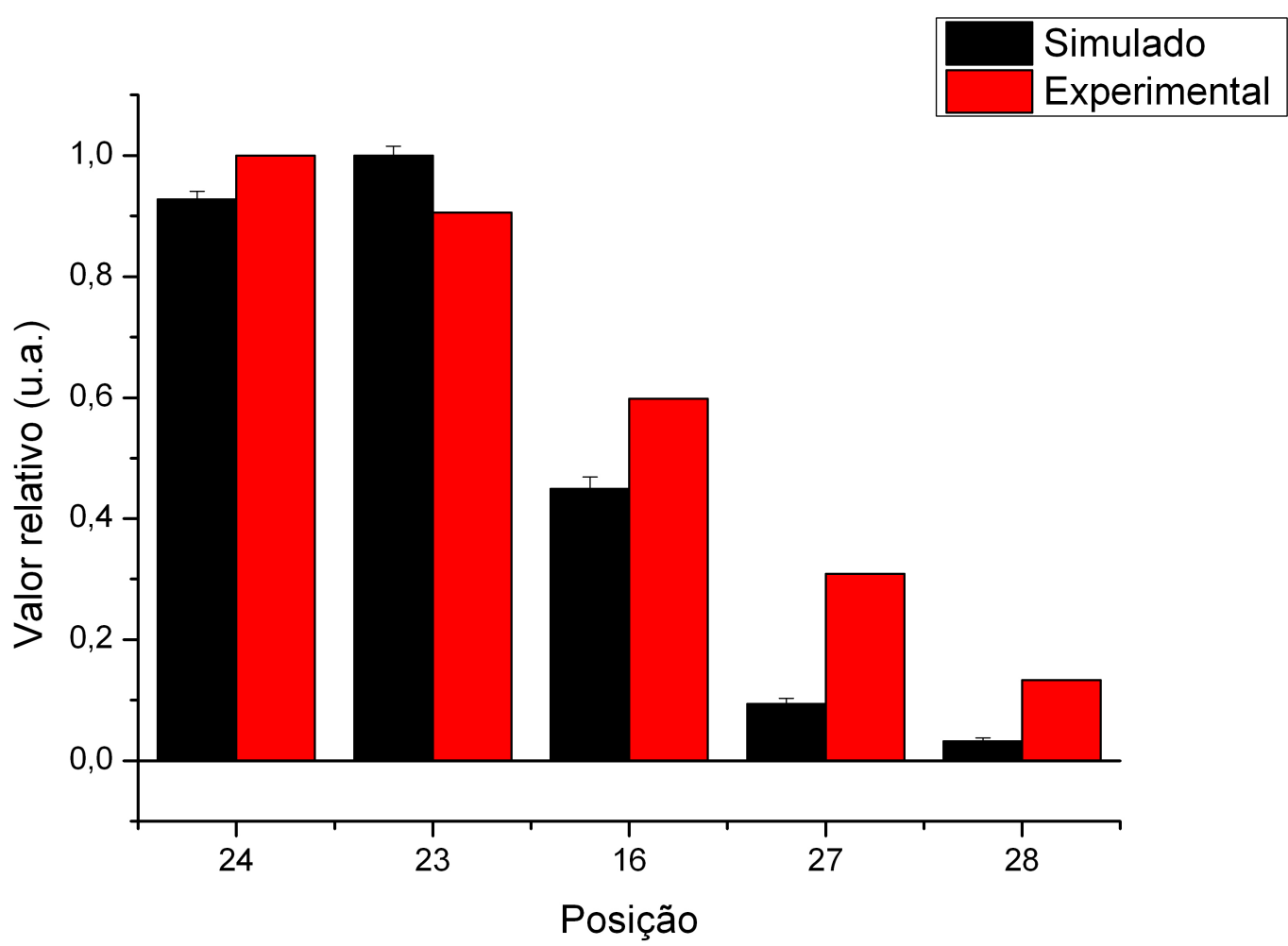

Figura 39 - Comparação dos valores experimentais com os valores simulados computacionalmente das pastilhas do tipo TLD 700, irradiadas com uma fonte de

${ }^{252} \mathrm{Cf}$, nas posições na direção longitudinal do detector em relação à fonte.

\subsection{DETECTOR SUBMETIDO AO ESPECTRO DE RADIAÇÃO CÓSMICA}

O detector de PMMA foi simulado computacionalmente utilizando o espectro de emissão de nêutrons encontrado em altitude de voo $(10000 \mathrm{~m})$, conforme preconiza a ISO 20785-1 (2006) e apresentado na Figura 2, tendo sido simulado em dois arranjos experimentais diferentes. O primeiro arranjo consistiu em simular um campo expandido e alinhado direcionado para o detector e o segundo arranjo consistiu em simular o detector inserido num campo isotrópico. 


\subsubsection{Campo de RC expandido e alinhado}

O primeiro arranjo consistiu em simular um campo expandido e alinhado direcionado para o detector, a fim de se obter a grandeza dosimétrica equivalente de dose a $10 \mathrm{~mm}$ da superfície do detector, empregando a mesma metodologia utilizada quando das simulações dos feixes monoenergéticos de nêutrons incidindo no detector, conforme detalhado na seção 4.2.

Os resultados desta simulação, com duração de 12000 minutos computacionais, envolvendo um campo expandido e alinhado com o espectro de radiação cósmica (Fig. 2) foram os seguintes:

- 24,2 $\pm 1,33$, para a dose absorvida pela unidade de fluência $(\mathrm{D}(10) / \Phi)$, em $\mathrm{pG} \times \mathrm{cm}^{2}$;

- $86,2 \pm 4,74$, para o equivalente de dose pela unidade de fluência $(\mathrm{H}(10) / \Phi)$, em pSv $\times \mathrm{cm}^{2}$;

- 3,56, para o fator de qualidade efetivo (Qeff), em Sv/Gy.

4.5.2 Simulação computacional da fonte de RC isotrópica.

Os resultados obtidos durante a simulação computacional envolvendo uma fonte com o espectro de emissão de nêutrons de radiação cósmica utilizando os dados da ISO 20785-1 (2006) como espectro de entrada (Fig. 2), são apresentados na Tabela 12. 
Tabela 12 - Valores da simulação computacional empregando o espectro de emissão de nêutrons de RC.

\begin{tabular}{ccccc}
\hline Posição & $\begin{array}{c}\text { Dose } \\
\text { Absorvida }\end{array}$ & Incertezas & $\begin{array}{c}\text { Dose } \\
\text { Absorvida }\end{array}$ & Incertezas \\
& $\begin{array}{c}\text { TLD 600 } \\
(\mathbf{p G y})\end{array}$ & $\begin{array}{c}\text { TLD 600 } \\
(\mathbf{p G y})\end{array}$ & $\begin{array}{c}\text { TLD 700 } \\
(\mathbf{p G y})\end{array}$ & $\begin{array}{c}\text { TLD 700 } \\
(\mathbf{p G y})\end{array}$ \\
\hline $\mathbf{1}$ & $5,03 \mathrm{E}-01$ & $1,43 \mathrm{E}-01$ & $3,99 \mathrm{E}-01$ & $2,95 \mathrm{E}-02$ \\
$\mathbf{3}$ & $5,61 \mathrm{E}-01$ & $1,41 \mathrm{E}-01$ & $3,99 \mathrm{E}-01$ & $2,70 \mathrm{E}-02$ \\
$\mathbf{2 2}$ & $2,85 \mathrm{E}-01$ & $5,43 \mathrm{E}-02$ & $3,52 \mathrm{E}-01$ & $1,54 \mathrm{E}-02$ \\
$\mathbf{2 1}$ & $3,82 \mathrm{E}-01$ & $4,89 \mathrm{E}-02$ & $3,75 \mathrm{E}-01$ & $1,67 \mathrm{E}-02$ \\
$\mathbf{1 6}$ & $5,13 \mathrm{E}-01$ & $1,14 \mathrm{E}-01$ & $3,40 \mathrm{E}-01$ & $2,73 \mathrm{E}-02$ \\
\hline
\end{tabular}




\section{CONCLUSÕES}

Após verificada a consistência dos resultados obtidos computacionalmente com aqueles obtidos experimentalmente por Federico (2011), serão tecidas as considerações e conclusões aplicáveis.

Com relação à obtenção da curva referente ao equivalente de dose ambiente por unidade de fluência $\left(H^{*}(10) / \Phi\right)$ de nêutrons em função da energia incidente, em um campo expandido e alinhado, em uma esfera ICRU, por meio de simulação computacional, foram obtidos os resultados apresentados na Tabela 5 , com variação máxima de $25,14 \%$ na faixa de energia de $10^{-4} \mathrm{MeV}$ e variação mínima de 0,56 \% na faixa de energia de 0,1 MeV, que estão de acordo com os valores obtidos por Leuthold et al. (1992) e dentro dos intervalos determinados pelos grupos de pesquisa citados, conforme apresentado na Figura 15. Isso indica que a metodologia de simulação adotada é adequada para este tipo de problema.

Empregando a mesma metodologia, foi confeccionada a curva referente ao equivalente de dose por unidade de fluência $(H(10) / \Phi)$ de nêutrons em função da energia (ICRP, 2007), em campo expandido e alinhado, em uma esfera ICRU, por meio de simulação computacional, levando-se em conta as sugestões do relatório ICRP 103 (ICRP, 2007), em relação aos valores dos fatores de ponderação para a radiação $\left(W_{R}\right)$. Os resultados alcançados mostrados na Tabela 6 e na Figura 19 comprovaram que as alterações significativas estão compreendidas no intervalo de energia abaixo de $1 \mathrm{MeV}$, do nêutron incidente, que leva em conta a maior contribuição de fótons secundários na dose absorvida, conforme previsto no relatório ICRP 103 (ICRP, 2007), verificando novamente que a metodologia aplicada nestes casos é adequada.

Baseado nesta metodologia, foram realizadas simulações computacionais para obtenção dos coeficientes de conversão de equivalente de dose por unidade de fluência $(H(10) / \Phi)$ no detector de polimetilmetacrilato (PMMA), proposto como objeto de estudo neste trabalho. Os resultados apresentados na Tabela 7, bem como na Figura 22, comprovam que tanto 0 detector quanto a esfera ICRU possuem comportamentos similares, apesar de possuírem pontos de máximo em intervalos de energia diferentes (entre 1 e 5 $\mathrm{MeV}$ ) em relação ao equivalente de dose. Com relação à grandeza dosimétrica fundamental dose absorvida, também foi notado um comportamento similar, 
exceto para os valores de $10^{-3}$ e $10^{-2} \mathrm{MeV}$, onde os valores da dose absorvida na esfera ICRU são superestimados em relação aos valores do detector, conforme mostrado na Figura 26.

Estes resultados foram obtidos com o intuito de verificar a possibilidade de confecção de uma curva de calibração entre a esfera ICRU e o detector. Pelo fato de possuírem pontos de máximo em intervalos de energia diferentes (entre 1 e $5 \mathrm{MeV}$ ), conclui-se que esta curva é viável apenas para o intervalo de energia compreendido entre $10 \mathrm{eV}$ e $700 \mathrm{keV}$, tendo como coeficiente de correlação $\left(R^{2}\right)$ do ajuste linear da curva igual a 0,9977 , conforme mostrado na Figura 28.

As simulações computacionais do detector de PMMA, foram realizadas com os pares de pastilhas TLD-600 e TLD-700 inseridas em suas respectivas posições pré-determinadas, com a finalidade de reproduzir fielmente as condições experimentais definidas ao longo das irradiações realizadas no Laboratório de Metrologia de Nêutrons do IRD com uma fonte de ${ }^{241} \mathrm{Am} / \mathrm{Be}$ e uma de ${ }^{252} \mathrm{Cf}$. Os resultados obtidos das simulações computacionais foram avaliados comparativamente utilizando os dados coletados nas irradiações realizadas no IRD, observando-se o mesmo comportamento nos resultados referentes às pastilhas do tipo TLD-700, tanto nos dados experimentais quanto nos dados simulados computacionalmente. Com relação às pastilhas dosimétricas do tipo TLD-600, as incertezas associadas ao processo de simulação são elevadas, não permitindo conclusões definitivas.

O perfil de dose absorvida foi avaliado tanto na direção radial (fonte de ${ }^{241} \mathrm{Am} / \mathrm{Be}$ ) quanto na longitudinal (fonte de ${ }^{252} \mathrm{Cf}$ ) do detector. Entretanto, para fins de dosimetria ocupacional, o comportamento demonstrado pelas pastilhas do tipo TLD-700 aproximam-se do comportamento esperado do tecido humano.

O comportamento do detector sujeito a um campo de energia com distribuição de energia similar ao de raios cósmicos foi estudado, tanto para um campo expandido e alinhado quanto para um campo isotrópico, conforme mostrado nas Tabelas 12 e 13. Estes resultados representam uma estimativa da situação real de um dosímetro em voo utilizado em uma aeronave. 


\section{REFERÊNCIAS BIBLIOGRÁFICAS}

CALDAS, L., V., E.; Comunicação em sala de aula, 2012.

CARNELL, R., C. ; Optimization of the photon response for a LiF thermoluminescent dosimeter ; United States Naval Academy, Trident Scholar Project Report; no. 253; 1998.

CHADWICK, M. B.; OBLOZINSKY, P.; HERMAN, M.; GREENE, N., M.; MCKNIGHT, R., D.; SMITH, D., L.; YOUNG, P., G.; MACFARLANE, R., E.; HALE, G., M.; FRANKLE, S., C.; KAHLER, A., C.; KAWANO, T.; LITTLE, R., C.; MADLAND, D., G.; MOLLER, P.; MOSTELLER, R., D.; PAGE, P., R.; TALOU, P.; TRELLUE, H.; WHITE, M., C.; WILSON, W., B.; ARCILLA, R.; DUNFORD, C., L.; MUGHABGHAB, S., F.; PRITYCHENKO, B.; ROCHMAN, D.; SONZOGNI, A., A.; LUBITZ, C., R.; TRUMBULL, T., H.; WEINMAN, J., P.; BROWN, D., A.; CULLEN, D., E.; HEINRICHS, D., P.; MCNABB, D., P.; DERRIEN, H.; DUNN, M., E.; LARSON, N., M.; LEAL, L., C.; CARLSON, A., D.; BLOCK, R., C.; BRIGGS, J., B.; CHENG, E., T.; HURIA, H., C.; ZERKLE, M., L.; KOZIER, K., S.; COURCELLE, A.; PRONYAEV, V.; VAN DER MARCK, S., C. ENDF/B-VII.0: Next Generation Evaluated Nuclear Data Library for Nuclear Science and Technology. Nuclear Data Sheets, 107, 12, pp. 2931-3059, 2006.

DIETZE, G. and SIEBERT, B., R., L. Photon and Neutron Dose Contributions and Mean Quality Factors in Phantoms of Different Size Irradiated by Monoenergetic Neutrons. Radiation Research, Vol. 140, No. 1, pp. 130-133, 1994.

DUDERSTADT, J., J.; HAMILTON, L.,J. Nuclear Reactor Analysis. John Wiley \& Sons, Inc., New York, 1976.

FAA, FEDERAL AVIATION ADMINISTRATION. Radiation Exposure of Air Carrier Crewmembers. U.S. Department of Transportation. 1990. (FAA Advisory Circular n. 120-52).

FEDERICO, C. A.; PEREIRA, H. H. C.; PEREIRA, M. A.; GONÇALEZ, O. L.; CALDAS, L. V. E. Estimates of cosmic radiation dose received by aircrew of DCTA's flight test special group. J. Aerosp. Tech. Man., v. 2, n. 2, pp. 137-144, 2010.

FEDERICO, C. A. Dosimetria da Radiação Cósmica no Interior de Aeronaves no Espaço Aéreo Brasileiro. Tese (Doutorado). Instituto de Pesquisas Energéticas e Nucleares, Universidade de São Paulo, São Paulo, 2011. 
FIORAVANTI, C. O início e o fim dos raios cósmicos. Pesquisa FAPESP, Ed. FAPESP, n² 200, São Paulo, SP, 2012.

FURUKAWA, M. Measurements of cosmic radiation doses during air travel by handy method with an electronic personal dosemeter. Radiat. Environ. v. 7, pp. 909-915, 2005.

GARBER, D.; DUNFORD, C. L.; PEARLSTEIN, S. (Eds.) ENDF-102 data formats and procedures for the evaluated nuclear data file. Report BNL-NCS 50496, National Nuclear Data Center, Brookhaven National Laboratory, New York, 1975.

GARNY, S.; LEUTHOLD, G.; MARES, V.;PARETZKE, H., G.; RÜHM, W. GEANT4 Transport calculations for neutrons and photons below $15 \mathrm{MeV}$. IEEE Trans. Nucl. Sci., v. 56, n. 4, 2009.

GLASSTONE, S.; SESONSKE, A. Nuclear Reactor Engineering. P. Van Nostrand Company, Inc., U.S.A. 1962.

GOLDHAGEN, P. Overview of aircraft radiation exposure and recent ER-2 measurements. Health Physics, v.79, pp. 526-544, 2000

IAEA. INTERNATIONAL ATOMIC ENERGY AGENCY. International basic safety standards for protection against ionizing radiation and for the safety of radiation sources. Safety Series, n. 115, Vienna,1996.

IAEA. INTERNATIONAL ATOMIC ENERGY AGENCY. Compendium of neutron spectra and detector responses for radiation protection purposes. Vienna, 2001.

IAEA. INTERNATIONAL ATOMIC ENERGY AGENCY. Nuclear data services. Disponível em: <http://www-nds.iaea.org/exfor/endf.htm>. Acesso em 29 de abril de 2013.

ICRP. INTERNATIONAL COMMISSION ON RADIOLOGICAL PROTECTION. Recommendations of the International Commission on Radiological Protection. Publication 60. Annals of the ICRP, v. 21, n. 1-3, 1991.

ICRP. INTERNATIONAL COMMISSION ON RADIOLOGICAL PROTECTION. Conversion coefficients for use in radiological protection against external radiation. Publication 74. Annals of the ICRP, v. 26, n. 3, 1997. 
ICRP. INTERNATIONAL COMMISSION ON RADIOLOGICAL PROTECTION. The 2007 Recommendations of the international commission on radiological protection. Publication 103, Annals of the ICRP, v. 37, n. 2-4, 2007.

ICRU. INTERNATIONAL COMMISSION ON RADIATION UNITS AND MEASUREMENTS. Linear energy transfer. ICRU Report 16,1970.

ICRU. INTERNATIONAL COMMISSION ON RADIATION UNITS AND MEASUREMENTS. Radiation quantities and units. ICRU Report 33,1980.

ICRU. INTERNATIONAL COMMISSION ON RADIATION UNITS AND MEASUREMENTS. Stopping powers for electrons and positrons. ICRU Report 37,1984 .

ICRU. INTERNATIONAL COMMISSION ON RADIATION UNITS AND MEASUREMENTS. Determination of Dose Equivalents resulting from external radiation sources. ICRU Report 39,1985.

ICRU. INTERNATIONAL COMMISSION ON RADIATION UNITS AND MEASUREMENTS. Determination of Dose Equivalents resulting from external radiation sources - part II. ICRU Report 43,1988.

ICRU. INTERNATIONAL COMMISSION ON RADIATION UNITS AND MEASUREMENTS. Measurement of Dose Equivalents from external photon and electron radiations. ICRU Report 47,1992.

ICRU. INTERNATIONAL COMMISSION ON RADIATION UNITS AND MEASUREMENTS. Stopping powers and ranges for protons and alpha particles. ICRU Report 49,1993.

ICRU. INTERNATIONAL COMMISSION ON RADIATION UNITS AND MEASUREMENTS. Quantities and units in radiation protection dosimetry. ICRU Report 51,1993.

ICRU. INTERNATIONAL COMMISSION ON RADIATION UNITS AND MEASUREMENTS. Conversion coefficients for use in radiological protection against external radiation. ICRU Report 57,1998. 
ICRU. INTERNATIONAL COMMISSION ON RADIATION UNITS AND MEASUREMENTS. Determination of operational dose equivalent quantities for neutrons. ICRU Report 66, 2001.

ICRU. INTERNATIONAL COMMISSION ON RADIATION UNITS AND MEASUREMENTS. Stopping powers of lons Heavier than Helium. ICRU Report 73, 2005.

ISO. INTERNATIONAL ORGANIZATION OF STANDARDIZATION. Dosimetry for exposures to cosmic radiation in civilian aircrafts - Part 1: conceptual basis for measurements. ISO, Report 20785-1, 2006.

LEUTHOLD, G.; MARES, V.; SCHRAUBE, H. Calculation of the neutron ambient dose equivalent on the basis of the ICRP revised quality factors. Radiat. Prot. Dosim., v. 40, n. 2, pp. 77-84, 1992.

MORGON, N., H.; COUTINHO, K. Métodos de química teórica e modelagem molecular. Editora Livraria da Física, 2007.

NIST. NATIONAL INSTITUTE OF STANDARDS AND TECHNOLOGY. The "Star Codes. Disponível em: <http://www.nist.gov/pml/data/star/index.cfm>. Acesso em 28 de março de 2013.

NEA. NUCLEAR ENERGY AGENCY. NJOY99.24 Data Processing System of Evaluated Nuclear Data Files ENDF Format. Los Alamos National Laboratory. Report LA-12740-M, 2000.

PAZIANOTO, M., T. Comunicação pessoal, 2012.

PELOWITZ, D. MCNPX user's manual version 2.7.0. Los Alamos: National Laboratory. Report LA-CP-11-00438, 2011.

PORTAL, G.; DIETZET, G. Implications of new ICRP and ICRU recommendations for neutron dosimetry. Radiat. Prot. Dosim., v. 44, pp. 165-171, 1992.

POSSANI, R., G. Re-Engenharia do Software SCMS para uma Linguagem Orientada a Objetos (Java) para Uso em Construções de Phantoms Segmentados. Dissertação de Mestrado, Instituto de Pesquisas Energéticas e Nucleares, Universidade de São Paulo, São Paulo, 2012. 
SANTOS, D. S. Comunicação pessoal, 2013.

SCHUHMACHER, H.; SIEBERT, B. R. L. Quality factors and ambient dose equivalent for neutrons based on the new ICRP recommendations. Radiat. Prot. Dosim., v. 40, n. 2, pp. 85-89, 1992.

SIQUEIRA, P.T.D. Comunicação em sala de aula, 2012

TERREMOTO, L., A. A. Fundamentos de Tecnologia Nuclear - Reatores. Apostila da disciplina TNR5764. Instituto de Pesquisas Energéticas e Nucleares, São Paulo, 2004.

TRANSPORT CANADÁ. Measures for Managing Exposure to Cosmic Radiation of Employers Working on Board Aircraft. Commercial and Business Aviation, 5 April 2001. (Advisory Circular. n. 0183)

WILSON, J. W.; GOLDHAGEN, P.; MAIDEN, D. L.; TAI, H. High altitude radiations relevant to the high speed civil transport (HSCT). NASA Technical Documentation NASA, 2008.

X-5 MONTE CARLO TEAM. MCNP - A General Monte Carlo N-Particle Transport Code, Version 5 Volume I: Overview and Theory. Report LA-UR-031987 (Revised 2/1/2008).

YORIYAZ, H. Fundamentos do Método de Monte Carlo para Transporte de Radiação. Apostila da disciplina TNR-5763. Instituto de Pesquisas Energéticas e Nucleares, São Paulo, 2012. 